\title{
Optimization of Thermal and Structural Design in Lithium-Ion Batteries to Obtain Energy Efficient Battery Thermal Management System (BTMS): A Critical Review
}

\author{
H. Fayaz ${ }^{1} \cdot$ Asif Afzal $^{2}$ (D) A. D. Mohammed Samee ${ }^{2} \cdot$ Manzoore Elahi M. Soudagar $^{3} \cdot$ Naveed Akram $^{4}$. \\ M. A. Mujtaba ${ }^{5} \cdot$ R. D. Jilte ${ }^{6} \cdot$ Md. Tariqul Islam $^{7}$. Ümit Ağbulut ${ }^{8} \cdot$ C. Ahamed Saleel ${ }^{9}$
}

Received: 20 August 2020 / Accepted: 13 March 2021 / Published online: 26 April 2021

(c) CIMNE, Barcelona, Spain 2021

\begin{abstract}
Covid-19 has given one positive perspective to look at our planet earth in terms of reducing the air and noise pollution thus improving the environmental conditions globally. This positive outcome of pandemic has given the indication that the future of energy belong to green energy and one of the emerging source of green energy is Lithium-ion batteries (LIBs). LIBs are the backbone of the electric vehicles but there are some major issues faced by the them like poor thermal performance, thermal runaway, fire hazards and faster rate of discharge under low and high temperature environment,. Therefore to overcome these problems most of the researchers have come up with new methods of controlling and maintaining the overall thermal performance of the LIBs. The present review paper mainly is focused on optimization of thermal and structural design parameters of the LIBs under different BTMSs. The optimized BTMS generally demonstrated in this paper are maximum temperature of battery cell, battery pack or battery module, temperature uniformity, maximum or average temperature difference, inlet temperature of coolant, flow velocity, and pressure drop. Whereas the major structural design optimization parameters highlighted in this paper are type of flow channel, number of channels, length of channel, diameter of channel, cell to cell spacing, inlet and outlet plenum angle and arrangement of channels. These optimized parameters investigated under different BTMS heads such as air, PCM (phase change material), mini-channel, heat pipe, and water cooling are reported profoundly in this review article. The data are categorized and the results of the recent studies are summarized for each method. Critical review on use of various optimization algorithms (like ant colony, genetic, particle swarm, response surface, NSGA-II, etc.) for design parameter optimization are presented and categorized for different BTMS to boost their objectives. The single objective optimization techniques helps in obtaining the optimal value of important design parameters related to the thermal performance of battery cooling systems. Finally, multi-objective optimization technique is also discussed to get an idea of how to get the trade-off between the various conflicting parameters of interest such as energy, cost, pressure drop, size, arrangement, etc. which is related to minimization and thermal efficiency/performance of the battery system related to maximization. This review will be very helpful for researchers working with an objective of improving the thermal performance and life span of the LIBs.
\end{abstract}

\section{Introduction}

The EVs (electric vehicles) and hybrid EVs (HEVs) are very popular in the current scenario and have been rapidly produced. These EVs can be one of the successful ways to mitigate the air pollution complications [1,2]. In EVs and HEVs, the LIB pack is among the most grave modules that

Asif Afzal

asif.afzal86@gmail.com

Extended author information available on the last page of the article provides the continuous power $[3,4]$ because of its large energy density [5] (up to $705 \mathrm{Wh} / \mathrm{L}$ ), power output (up to $10,000 \mathrm{~W} / \mathrm{L}[6]$ ), high voltage ability [7] and high cycling output [8]. LIBs are also being used as power sources in various electronic devices $[9,10]$, power storage devices [11, 12] in defence and aircraft applications [13, 14]. However, the LIBs still face obstructions which restrict their scope of application $[15,16]$. One of the main limitations is the temperature effect on the smooth functioning of the LIBs. The optimal temperature zone for LIBs is usually-20-60 ${ }^{\circ} \mathrm{C}$ [17]. Pesaran et al. [17] informed that LIBs have an optimal temperature range of $15-35^{\circ} \mathrm{C}$. When the temperature is out 
of this safe zone, LIBs can quickly deteriorate with a greater risk of facing safety issues like fire and explosion.

Temperature effects can usually be classified into two categories: low temperature and high temperature cases [18-21]. Low temperature effects occur mainly in elevatedlatitude country regions, like those of Russia, Canada and Greenland $[22,23]$. The ambient temperatures in these regions are considerably lower than $0{ }^{\circ} \mathrm{C}$ in winter. These extreme temperatures will reduce the performance and life of LIBs, particularly for those used in pure EVs, HEVs, and plug-in HEVs (PHEVs) [22, 24]. Another cold region which requires the application of LIBs is the outer space. For instance, the climate on Mars [25] could be as cold as $-120^{\circ} \mathrm{C}$, posing significant problems towards the use of LIBs for space research in astro-vehicles. In this low ambient temperatures, LIBs can exhibit sluggish chemical-reaction behaviour and charge-transfer speed [17], which contributes to the significant reduction in ionic conductivity in the electrolytes [26] and lithium-ion diffusivity inside the electrodes [25]. This reduction can lead to a decrease in power and energy efficiency and a loss in performance.

Despite the low temperature impacts are mainly confined for the low temperature applications, while the high temperature impacts occur in a wide range of applications, involving not only high temperature applications but also cold temperature applications. The high internal temperature is induced by generating heat inside the LIBs, which mostly occurs at high current state activities like rapid charging rate and quick discharging rate $[27,28]$. The high temperature impacts can also lead to battery efficiency degradation including the loss of capacity and energy [29-32]. Typically, the leakage of lithium and the deterioration of active substances during elevated temperatures can lead to the loss of the capacity [33], while the rise in internal resistance is accountable for the reduction in power [33]. When the temperature becomes out of balance, it can cause thermal runaway. When creating a battery system, cell, or pack the heat transfer rate should be sufficiently high such that the battery rarely crosses the temperature of the thermal runaway. If it crosses, then irreversible decay of the battery structure, i.e., damage to the electrolytes and electrodes takes place. In general, all reactions to decomposition are exothermic (generates heat) which means that once the thermal runaway threshold is reached, the temperature increases gradually. It irreversibly causes a self-heating chain reaction and eventually cell destruction [34] and explosion [35, 36].

The temperature non-uniformity and its rise in battery cells are the key issues and limitations for various applications. LIBs reaction kinetics are problematical by the inclusion of liquid electrolyte mixtures and solids of multi and single phase. Mixing, phase change and various electro-chemical reactions generate the heat in the cell [37-42]. Temperature is affected by several features of a batteries including electro-chemical action of the device, charge admission, cyclic performance, energy/ power capacity, durability and cost of life-cycle. However, capacity rises as the working temperature increases, the magnitude of capability fade also increases. Also, a weak performance was observed with decreased working temperature [43, 44]. Furthermore, the increase of extreme or unequal temperature in a system or pack significantly decreases its life cycle [45]. Proper temperature management of LIBs is therefore vital to the efficient and safe functioning of the batteries. Heat is produced and given off from the cell in the process of respective charging and discharge. Unless the heat produced in the LIB system or cell is not properly transferred, it will then be accumulated, increasing the temperature of individual battery and of the total system [46]. The amount of rate of heat generation inside a battery totally under load determines the dimension and configuration of the battery cooling system (BCS) [45].

Researchers instead of focusing on just a novel BTMS and its performance analysis are shifting in obtaining an ideal situation and optimal condition where the tradeoff between several BTMS characters is well established. Experimental designs and soft computing techniques like meta-heuristic algorithms are commonly reported to obtain the optimal situation of thermal and structural aspects. The reviews reported previously in BTMS are not pertinent to optimization of BTMS hence this motivation has led to this article. The BTMS, algorithms for BTMS optimization, cooling methods for BTMS, optimization studies on different BTMS, and future directions in this field are provided in detail.

\section{Battery Cooling Systems (BCS) or BTMS}

The main aim of a system that is capable of thermal management is to provide a battery pack at an acceptable mean and consistent distribution of temperature (or even minor fluctuations among the battery modules of the battery cell) as defined by the battery supplier. Nevertheless, the battery module thermal management system must be compact, light, cheap, easily packed and consistent with the position in the vehicle as defined by the vehicle manufacturer. It must also be accurate, and readily available for maintenance purposes. Establishing an appropriate thermal management system will efficiently disburse heat out of the battery pack and assist in minimizing the excessive increase in temperature, enhance stability and protection during charging and discharging. Thermal management of LIBs are of two types: cooling and heating. Battery packs running under extreme temperature situation or high rate charging or discharging will have to be cooled, while battery packs working under low temperature must be heated to be able to start and sustain a reasonably 
high energy output. Figures 1 and 2 depict a general BTMS or BCS and the general diagram of modelling of BTMS, respectively.

Using a hierarchical model's decomposition process, the BTMS can be disintegrated into few major parts/sections, such as the battery cell, air intake system, and battery module as shown in Fig. 3. Every sub-system is further disintegrated into secondary sub-systems classified into various fields, e.g., the battery module can be classified into fluid dynamics, thermodynamics, and structure.

\section{Governing Equations for Prismatic and Cylindrical LIBs Modelling}

Various batteries (prismatic, cylindrical and pouch type) are modelled differently because of the variants in geometry, chemical configuration, and computational level accuracy required by the simulation. The way packs are organised in a specific battery module also influences the way it has to be mathematically modelled. The governing equations of the heat transfer and fluid flow for the case of prismatic and cylindrical battery cells are discussed.

\subsection{Prismatic Battery Cells}

Figure 4 shows the $180 \mathrm{Ah}$ parallel-plate prismatic LIB. This LIB is made of the anode columns, cathode columns, laminated core, polymer shell, safety vents, and or plates, and gasket [49].

To solve the transient 3D flow problems of battery cells, the continuity equation, energy equation, and the $u$ and $v$ equation (momentum), are written as follows:

- Continuity equation

$$
\frac{\partial \rho}{\partial \tau}+\nabla \cdot(\rho \hat{u})=0
$$

- Momentum in $X$-direction

$$
\frac{\partial(\rho u)}{\partial \tau}+\nabla \cdot(\rho u \hat{u})=-\frac{\partial P}{\partial x}+\nabla \cdot(\mu \nabla u)+s_{m x}
$$

- Momentum in $Y$-direction

$$
\frac{\partial(\rho v)}{\partial \tau}+\nabla \cdot(\rho v \hat{u})=-\frac{\partial P}{\partial y}+\nabla \cdot(\mu \nabla v)+s_{m y}
$$

- Momentum in Z-direction

$$
\frac{\partial(\rho w)}{\partial \tau}+\nabla \cdot(\rho w \hat{u})=-\frac{\partial P}{\partial z}+\nabla \cdot(\mu \nabla w)+s_{m z}
$$

The energy conservation equation of a prismatic battery is given by [50]

$\rho C_{p} \frac{\partial T}{\partial \tau}=\frac{\partial}{\partial x}\left(\lambda_{x} \frac{\partial T}{\partial x}\right)+\frac{\partial}{\partial y}\left(\lambda_{y} \frac{\partial T}{\partial y}\right)+\frac{\partial}{\partial z}\left(\lambda_{z} \frac{\partial T}{\partial z}\right)+q$

where $\rho$ and $C_{p}$ are the fluid density and the specific heat, respectively. $\lambda_{x}, \lambda_{y}$ and $\lambda_{z}$ are the heat conduction in the respective $X, Y$ and $Z$ direction. $q$ Represents the heat generation rate per unit volume. The ' $q$ ' volumetric rate of heat production is estimate from the ' $Q$ ' overall generation of heat generation in the pack/cell divided by $V$ the battery volume and the equation is written as follows:

$q=\frac{Q}{V}$

The LIBs heat generation constitute irreversible heat, ohmic heat, and reversible heat are given by [51]:

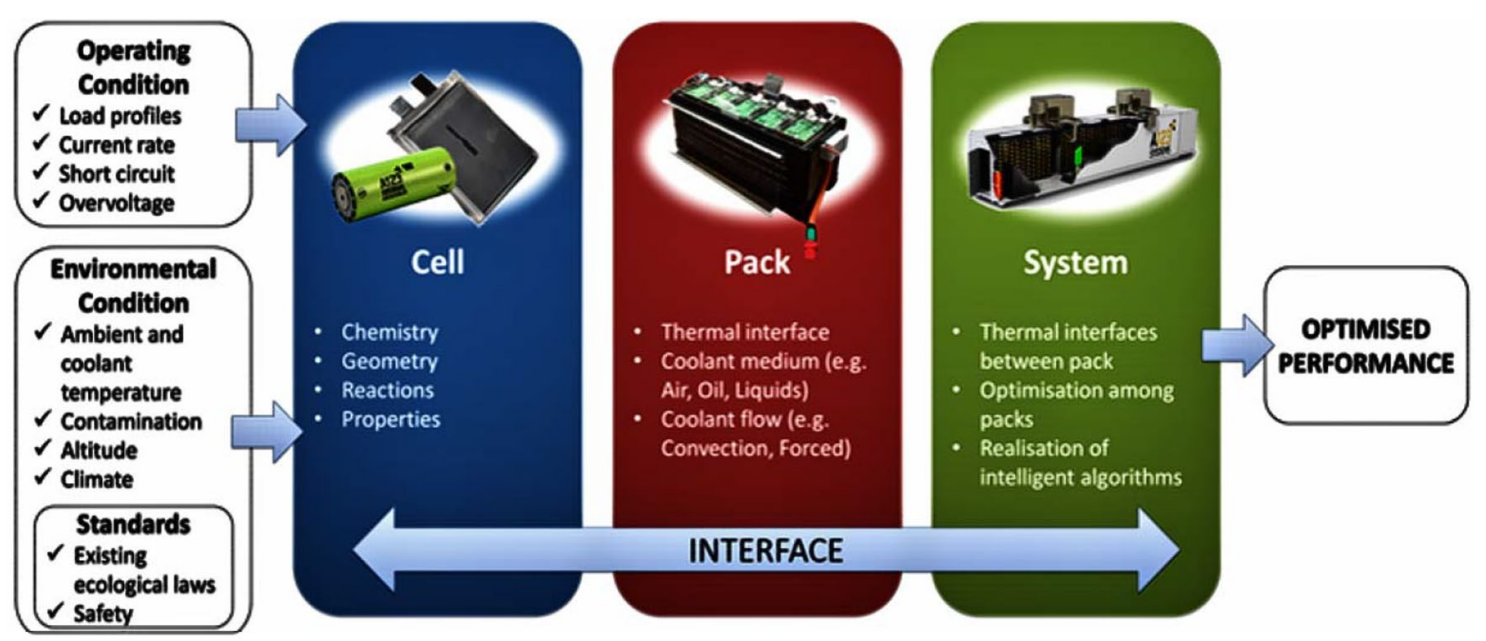

Fig. 1 Systems and sections involved in BTMS [46] 
Fig. 2 Coupling of different thermal models with electrical models [47]

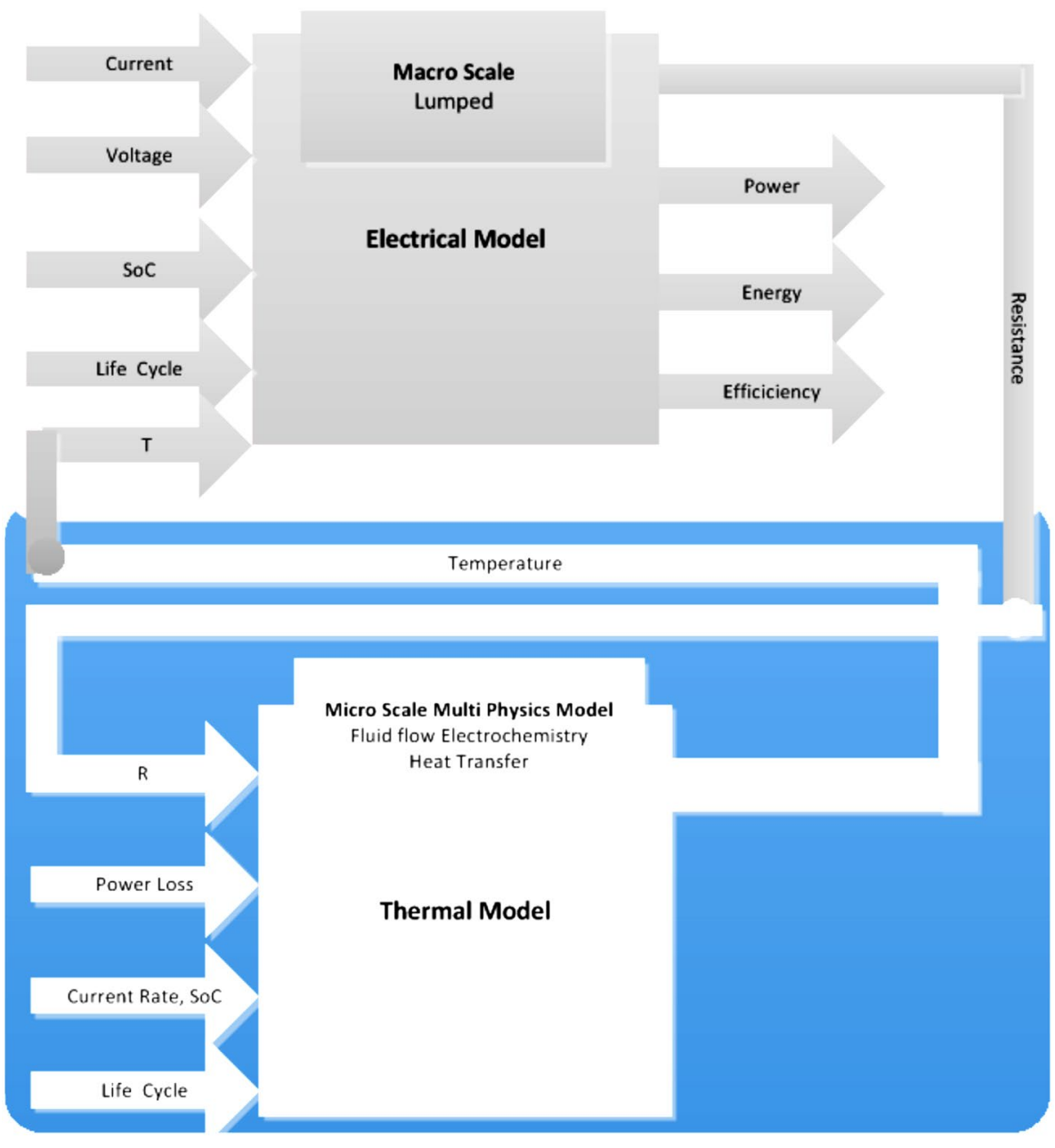

$Q=I\left(E_{o c}-U\right)-I T \frac{d E_{o c}}{d T}$

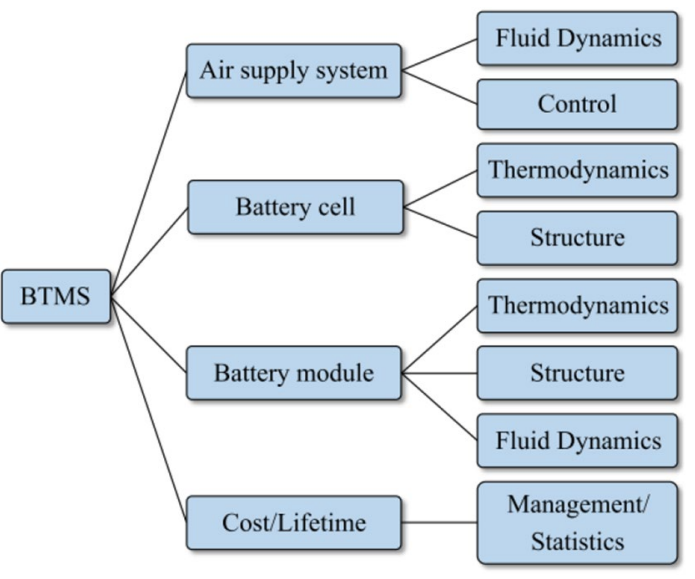

Fig. 3 A categorized split-up of BTMS [48]

\subsection{Cylindrical Battery Cells}

Figure 5 shows the sectional view of battery system with specific direction of flow of air [52]. The governing equations employed to analyse time-dependent 3D flow problems including heat transfer related to battery cells of cylindrical shape are the equation of continuity, momentum equation and energy equation [52], which is discussed in equation (1)-(4). The differential equation for the battery cell is given by [52]:

$m C_{p} \frac{\partial T_{c}}{\partial \tau}=\nabla\left(\lambda \nabla T_{c}\right)+Q$ 
Fig. 4 Prismatic cell of battery (a) realistic model (b) layered core (c) A single cell for analysis [49]

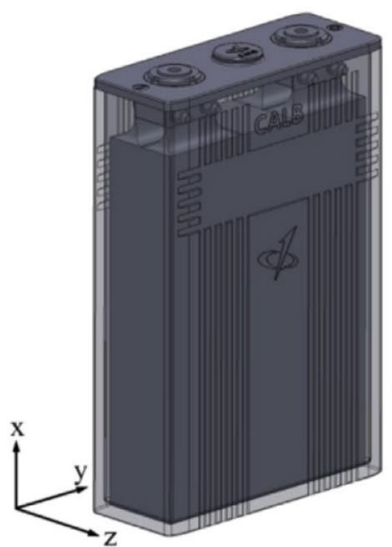

(a)

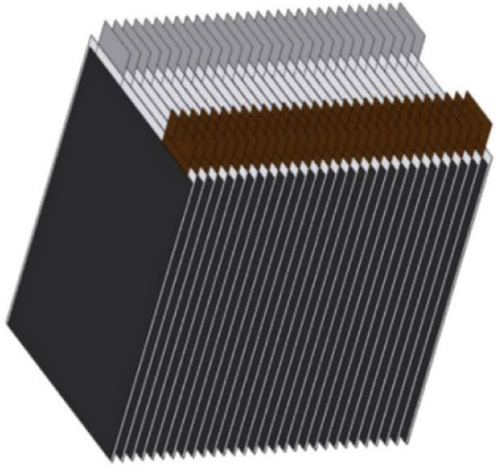

(b)

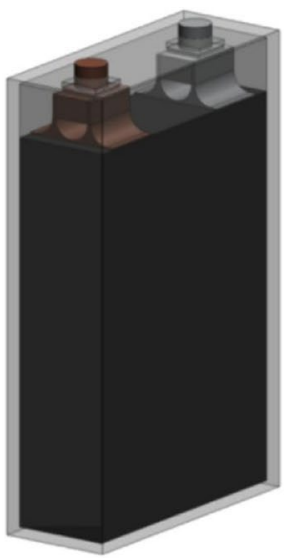

(c)

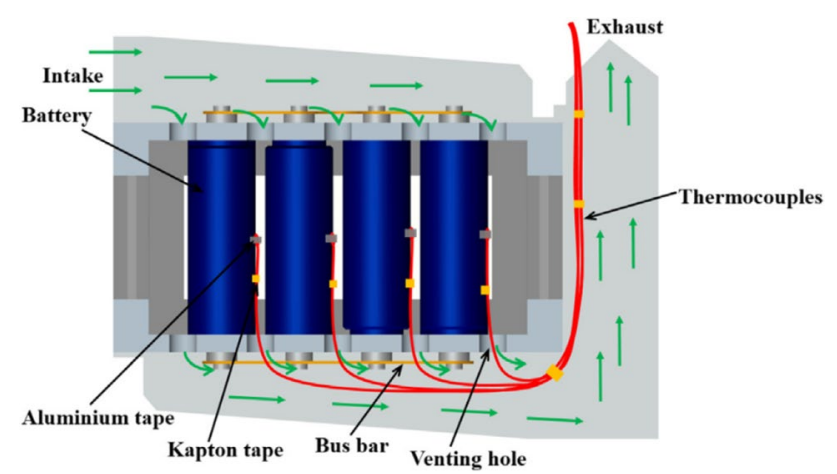

Fig. 5 Sectional view of battery system with specific direction of flow of air [52]

\section{Different Cooling Methods Used in BTMS or BCS}

Pesaran [53] identified four critical functions of BTMS as: provide heat extraction coolant flow from inside the battery, raise the battery temperature by heating whenever the system is at very low temperature, shielding to avoid rapid fluctuations in battery temperature, and a mechanism to expel possibly dangerous fumes from inside the module [53]. Additionally, to adapt to EVs, BTMS must ensure features such as high performance, simplicity, low weight, reduced cost, low use of parasitic power and fast packaging, and easy maintenance [46, 54].

BCS can be external or internal while limited internal BCS has been documented for LIBs which require further research. There has been a detailed discussion of BCS external to the battery. External BCS can be categorized into several different ways. First, it can be categorized based on the method/technique used for cooling such as liquid cooling, gaseous cooling (plate type or use of mini-channel), heat pipe and PCM cooling [55]. Another selection norms is power usage in which the passive cooling uses only the exposed environment, whereas active cooling requires a cooling energy source [55]. Eventually, indirect and direct cooling are classified based on the medium is in straight connection or not with the battery [55]. Jaewan et al. [56] also classified the BTMS based on thermal cycle as BTMS with vapour compression cycle (VCC) and VCC-free BTMS. Figure 6 shows BTMS classification depending up on the cooling medium [57].

\subsection{Air-Based BTMS}

BTM air-cooled system serves the function of passively cooling of a pack by allowing the air to pass through the module. The system of air-cooling can be classified as natural convection cooling and forced (artificial) convection cooling dependent on cooling system which can use a fan. Owing to the benefits of basic design, simple maintenance and reduced cost, the method of air cooling is commonly employed in marketable EVs, and owing to the low viscosity of air, parasitic power consumption is small during the overall system operation cycle. Figures 7 and 8 show a passive air cooling system using a cabin air (natural air cooling) and a simple forced air cooling system, respectively.

The heat transfer coefficient correlation has been employed for evaluation of transient output from the battery, where the $\mathrm{Nu}$ (Nusselt number) and Re (Reynolds number) are interrelated by Equation 9 [58]:

$N u=0.374 R e^{0.8014}$

\subsection{Plate-Based BTMS}

The easiest way of keeping an EV battery pack temperature is by air cooling but since the coefficient of heat transfer of air is very small, so the best option to cool the battery 


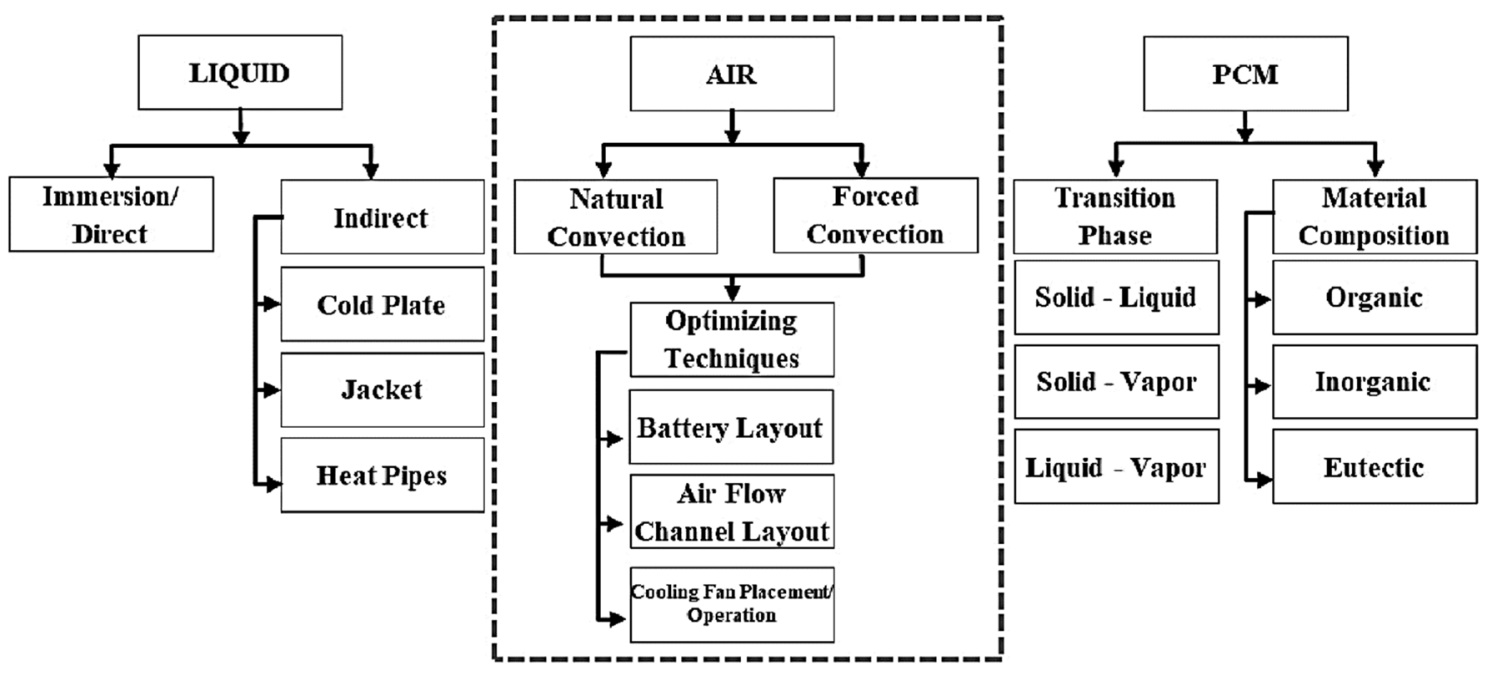

Fig. 6 BTMS classification depending up on the cooling medium [57]

Fig. 7 Passive air cooling system [53]

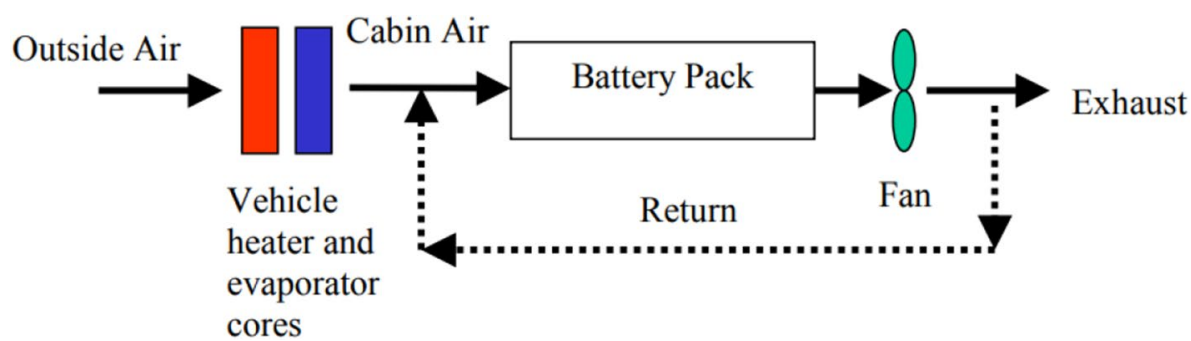

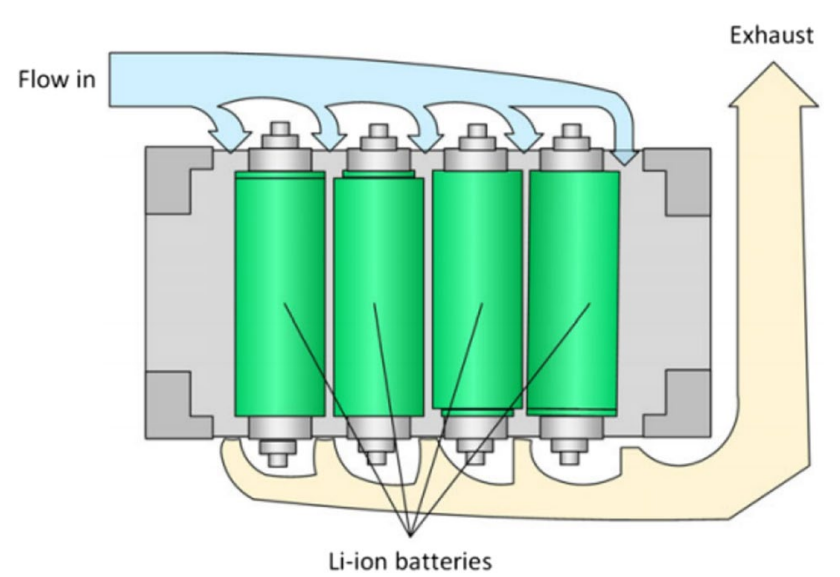

Fig. 8 Forced air cooling system [58]

pack is by liquid cooling, where a cold plate serves as an interface of heat transfer between battery cells and flowing fluid [59]. The liquid cooling mechanism will extract heat from the battery via the cold plate, which in recent years has attracted many researchers [59,60]. Cold plates are thin metallic assemblies containing internal channels from which a coolant flow. The heat produced in the battery cells is carried into the cooling plate and then through the cooling plate at a rate calculated by the rate of heat production in the cell. The heat is then fed away from the battery by the coolant and discharged outside the cell. A typical BTM system using mini channel cold plate is shown in Fig. 9.

\subsection{PCM-Based BTMSs}

Active BTMSs based on liquid and pressured air-centred are that uses energy using equipment's like pumps, compressors, and fans to push the coolant flow through the battery modules. Other type of BTMS are among the passive type, where the cooling is not assisted by energy assisted devices and a control system is not needed to adjust the system constraints to accomplish the necessary cooling load. The PCM-based BTM system is an illustration of passive cooling systems. Whenever a material is converted from liquid type to gaseous type or from gaseous form to liquid form, it will absorb huge quantity of energy, and release it respectively. This concept is generally used to improve the heat removal ability within the LIB. While liquid and air centred arrangements are regarded the best influencing methods of battery cooling, both have some disadvantages, including high energy usage and system complexity. PCM based passive systems 


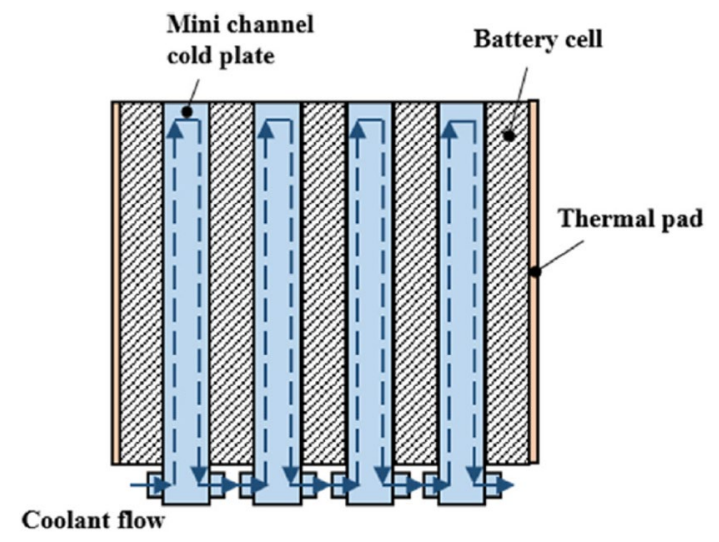

Fig. 9 Mini channel cold plate cooling [56]

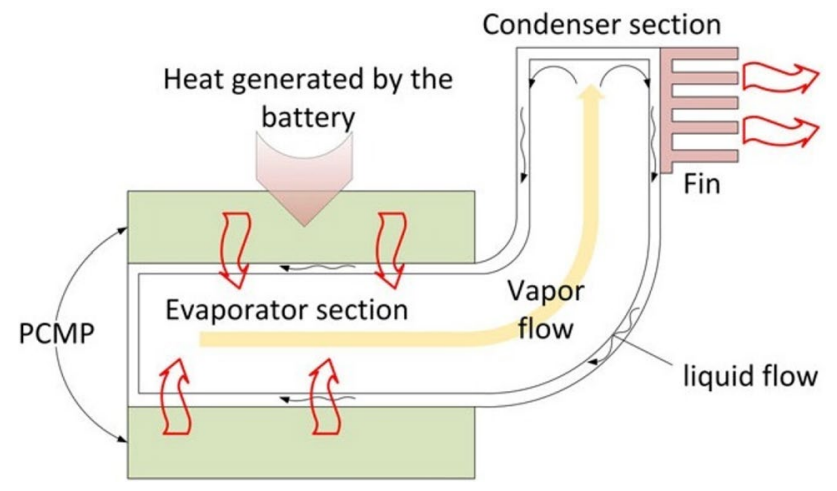

Fig. 10 PCM based cooling for battery management system [55]

therefore are among the benefits of high accumulation of thermal energy and negligible power usage. Over the past few decades many researchers are analysing PCM based management systems, employing experiments and computations to evaluate the performance of these systems. A typical PCM based management systems is shown in Fig. 10.

\subsection{Heat Pipe Based BTMS}

For many commercial and industrial purposes, heat pipes have been widely used as the device to maintain the temperatures within the permissible limits. This is primarily due to their established features of possessing highly efficient thermal conductivity. The overall thermal conductivity approximately $91 \times$ larger relative to that of copper rod of the equivalent size [61]; thus, these are also called 'thermal superconductor' $[62,63]$. It can also sustain the evaporator surface homogeneously at almost constant temperature. Furthermore, this device has versatile geometry that can suit spaces of variable size. These appealing features make heat pipe a strong candidate for refrigeration of HEV or EV

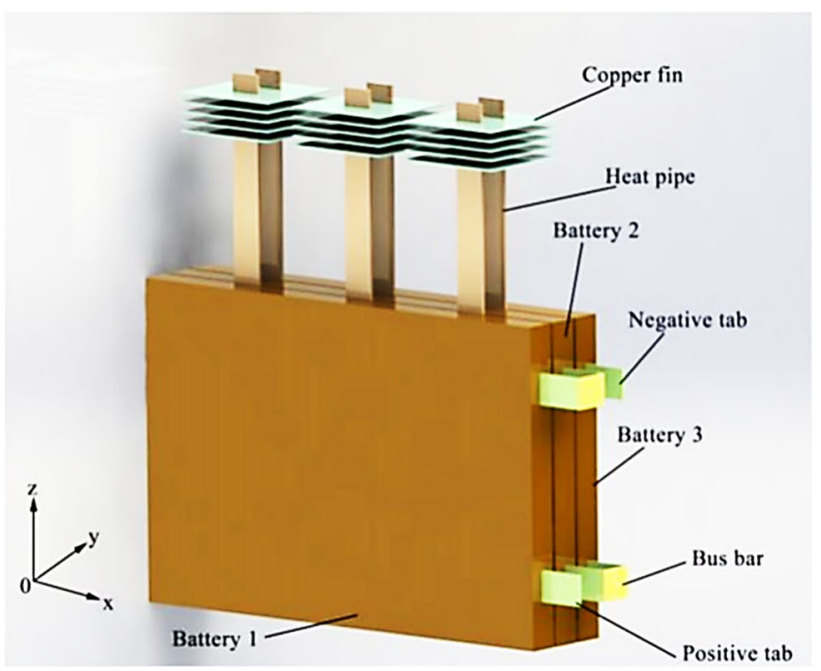

Fig. 11 BCS of heat pipe having fins [64]

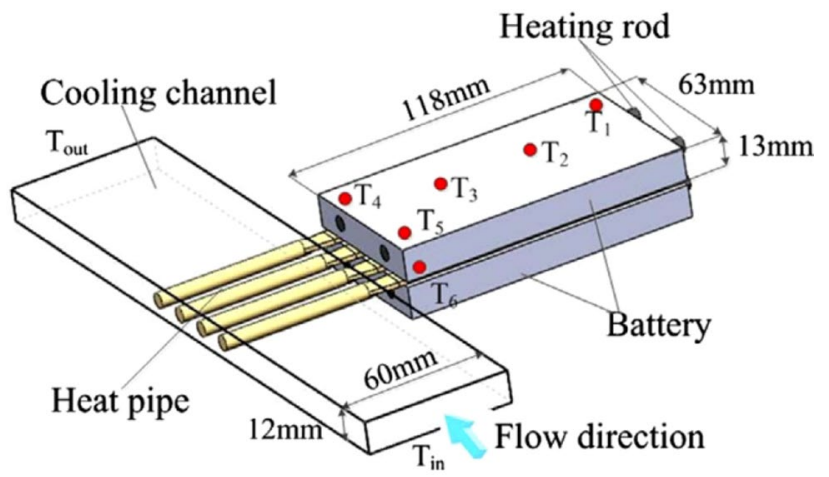

Fig. 12 BCS of heat pipe with cooling channels [65]

batteries. Battery cooling system using heat pipe and fins, or cooling channels is shown in Figs. 11 and 12, respectively.

\section{Optimization Algorithms for BTM Systems}

LIBs are the most popular option for EVs and HEVs, as they possess the benefits of minimal memory effect, long cycle life, large energy density and power, and quick charging and discharge speeds [24]; but the batteries are extremely temperature sensitive. Irregular temperature will cause the batteries to degrade partly. Increased temperature will not only decrease battery operational life but also risk battery safety and sometimes cause significant damage [36]. The optimal LIB operating temperature range is $25-40{ }^{\circ} \mathrm{C}$ while the difference in maximum temperature difference must not be greater than $5^{\circ} \mathrm{C}$ between the batteries [24]. Therefore, a BTMS is very important to keep up the functioning environments of the battery pack within the finest limits along 
with to safeguard safety and consistency of the battery cell. However, the thermal performance and pressure drop of the battery pack are always contradictory. To obtain the trade-off between the conflicting parameters or to obtain maximum heat transfer rate so as to keep up the temperature within the permissible limits while minimizing the pumping power requirement, optimization is performed and it has a very prominent part in modern thermal management of batteries.

There are many optimization algorithms used in the literature depending upon the type of the problem. Some of the algorithms are genetic algorithms [66], particle swarm optimization [66], cuckoo search [66], artificial bee colony optimization [67, 68], evolutionary algorithms [41, 69], simulated annealing [70], memetic algorithm [71], differential evolution [66], tabu search [72], hill climbing with random restart [73], gravitational search algorithm [70], nelder-mead simplicial heuristic [74], dynamic relaxation [75], reactive search optimization (RSO) [76], stochastic tunnelling [77], harmony search [66], grey wolf optimizer [78], bat-inspired algorithm [79], mine blast algorithm [80].

\subsection{Genetic Algorithms}

GAs are heuristic technique of solution-searching or optimization, initially inspired by the Darwinian theory of evolution through (genetic) selection. A GA uses a highly theoretical interpretation of evolutionary processes to create responses to specific problems. Each GA operates on artificial chromosomal populations. Those are strings in a finite (usually binary) alphabet. Every chromosome is a solution to a problem and also has a fitness which is a true number and a measure of quality of a solution for the individual fixed problem. Beginning with a randomly produced population of chromosomes, a GA performs a selection and recombination process based on fitness to create a successor group, a next generation. Parent chromosomes are chosen during mutation, and their genetic information is reprocessed to generate children chromosomes. This would then move through the community of the successors. Since iteration of this operation is carried out, a sequence of Successive generations grows, and the average chromosome fitness continues to increase before some stopping criteria has been reached. In this way a GA 'evolves' a possible solution to a particular problem [81].

\subsubsection{A genetic Algorithm's Framework}

The $G A$ is built using different components. This is a key strength since it implies that basic components can be replicated, with trivial adjustment in several different GA's, thus encouraging implementation. The main elements are the chromosome encryption, the fitness value, choice/selection, replication and the mutation system.

\subsubsection{Chromosome Encryption}

A GA modifies chromosome populations that are string depictions of responses for a specific question. The chromosomes can be thought analogues to biotic chromosome of DNA made from a series of letters $\{A, G, C, T\}$. A specific location in such a chromosome is known as gene and hence the character at that location is alluded as the allele. Any specific depiction used is called the GA encoding for a given query. The traditional GA encodes problems using a binary digits-string depiction. Binary digits-string chromosomes are a group of genes with alphabet character $\{0,1\}$ as allele values.

\subsubsection{Fitness Function}

It is a calculation method used to assess the chromosome performance as a response to a specific problem. Because of the biological similarity the chromosome is called genotype, while the response it signifies is referred to as phenotype. The procedure of translation is very complex. In timetabling and manufacturing scheduling GAs, for example, a chromosome is transmitted into set of planned activities dealing with various interacting resources. The fitness calculation will then assess the performance of this schedule in terms of different criteria and objectives such as conclusion time, resource use, cost minimisation, etc.

\subsubsection{Selection/Choice}

In $G A$, fitness is used as a determiner of the performance of the responses in a $G A$ community defined by genes (chromosomes). The selection portion of a $G A$ is formulated to use fitness through selective pressure to direct chromosomal evolution. Then chromosomes are chosen for replication based on fitness. Greater the fitness value, higher is the selection chances as compared to smaller fitness values, thereby generating a selective competition for more suitable solutions. Typically selection is for substitution, which ensures that highly compatible chromosomes have the opportunity to be picked more number of times or even recombined for themselves. The conventional method used in selection is Roulette Wheel (or proportional fitness) selection. This assigns a probability for each chromosome to be selected in proportion to its relative fitness [81].

\subsubsection{Recombination}

Recombination is the method of recombining the chromosomes chosen from a target population to form representatives of a successor population. The aim would be to mimic the blending of genetic information that may occur during organism reproduction. As recombination selection is biased 
in favour of greater fitness, the balance of probability is that better matched chromosomes will emerge as an outcome.

\subsubsection{Evolution}

Resulting chromosomes are transferred into the successor population after recombination. The selection/recombination processes will then be repeated until it generates a complete population of the successor. At a certain point the population of the successor will become a new source (next generation) population. This $G A$ is repeated over a couple of generations before suitable stopping conditions are met. This might involve a fixed number of generations that have elapsed, achieved convergence to the perfect fitness solution or solution which meets a collection of restraints to the fullest.

\subsubsection{GA Design}

In designing a GA for a particular application, there are several options that must be made. Choosing encoding relies on the nature of the issue. Non-bit string representations are popular now and include integer sequences or floating point values. As the density of the allele set increases, for example, where the strings comprise of floating point numbers, the set of potential chromosomes becomes significantly larger. So, several new (or non-classical) GAs use a few approaches to guarantee that the set of feasible chromosomes matches closely with the set of possible solutions of the problem. There are also other options to make after an encoding is picked. These include: the fitness function form; population size; crossover and mutation operators and their corresponding rates; the evolutionary strategy to be implemented; and suitable conditions for stopping / re-starting. The usual approach to design is a mixture of experience, problem-specific modelling and experimentation with various evolution schemes and other parameters.

\subsection{Response Surface Methodology (RSM)}

RSM is an experimental design tool for determining the design factor settings to enhance or optimize a process or product's output. It incorporates DOE, correlation and regression and optimization techniques in a general-purpose scheme to optimize the predicted value of a stochastic solution.

\subsubsection{Problem Setting and Background}

Mathematically, RSM solves:

$\operatorname{Max} F(x)=E[Y(x)]$ where $Y$ is a random variable the mean of which is unidentified relation of D-dimensional factor vector $x$ and the variance of which (emerging from experimental error) is a constant whose value is not known, represented by $\sigma^{2}$; and where the optimization is over $\mathrm{x}$ in certain $R$ region. Usually the limits defining $R$ are not modelled, therefore setting is generally deemed unconstrained optimisation Problem. RSM fits a series of local regression models, initially linear, and subsequently quadratic. The model is fitted with experimental data based on a recommended set of $x$ vectors referred to as the experiment design [82]. The linear model has the form:

$Y\left(x_{l}\right)=\beta_{0}+\sum_{j=1}^{d} \beta_{j} x_{i j}+\varepsilon_{i},\left(\varepsilon_{i}\right) \sim i . i d N\left(0, \sigma^{2}\right)$

where $i$ is the indexes of the investigational trial and $j$ the component of the $X_{i}$ vector. The fitted model is represented as:

$E\left[Y\left(x_{l}\right)\right]=\hat{y}=b_{0}+\sum_{j=1}^{d} b_{j} x_{i j}=b_{0}+b^{\prime} x_{i}$

where the fitted coefficients are determined using least square. If the test contains of $\mathrm{n}$ trials, then $\epsilon$ is presumed to be a normal random n-vector with a mean the zero vector. Every fitted local model is used to estimate a search direction or Sub-region in $R$ where $E[Y(x)]$ is estimated to rise or be optimum.

\subsubsection{RSM Algorithm}

RSM has mainly 4 operations: scaling and transformation, selection, Stage 1 modelling and searching, and Stage 2 modeling and searching.

1. Scale $x$ variables (for instance, to provide roughly equivalent units of change) and transform $\mathrm{Y}$ values (for instance, to provide uniform variance responses over several distinct $x$ values).

2. Screen for crucial $\mathrm{x}$ vector components (referred to as factors).

3. Phase 1:

(a) Choose an experimental method suitable for fitting a regression model of first order.

(b) Perform the test, fit the relevant model, determine significance and fit.

(c) If the model is reasonable, define a direction of search and perform a series of tests in that direction.

(d) Back to step 3a. 
4. Stage 2:

(a) Choose the an experiment design suitable for fitting a model of 2 nd order regression (it may be an improvement in an original 1st order design).

(b) Perform the test, fit the relevant model, determine significance and fit.

(c) If the model is reasonable, determine if it has defined an optimum, saddle point, or slope.

(d) If the experimental array includes a ridge or optimal solution, move on to phase 5 .

(e) Otherwise, define a direction of search and perform a series of tests in that direction.

(f) Back to step 4 a.

5. Convey optimum settings or a near-optimum setting ridge in original units $\mathrm{x}$.

\subsection{Particle Swarm Optimization (PSO)}

It is a stochastic algorithm focused on population, inspired by certain animal's intelligent cooperative behaviour such as herds of birds or group of fish for finding optimal solution. It was launched in 1995, has observed a lot of improvements. As investigators have mastered the technique and produced new versions to meet various demands, new applications have been built in a host of fields. PSO algorithm is a kind of swarm-based selection process in which each entity is referred to as a particle described as a potential result of the optimized problem in D-dimensional search area, and memorizes the specific location of the swarm and its own, and also the speed. In every generation, the information on particles is merged to adjust the speed of each dimension that is adopted to compute the new position of particle. Particles evolve and change their state in the multi-dimensional search before they enter balance or optimal state, or beyond the computation limits. Distinct connection is initiated between various dimensions of the problem space using the objective functions [82]. Several empirical researches have shown this algorithm is an important method for optimization. The PSO algorithm flowchart is indicated in Fig. 13 [83].

\subsection{NSGA-II}

NSGA [84] is a common, non-domination based, multiobjective optimization genetic algorithm. This is a highly powerful algorithm, yet it often widely criticized because of its computational difficulty, absence of elitism and the optimal sharing variable value. A revised version has been generated, NSGA-II [85], and it has an enhanced arranging algorithm, integrates superiority, and non-membership variable requires to be selected a priori.

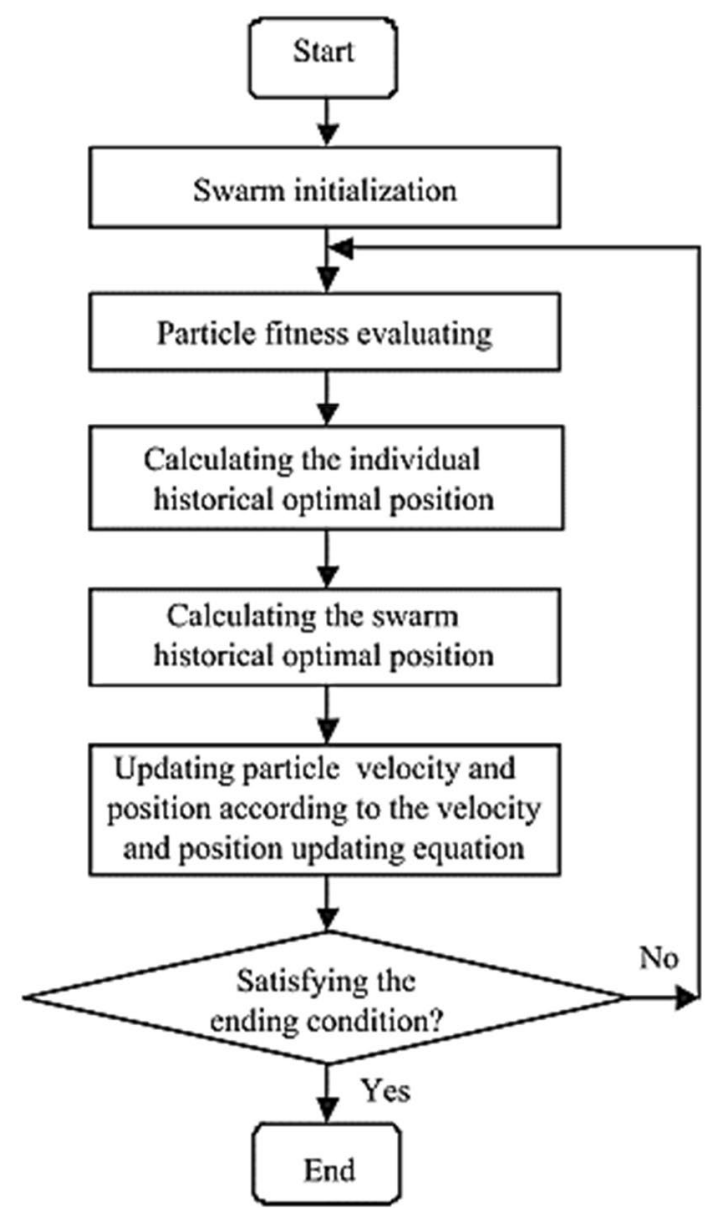

Fig. 13 PSO algorithm flowchart [82]

\subsubsection{Description of NSGA-II}

- Initialization of population. The population can be configured depending upon the problem interval and limitations of the problem.

- Non-dominated sort. The configured population is organised on a non-dominance basis [86]. Quick sort algorithm [85] is used for this purpose and has the following procedure

- Do the following for every single $\mathrm{z}$ in primary population $\mathrm{Z}$

- Initially set $\mathrm{R}_{\mathrm{z}}=0$; this collection will cover all individuals controlled by $z$.

- Initially set $\mathrm{m}_{\mathrm{z}}=0$. This is going to be the number of individuals which controls $z$.

- For every single $s$ in $Z$

- * If $s$ is dominated by $z$ then add $s$ to $R_{z}$ i.e. $R_{z}=R_{z} U\{s\}$

- * Then if $s$ dominates $\mathrm{z}$ then $\mathrm{m}_{\mathrm{z}}=\mathrm{m}_{\mathrm{z}}+1$.

- If $\mathrm{m}_{\mathrm{z}}=0$ i.e. neither person rules $z$ so $z$ applies to the ist front; Set individual $\operatorname{rank} z=1$. 
- This is done to all of the residents in primary population $\mathrm{Z}$.

- Assign the front counter to 1 .

- Following is performed when the $\mathrm{i}_{\mathrm{th}}$ front non - zero i.e. $\mathrm{Cj}=0$;

- $\mathrm{S}=0$; The set for storage of the individuals for $(\mathrm{i}+1)^{\text {th }}$ front.

- For every single $\mathrm{z}$ in front $\mathrm{Cj}$

- * For each $\mathrm{s}$ in $R_{z}\left(R_{z}\right.$ is the group of individuals governed by z)

- $\mathrm{m}_{\mathrm{s}}=\mathrm{m}_{\mathrm{s}}-1$, decrease the individual $s$ dominance count.

- If $\mathrm{m}_{\mathrm{s}}=0$ then neither person rules $z$ on subsequent fronts. So set to $\mathrm{s}_{\mathrm{rank}}=\mathrm{i}+1$. Upgrade set $S$ with single s i.e. $S=S U S$

- Increase the front counter to 1 .

- The set $S$ is now the subsequent front, and therefore $C j=$ $S$.

- This optimizer is superior to previous NSGA ([5]) because it uses the knowledge of an individual $\left(R_{\mathrm{z}}\right)$ dominated set and the list of $m_{z}$ dominated individuals.

\subsubsection{Crowding Distance (CD)}

When the non-dominated sort is finished, the $C D$ is allocated. Since the persons are selected based on the level, a value of $C D$ within the population is set for every person.

$C D$ is allocated front wise, and it is insignificant to equate the crowding distance among several individuals in separate front. The distance to crowing is computed as under For every $C j$ front, $n$ is the number of persons.

Initialize zero $C D$ for all persons i.e. $F i\left(d_{k}\right)$ to 0 ,

Where $k$ refers to the $\mathrm{k}^{\text {th }}$ individual in front $C j$.

For every indiviual objective function $\mathrm{m}$

$\propto$ Identify the persons in front $C j$ using objective $m$ i.e.

$\mathrm{L}=\operatorname{sort}(C j, \mathrm{~m})$.

Allocate infinity distance to the border values for each

person in $C j$ i.e. $\mathrm{L}(\mathrm{d} 1)=\infty$ and $\mathrm{L}(\mathrm{dn})=\infty$

$*$ for $\mathrm{t}=2$ to $(\mathrm{n}-1)$

$\mathrm{L}(\mathrm{t}) \cdot \mathrm{m}$ is the value of the $\mathrm{m}^{\text {th }}$ objective function in $\mathrm{L}$.

The general concept behind the crowing distance is to find in $\mathrm{n}$ - dimensional hyper space, the euclidean distance between each person of a front that is based on $\mathrm{m}$ objectives.

\subsubsection{Selection}

If the entities are categorized by non-dominance and assigned $C D$, a crowded-comparison-operator (Án) is used to make the choice. The distinction is rendered as below based on the
(1) Non-dominance rank $d_{\text {rank }}$ i.e. the rank of persons in front $C j$ is $\mathrm{d}_{\text {rank }}=\mathrm{i}$.

(2) crowding distance $\mathrm{Cj}(\mathrm{dk})$

Z Án s When

$\mathrm{Z}_{\text {rank }}<\mathrm{s}_{\text {rank }}$

Or if $\mathrm{z}$ and s pertain to the similar $C j$ front, $C j\left(\mathrm{~d}_{\mathrm{z}}\right)>C j$ $\left(d_{s}\right)$, i.e. the crowing distance must be larger .

The individuals are chosen using a binary tournament selection with the help of crowed-comparison-operator.

\subsubsection{Biological Operators}

The crossover and polynomial mutation in Real-coded GA's is carried out uisng Simulated Binary Crossover (SBX) operator [86].

\subsubsection{Recombination/Selection}

The offspring population is combined with the population of the new generation, and a decision is made to create individuals of the next generation. With the inclusion of both preceding and current finest people, elitism is assured. Population now is sorted out through non-dominance. Subsequently, the new generation is filled by each front until the population growth is greater than the existing population size. When the population reaches $\mathrm{N}$ by adding all the individuals in front of $C j$, the individuals in front of $C j$ are chosen in descending order based on their crowding distance until $\mathrm{N}$ is the population size.

And so the process continues to produce the following generations.

\subsection{Ant Colony Optimization (ACO)}

Ant Colony Optimization (ACO) is a metaheuristic motivated by the formation of pheromones path and accompanying action of other ant species. Artificial ACO ants are probabilistic response building processes that create candidate responses for the problem example under consideration by utilizing (artificial) pheromone knowledge that is adapted related to the search experience of the ants and potential heuristic information available to them.

\subsubsection{The Metaheuristic}

The algorithm for ACO metaheuristic for implementations to static combinatorial optimization problems is shown below. The main loop consists of three main stages, following the assigning of initial variables and pheromone paths. Firstly, $\mathrm{m}$ ants create solutions to the problem instance being considered, influenced by the pheromone knowledge and probably by the heuristic information known. If the ants have concluded their responses, these could be strengthened in 
an optional step of local search. Ultimately, the pheromone paths are adapted to indicate the ants' search experience just before beginning of the next iteration.

\subsubsection{Initialization}

In the beginning of the algorithm, parameters are specified and all pheromone variables are set to a value $\tau 0$ (algorithm parameter).

\subsubsection{Construct ant Solutions}

A group of $m$ ants builds the solutions to handle the problem instance. To do the same, every ant begins with a solution $s 1=0$, initially zero. An ant expands its present temporary solution at each development stage by selecting a viable solution portion and linking it to its present temporary solution. $\mathrm{N}(\mathrm{sp})$ is the collection of solution elements that can be incorporated while preserving viability, and is implicitly specified by a solution building method employed by the ants. If a provisional solution could not be expanded while preserving viability, it relies on the basic construction process whether the solution construction is discarded or if a complete solution is designed.

The solution element to be added is chosen on a probabilistic basis at each building step. Different ways of describing the distributions of probabilities were considered. The most frequently used rule is Ant System [87]:

$p\left(C_{i}^{j} \mid S_{p}\right)=\frac{\tau_{i j}^{\sigma}\left[\eta\left(C_{i}^{j}\right)\right]^{\beta}}{\sum C_{i}^{\prime} \in N\left(S_{p}\right) \tau_{i^{\prime}}^{\sigma}\left[\eta\left(C_{i}^{l}\right)\right]^{\beta}} \cdot \forall C_{i}^{j} \in N\left(S_{p}\right)$

where $\eta($.$) is a simple function assigning a heuristic value$ to each viable solution variable, generally referred to as the heuristic information. Parameters $\sigma$ and $\beta$ assess the relative effect of pheromone trails and heuristic knowledge and effect algorithm behavior accordingly. If $\sigma$ is having a zero value, the selection probabilities are proportional to $[\eta i j]^{\beta}$ and it is more expected to select a solution component with a large heuristic value: this sample corresponds to a stochastic greedy algorithm. If $\beta$ is having a zero value, then only the pheromones amplification is at work.

\subsubsection{ApplyLocalSearch}

When comprehensive candidate solutions are achieved, the application of local search algorithms can subsequently enhance these.Local search is more commonly one example of what was called daemon behavior [88]. Those are useful to impose problem-specific actions that single ants could not execute.

\subsubsection{UpdatePheromones}

The purpose of the pheromone update is to create solution components that are part of good solutions more favorable for ants functioning in the following iterations. Essentially, there are two methods used to accomplish that goal. The first is the deposition of pheromones that enhances the pheromone level solution components that are aligned with a specified set of good solutions Supd. The second is evaporation of the pheromone trail, which is the method by which the pheromone deposited by preceding ants reduces over time. From a practical perspective, evaporation of the pheromone is needed to minimize a too rapid convergence of the algorithm towards a sub-optimal area.

\section{BTMS Optimization Analysis Using Experimental and Numerical}

\subsection{Air Cooling-Based}

In recent years several researches are reported in order to boost cooling performance of battery by using methods to optimize the air flow channel geometry, the pack arrangement, and fan positioning or working. A thorough critical evaluation of each method is provided in this section, the outcomes and characteristics of each process are also highlighted. Mohsen et al. [89] carried out parametric optimization to optimize the parameters influencing the cooling of LIB cells using genetic algorithms. A battery pack with 150 battery cells (cylindrical) with tubes having a fan (for air cooling) was used for the study. They found an optimum value of NTU for maximum tube diameter and for air velocity of around $2.5 \mathrm{~m} / \mathrm{s}$ using genetic algorithm. Oliver et al. [90] defines an aging model and applies real world boundary conditions and different cooling approaches to optimize the life of the battery under these conditions. Using the optimization technique, a trade-off between the conflicting parameters of efficiency and fuel economy of the vehicle was achieved along with the extended battery life. Severino et al. [91] used PSO algorithm for multi-objective optimization (MOPSO) of BTMS design as shown in Fig. 14. This MOPSO was proposed for design optimization of six battery packs arranged as shown in Fig. 15. The Pareto front solutions obtained from MOPSO are also shown with maximum temperature as one the objective function to minimize in Fig. 16. BTMS power consumption and battery area are also chosen as objective function to be minimized. Improvised design of six cells was obtained using the proposed MOPSO algorithm.

Zhang et al. [92] carried out multi-objective optimization for recognition of critical parameters in Lithium-ion batteries. A classic battery (cylindrical) with spiral cells is 
Fig. 14 Particle swarm algorithm for optimization of battery thermal designs [91]

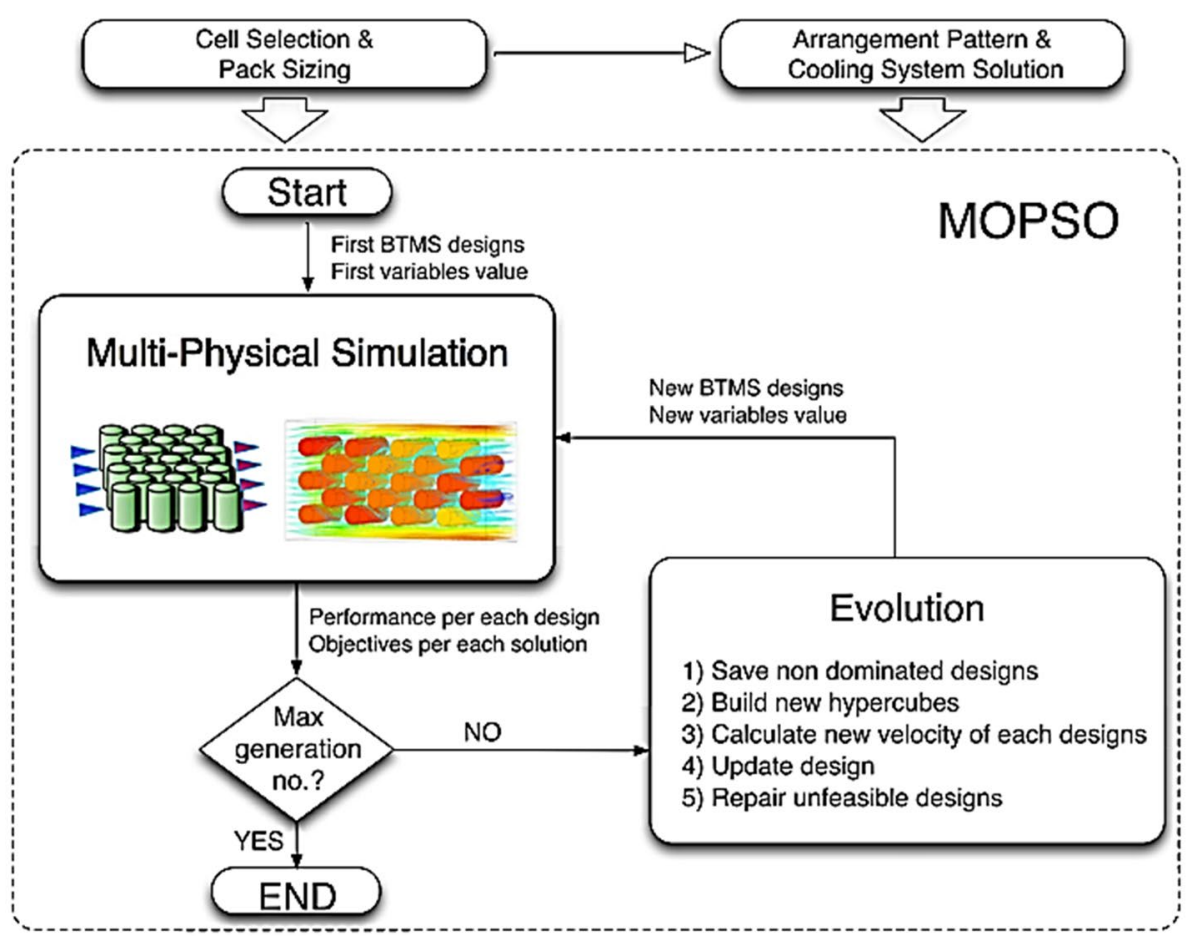

illustrated in Fig. 17 below. Modified NSGA-II and TOPSIS algorithms were used to optimize the parameters. Terminal voltage and surface temperature were used as the objective functions to be optimized. They obtained two Pareto fronts (two optimal solutions) using NSGA-II algorithm. The TOPSIS method was then used to find the result from these Pareto fronts. The flow chart of the algorithm is provided in Fig. 18. The optimization results were in good agreement with the experiments.

Liu et al. [93] analysed and optimized the BTM of EV's using reciprocating air flow cooling model created using Ansys-Fluent. The optimization was done using DOE by constructing an orthogonal experiment and doing the statistical analysis. The main objective was to reduce the temperature (maximum) and temperature difference within the battery cells. The parameters used for optimization were reciprocating period, velocity of air and inlet temperature of air. They found a significant reduction in temperature (maximum) and temperature difference using this reciprocating air flow model. Jelle et al. [94] developed Porous Electrode Model (PEM) to explore the thermal performance of LIBs used in EV's. The impact of cathode density on the current discharge capacity of the model was evaluated. They found good agreement between the experimental and developed Porous Electrode Model and hence evaluated the performance of the battery. Shahabeddin et al. [95] carried a 3D transient thermal investigation of a LIB having prismatic cells. Air was used as a cooling media and pin fins of height varying along the width of the channel was proposed for the analysis (Fig. 19). The authors analysed the impact of fin arrangement, air velocity, and temperature of intake air on the thermal behaviour of the battery system. The analysis showed clearly that the using fin not merely reduces the bulk temperature however also reduces the temperature difference between the packs. Also increasing the air velocity and temperature at the inlet, reduces the maximum temperature in the battery cells.

Zhang et al. [96, 97] used genetic algorithm to optimize multiple functions which were conflicting functions i.e. temperature rise and charging time, with polarization constraints for LIBs. The flowchart to estimate the charge current using GA is shown in Fig. 20. The result indicated a significant reduction in charging time with fair rise in temperature, emphasizing its benefits compared with traditional methods. The battery temperature at time $\mathrm{P}$ is given as:

$T_{\text {cell,p }}-T_{\text {cell, } p-1}=\frac{f^{2} R_{\Omega}+f U+T_{c e l l, p-1} f \frac{d E}{d T_{\text {cell }}}-A h\left(T_{\text {cell }, p-1}-T_{a m b}\right)}{m C_{\text {cell }}}$

where ' $\mathrm{m}$ ' is the mass of the battery.

Dylan et al. [98] carried out multi objective optimization to decrease the temperature (maximum) within the battery packs, pressure drop, and price of the BTMS using air as a cooling medium. The optimization and simulation were done using COMSOL Multiphysics software. With the help of simulation, they found that with increase in flow rate, the average and maximum temperature decreases but pressure drop increases. Hence the trade-off between these parameters were obtained using the multi objective optimization. Kerler et al. [99] developed Meta models (model of a model) to 


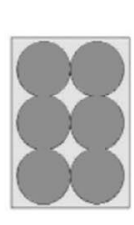

(a)

Design 12

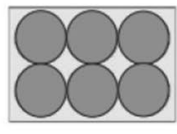

(c) Design 3

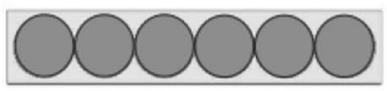

(e) Design 5

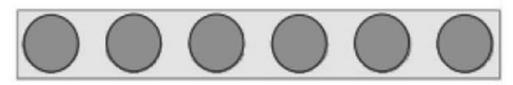

(f) Design 6

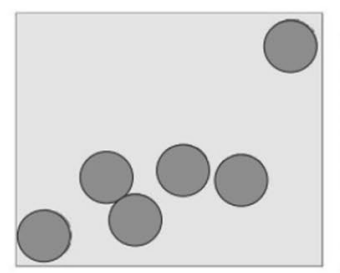

(a) Solution 1

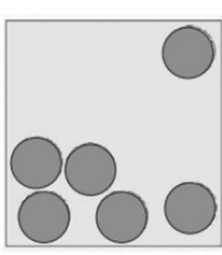

(b) Solution 2

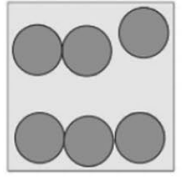

(c) Solution 3

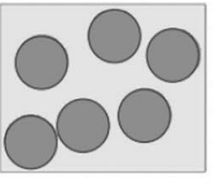

(d) Solution 4

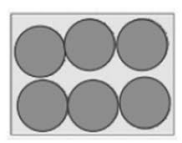

(e) Solution 5
Fig. 15 Conventional designs 1-6, and Pareto front optimization solutions $1-5$ of cell arrangement [91]

analyse the behaviour of the battery cells with time applying Ansys software. Minimizing the temperature (maximum) of the battery and temperature difference among the packs were the main objectives of these simulations. The complex Meta models developed accelerated the simulation process by a size of over 1,000 without dropping much outcome accuracy. This allows for fast optimization of the shapes of the battery cells for a given current cycle. Using this technique, a reduction in maximum temperature of about $30{ }^{\circ} \mathrm{C}$ was obtained. The methodology for creating such meta-models using thermal finite element based simulations and some examples of BTMS analysis method for optimization are shown in Fig. 21. Table 1 provides details of optimization for air based BTMS.

\subsection{Heat Pipe-Based}

Yong et al. [100] proposed a design optimization procedure for loop heat pipe to cool the LIBs used in military aircraft. The loop heat pipe (LHP) experimental setup used for cooling of the battery cells is shown in Fig. 22. The main objective was to reduce the weight of the LHP at high altitudes with a constraint of maintaining the battery operating temperature at $10{ }^{\circ} \mathrm{C}$. For the numerical analysis, the entire system of LHP is analysed by building thermo hydraulic model along porous wick and groove section model. The optimization was carried using RSM. The flow chart of the optimization algorithm is shown in Fig. 23. The temperature distribution at the groove section is shown in Fig. 24. From the optimization result, they found a $12 \%$ reduction in the weight of LHP as compared to the reference design.

Kirill et al. [5] presented a thermal protection system design for LIBs used in hybrid machines and a technique for optimizing them. The framework proposed consists of the use of metal plates and heat pipes in the battery cells. The main objective was to reduce the non-uniform distribution of temperature within the battery cells. The model was developed in COMSOL Multiphysics environment and optimization was carried out using Matlab. Multi-dimensional Minimization optimization was used to reduce the nonuniformity of temperature. The algorithm and the proposed arrangement of heat pipes is shown in Figs. 25 and 26 below. Based upon the optimization, they were able to reduce the number of heat pipes in the design of thermal protection system of the battery.

Yonghuang et al. [101] carried an experimental investigation (Fig. 27) and optimization studies to improve the cooling performance of BTMS using heat pipes and fins for prismatic and pouch type LIBs. Various design parameters used for the study were volume flow rate of the coolant, temperature of the coolant, number of heat pipes etc. The authors found that addition of fins decreased the maximum temperature and temperature difference between the cells. Also, water and methanol were good working fluids in the heat pipe for cooling of the battery cells.

In another study, Yonghuang et al. [102] carried a numerical and optimization studies by proposing a BTM system having heat pipes, fins, vortex generators and heat spreaders. Both steady and transient heat transfer simulation were carried out to determine the thermal performance characteristics of the proposed BTM system with heat pipes (HPTMS). 
Fig. 16 After many generations of particle swarm the Pareto front surface obtained from optimization of temperature [91]
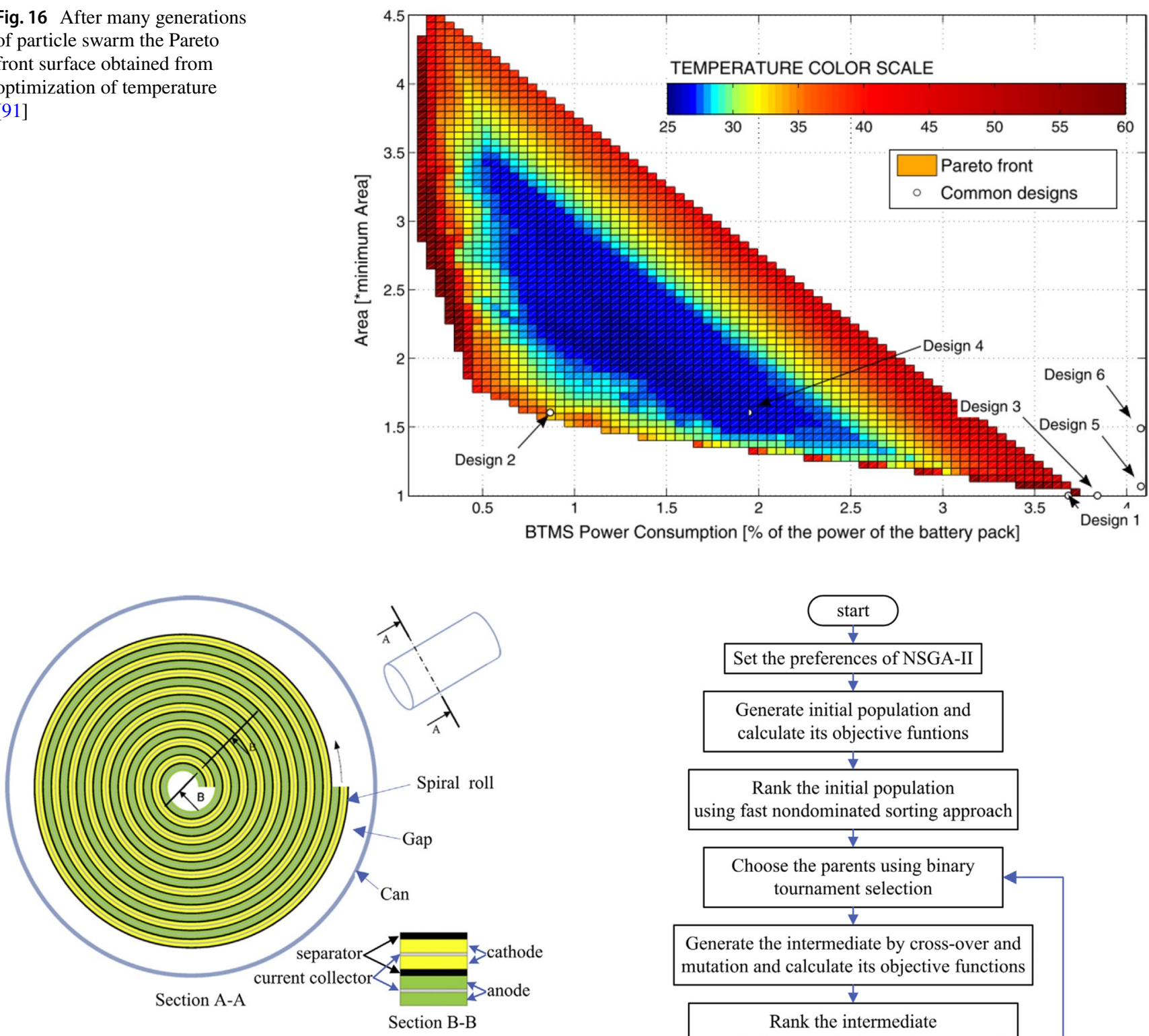

Fig. 17 Cylindrical LIB cross-sectional view [92]

The main aim was to improve the cooling performance of the proposed system. Modelling and simulation were carried out using Ansys-CFX. Figure 28 shows the CFD model used for the simulations and the boundary conditions are shown in Fig. 29. The proposed thermal resistance model to improve temperature uniformity of the system is also shown in the Fig. 30. The authors found that the presence of vortex generator at the front side of the heat pipe significantly improves the temperature distribution of the battery cells. It was also found that the addition of fins and copper spreaders significantly improves the thermal performance of BTM system. Details of numerical BTMS optimization work are listed in Table 2.

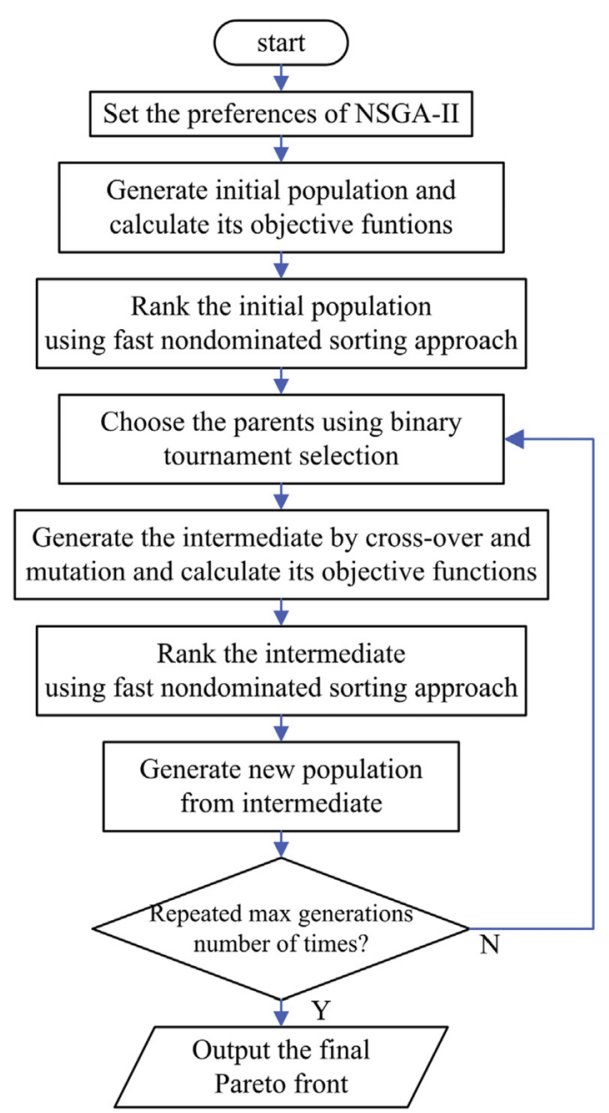

Fig. 18 Flow chart of NSGA-II algorithm [92]

\subsection{Plate Cooling-Based}

Jarrett and Kim [103] applied cooling plate for BTMS and carried modelling and simulation using numerical methods. 
Fig. 19 Number of fins for different cases [95]
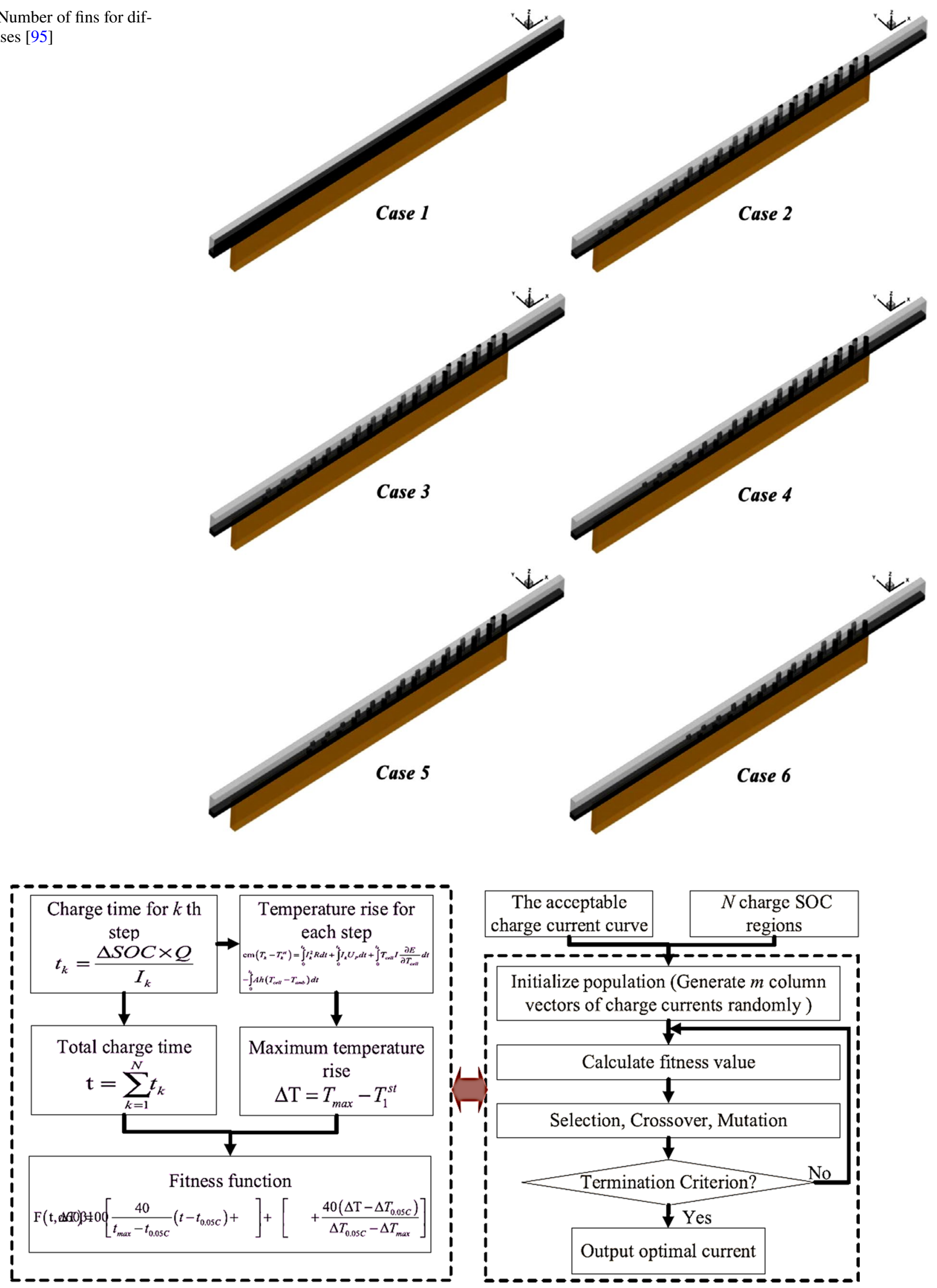

Fig. 20 Flowchart to estimate charge current using GA [96, 97] 


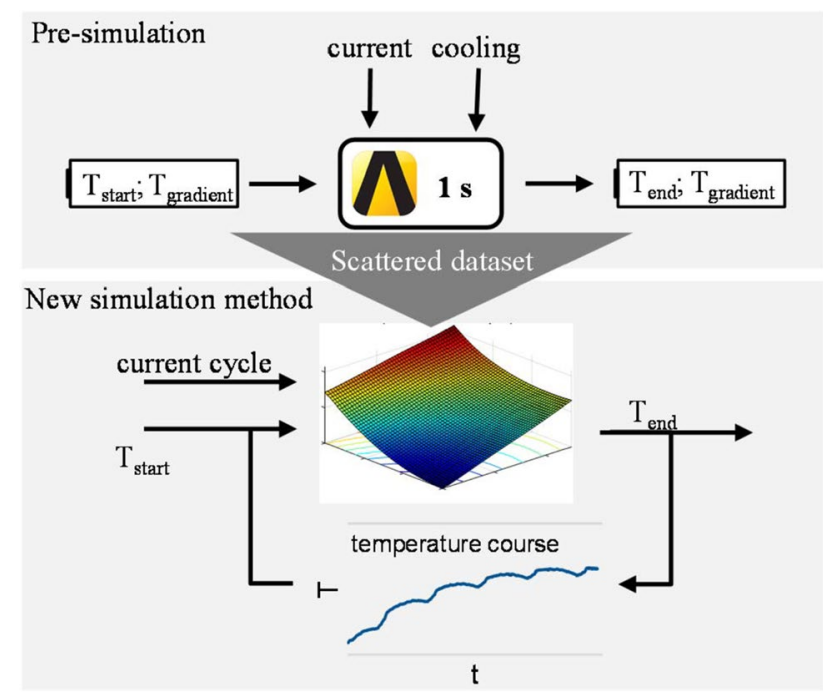

Fig. 21 Methodology for creating meta-models using thermal finite element model [99]
Optimization was performed by changing the channel position and width. The objective functions selected for optimization were temperature uniformity, average temperature, and pressure drop. 18 designs of channel based on position and width were adopted as shown in Fig. 31. A single design led to optimized average temperature and pressure while temperature uniformity was not achieved.

Anthony [104] studied the BTM system having cold plates inserted between the battery cells. The study was done by developing a thermal model using CFD. Later optimization study was also performed to find optimum configuration of the cold plate considering three main objectives: temperature distribution uniformity, decrease of peak temperature of the battery cells and drop in pressure of the liquid coolant. By applying this optimization technique, an improvement of about $70 \%$ was observed in comparison with the benchmark design. Jarrett and Kim [59] analysed the design process of a serpentine cooling plate used in EV batteries by determining the influence of various boundary conditions on the battery cooling plates. The serpentine cooling plate geometry used

Table 1 Summary of BTMS analysis method for optimization

\begin{tabular}{|c|c|c|c|c|c|c|}
\hline Battery & Battery type & Cooling fluid & $\begin{array}{l}\text { BTMS analysis } \\
\text { method }\end{array}$ & Objective functions & $\begin{array}{l}\text { Method of optimiza- } \\
\text { tion and tool used }\end{array}$ & References \\
\hline General & $\begin{array}{l}\text { Battery pack with } 150 \\
\text { cylindrical battery } \\
\text { cells }\end{array}$ & Air & Experimental work & $\begin{array}{l}\text { Variables of cooling } \\
\text { such as air velocity, } \\
\text { NTU, tube diameters, } \\
\text { to minimize power } \\
\text { consumption }\end{array}$ & Genetic algorithm & {$[83]$} \\
\hline Race car battery & Battery packs & Air & $\begin{array}{l}\text { Numerical using } \\
\text { COMSOL }\end{array}$ & $\begin{array}{l}\text { BTMS power con- } \\
\text { sumption, battery } \\
\text { area and maximum } \\
\text { temperature }\end{array}$ & $\begin{array}{l}\text { Particle swarm algo- } \\
\text { rithm. Matlab }\end{array}$ & [91] \\
\hline General & $\begin{array}{l}\text { Cylindrical battery } \\
\text { cells }\end{array}$ & Air & Experimental work & $\begin{array}{l}\text { Twenty-five different } \\
\text { parameters related to } \\
\text { battery cooling }\end{array}$ & $\begin{array}{l}\text { Modified NSGA-II and } \\
\text { TOPSIS algorithms }\end{array}$ & [92] \\
\hline EV's & $\begin{array}{l}\text { Cylindrical battery } \\
\text { cells }\end{array}$ & Air & $\begin{array}{c}\text { Numerical using } \\
\text { Ansys Fluent }\end{array}$ & $\begin{array}{l}\text { The peak temperature } \\
\text { within the cell and } \\
\text { the temperature } \\
\text { difference within the } \\
\text { active material }\end{array}$ & DOE & [93] \\
\hline Hybrid EV's & Prismatic battery cells & Air & $\begin{array}{l}\text { Numerical using } \\
\text { Ansys Fluent }\end{array}$ & $\begin{array}{l}\text { Bulk temperature, tem- } \\
\text { perature uniformity } \\
\text { and peak temperature } \\
\text { within the cell, fin } \\
\text { height of pin fins, } \\
\text { inlet air temperature. } \\
\text { Inlet air velocity }\end{array}$ & Ansys-Fluent & {$[95]$} \\
\hline General & Cylindrical & Air & Experimental work & $\begin{array}{l}\text { Charging time and } \\
\text { temperature rise opti- } \\
\text { mization strategy for } \\
\text { lithium-ion batteries }\end{array}$ & Genetic algorithm & {$[96,97]$} \\
\hline EV's & $\begin{array}{l}\text { Cylindrical with } 25 \\
\text { different cell sizes }\end{array}$ & Air & Ansys and Matlab & $\begin{array}{l}\text { The highest tempera- } \\
\text { ture within the cell } \\
\text { and the temperature } \\
\text { difference within the } \\
\text { active material }\end{array}$ & $\begin{array}{l}\text { Meta-model based } \\
\text { rapid simulation } \\
\text { technique }\end{array}$ & [99] \\
\hline
\end{tabular}


Fig. 22 Experimental set up of loop heat pipe for BTMS [100]

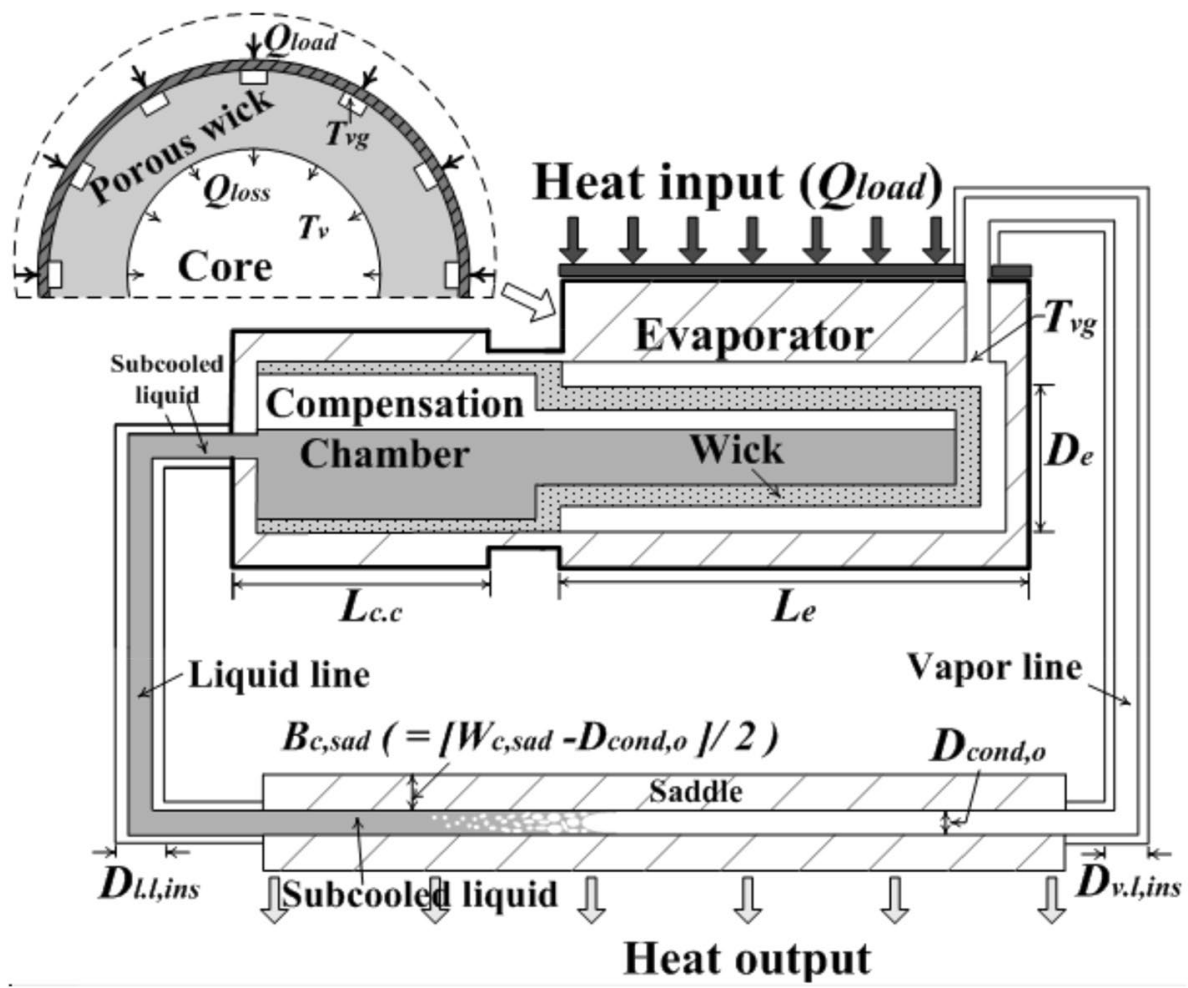

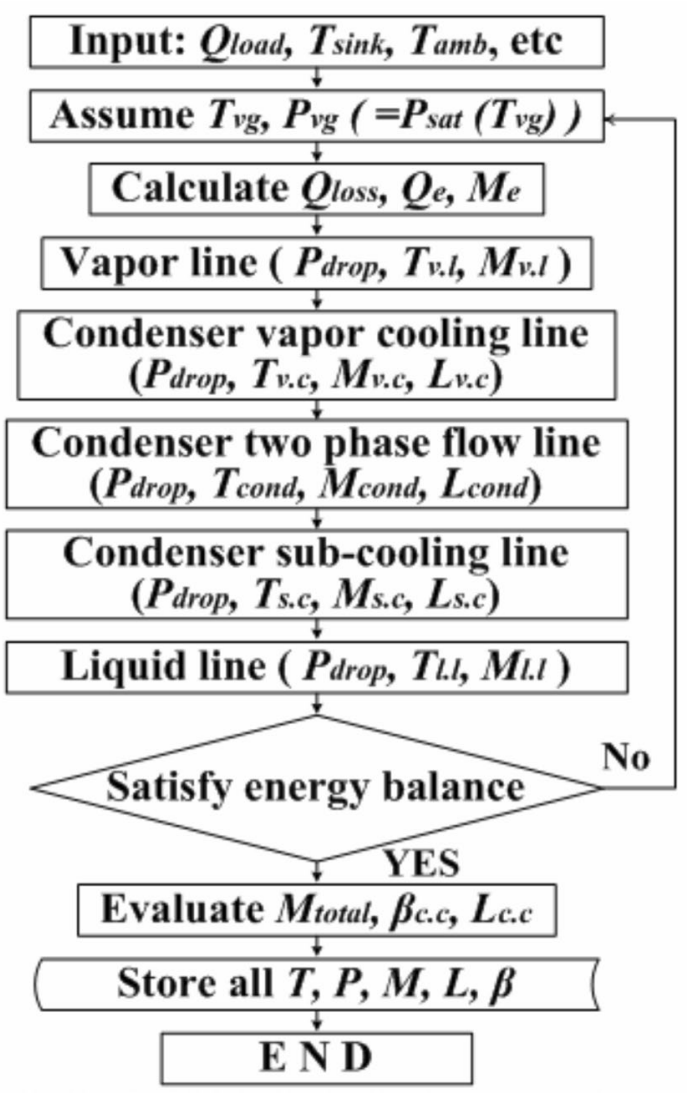

Fig. 23 Flow chart of optimization algorithm [100]

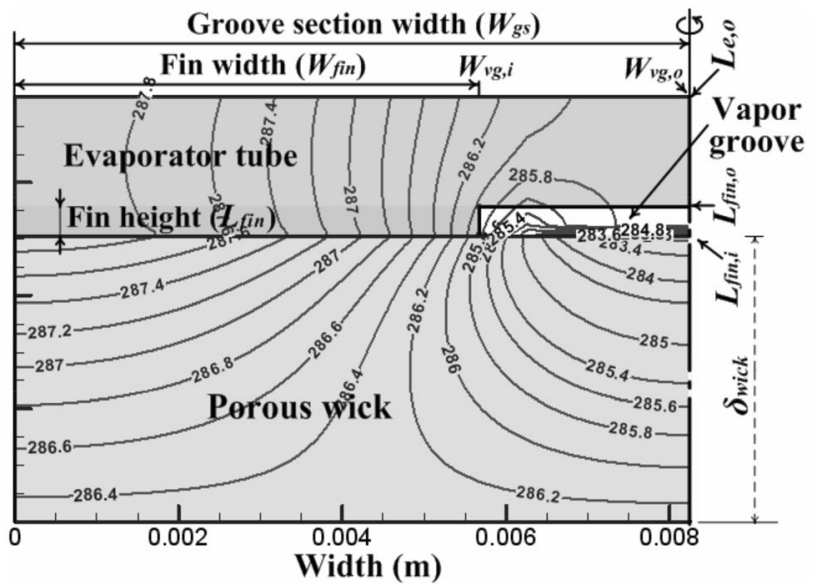

Fig. 24 Temperature distribution at the groove section [100]

for the study is shown in Fig. 32. In this plate, the coolant approaches at its upper left edge with a steady volume flow rate, while the opposite edge was maintained at atmospheric pressure. Heat flux boundary condition was applied at the lower face of the plate to simulate the heat generation of the battery and thermal symmetry boundary condition was applied at the upper face of the plate. The authors found that the design was very sensitive when boundary condition related to temperature uniformity was used. Matlab was used for optimization. Optimum cooling plates are shown in Fig. 33. The authors found that optimization for uniform 


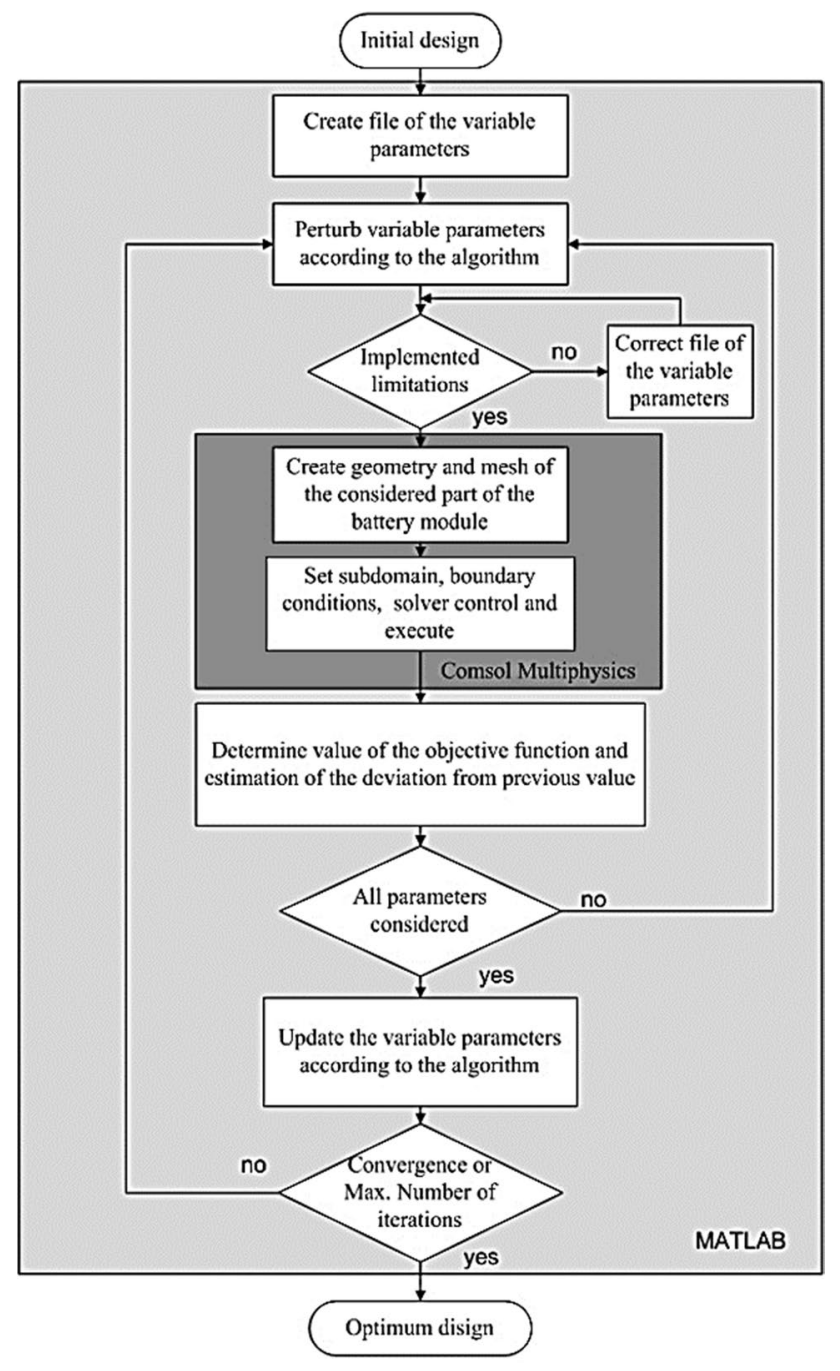

Fig. 25 Flow chart of optimization algorithm [5]

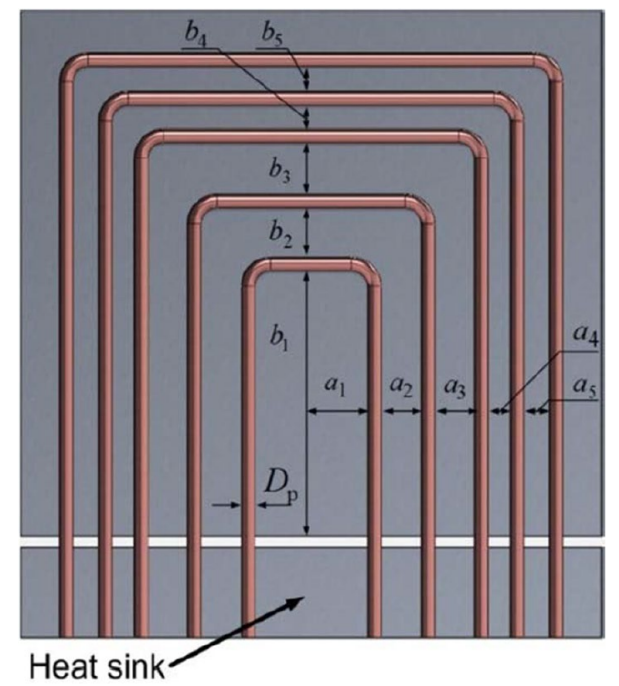

Fig. 26 Heat pipes placement for optimization [5]
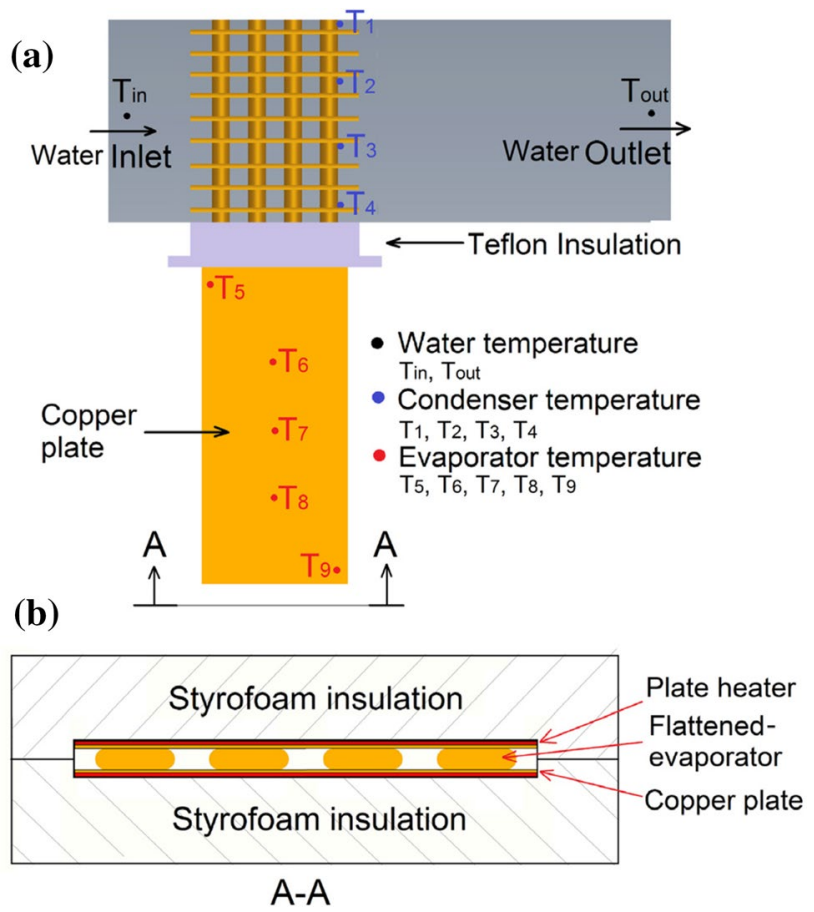

Fig. 27 Typical experimental setup of BTMS with heat pipes [101]

distribution of temperature was sensitive to both heat generation rate and volume flow rate of the coolant.

Joshua et al. [105] conducted CFD analysis using AnsysFluent to determine the effect of intake coolant temperature and flow rate of coolant on cooling efficiency of a BTMS inserted with a cooling plate. Multi-objective optimization (using Matlab) was then performed to obtain a tradeoff between the conflicting parameters like maximization of cooling efficiency and minimization of pressure drop. Using this analysis, a dynamic thermal management model was designed which give more efficiency than static onedimensional model designed for fixed flow rate and intake temperature. Zhang et al. [106] studied the influence of tab placements on pack temperature distributions of Lithium-ion battery cells. The six possible tab arrangements used in the study are shown in Fig. 34. Modelling and simulation were carried out using COMSOL Multi physics software. Lowering the peak temperature and improving the temperature uniformity of the battery pack were the two objectives of this study. So, optimization was performed to achieve the objectives. The results indicate an improvement in temperature distribution uniformity of the battery cells for symmetrical arrangement of the tabs. For positioning the tabs on the reverse or large side(s) of the battery cell, a reduction in peak temperature and an improvement in temperature distribution uniformity of the battery cells was observed. Details of optimization method for plate based cooling for BTMS is presented in Table 3 . 
Fig. 28 Proposed HPTMS (a) design at pack level (b) view from right side (c) view from front (d) testing unit of HPCP [102] (a)

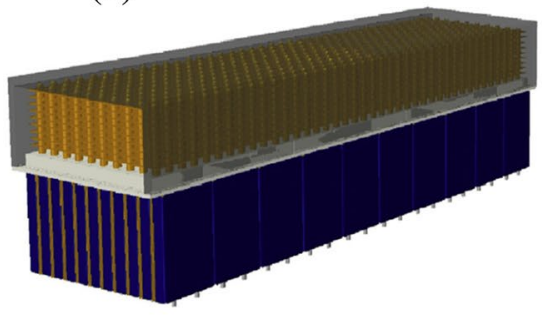

(c) (b)

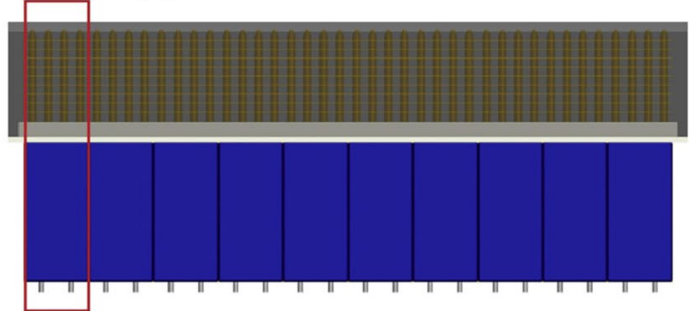

(d)
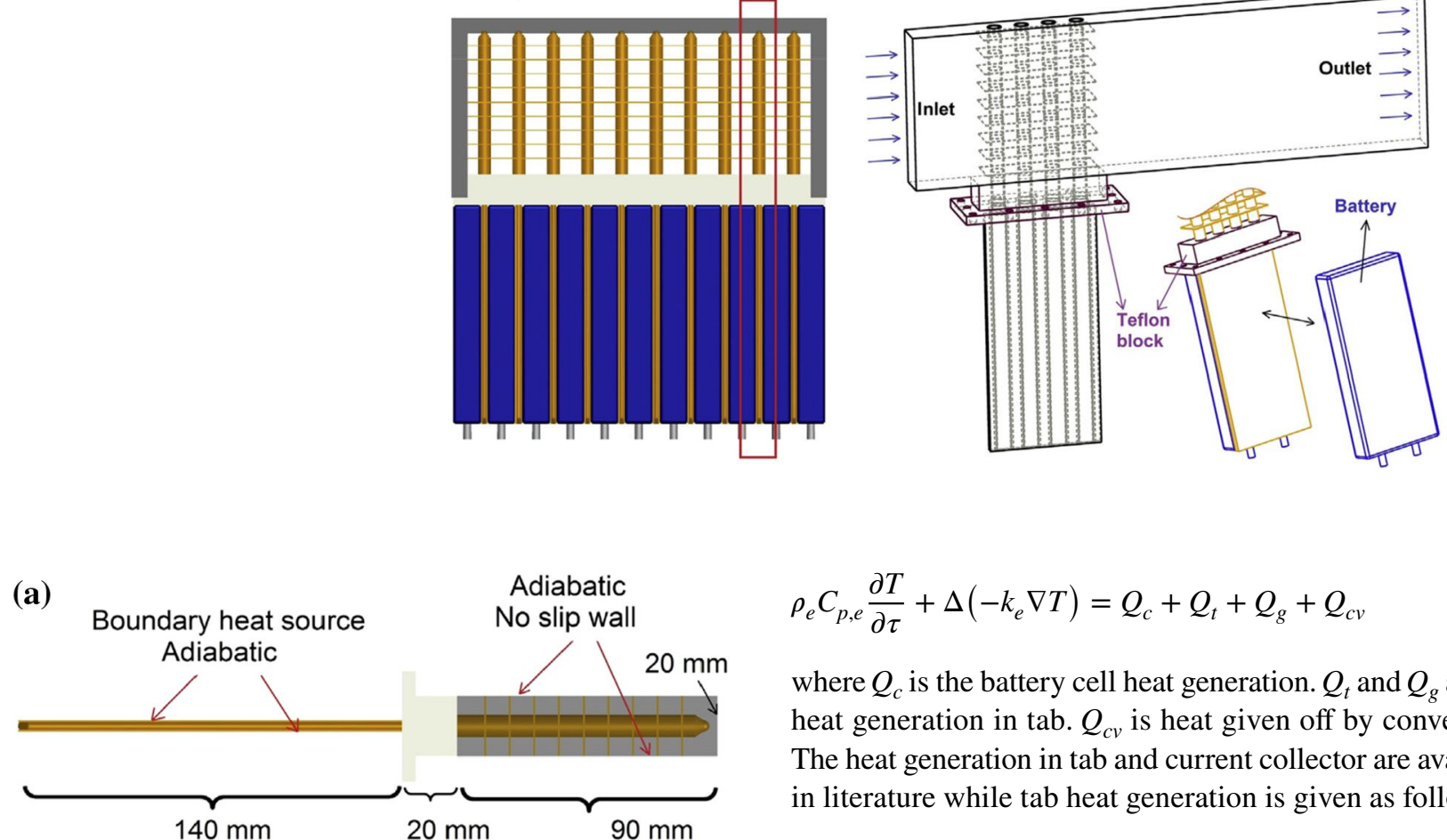

$\rho_{e} C_{p, e} \frac{\partial T}{\partial \tau}+\Delta\left(-k_{e} \nabla T\right)=Q_{c}+Q_{t}+Q_{g}+Q_{c v}$

where $Q_{c}$ is the battery cell heat generation. $Q_{t}$ and $Q_{g}$ are the heat generation in tab. $Q_{c v}$ is heat given off by convection. The heat generation in tab and current collector are available in literature while tab heat generation is given as follows:

$Q_{t}=I_{t}^{2} R_{t, i} \frac{1}{2 n_{c c, i}}$

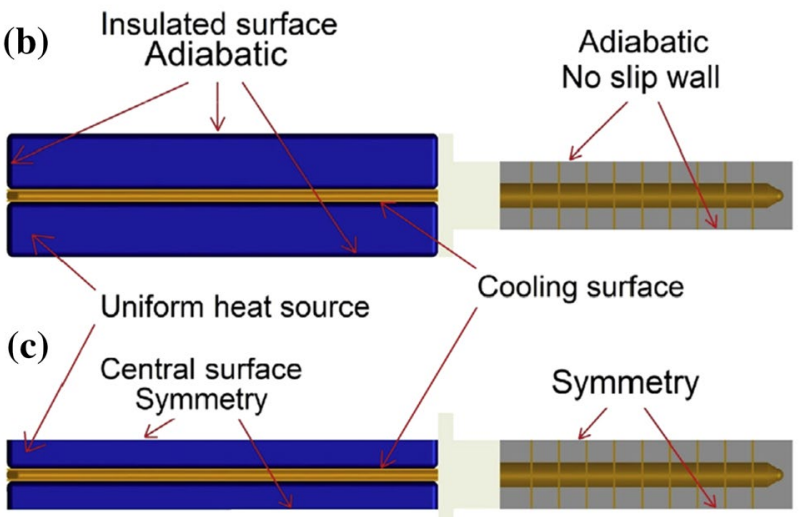

here $\mathrm{i}$ represents electrode (+ ve or $-\mathrm{ve}$ ). $R_{t}$ is the resistivity of tab. $n_{c c}$ is current collector numbers.

\subsection{PCM Cooling-Based}

Guiwen et al. [107] used composite PCM consisting of paraffin and expanded graphite with enhanced thermal conductivity for the thermal management of battery cells. Optimization was performed to find the optimum composition of expanded graphite in Paraffin composite PCM. The authors found a significant reduction in the temperature with an EG mass fraction varying from 9 to $20 \%$. Javani et al. [108] conducted exergy and energy analysis on BTMS consisting of a storage unit with PCM running parallel to a refrigeration system. Multi objective optimization is also carried to obtain a trade-off between the two conflicting parameters namely the exergy efficiency which is to be maximized and the total system cost to be minimized. Genetic algorithm was used for optimization. After getting the Pareto frontier, a particular 
Fig. 30 Proposed thermal resistance model to increase the uniformity of temperature in system [102]

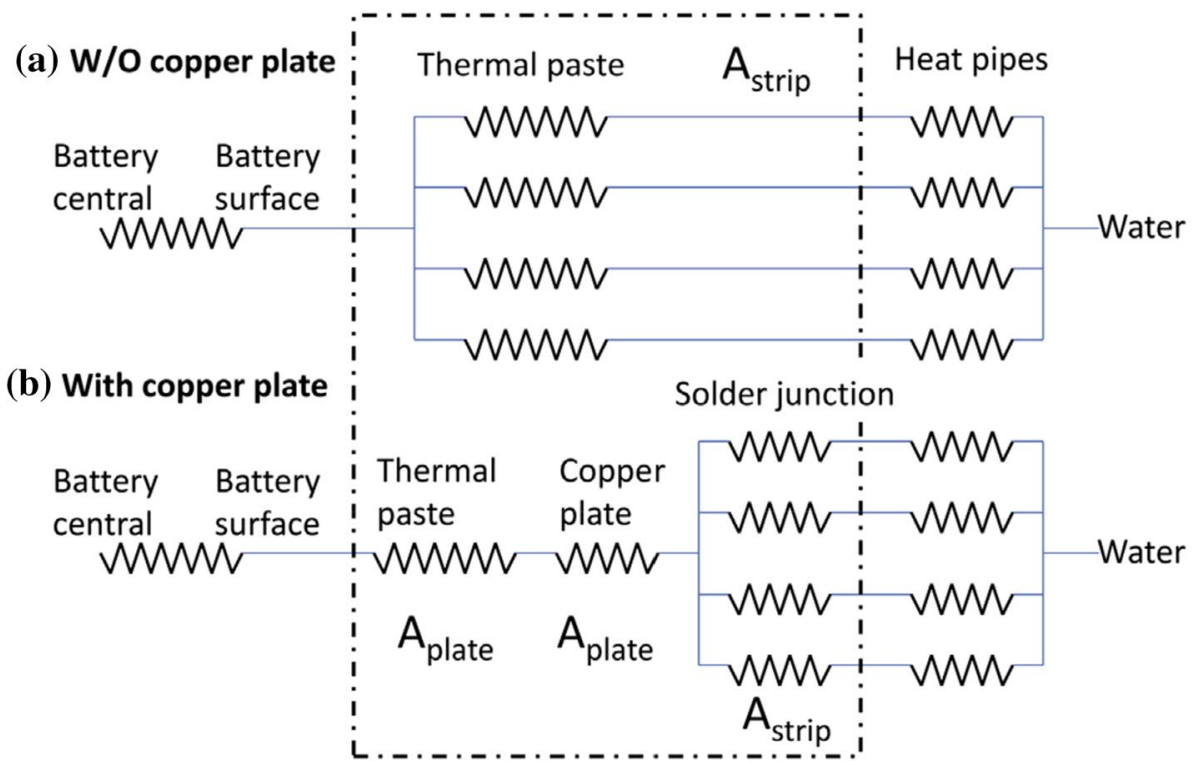

Table 2 Review of numerical BTMS optimization work

\begin{tabular}{lllll}
\hline Battery & Battery type & Cooling fluid & $\begin{array}{l}\text { BTMS analysis and optimiza- } \\
\text { tion tools }\end{array}$ & Objective functions \\
\hline Hybrid machines & Pouch-type battery cells & Liquid coolant & $\begin{array}{l}\text { Numerical using COMSOL } \\
\text { Multiphysics }\end{array}$ & $\begin{array}{c}\text { Reduction of non-uniform } \\
\text { spreading of temperature } \\
\text { contained by the battery } \\
\text { packs }\end{array}$ \\
General & 110 Prismatic cells & Water and methanol & $\begin{array}{c}\text { Numerical using COMSOL } \\
\text { Multiphysics }\end{array}$ & $\begin{array}{c}\text { Improving battery cooling } \\
\text { capacity and temperature } \\
\text { distribution }\end{array}$ \\
EV's & Prismatic battery cells & Air & [101] & $\begin{array}{c}\text { Nomeling effectiveness of the } \\
\text { proposed BTM system }\end{array}$ \\
\hline
\end{tabular}

desired optimal solution was obtained using LINMAP algorithm. From optimization they determined the maximum exergy together with lowest total cost.

\subsection{Mini-Channel Cooling-Based}

Liu et al. [109] developed a new tree type mini channels on the surface of battery and optimized the battery temperature using ANOVA (analysis of variance) and genetic algorithm. The heat sink shown in Fig. 35 was accessed for the angle of the channels (oblique) and width of inlet channel. Maximum temperature as single objective and in multi-objective temperature difference was also added as objective function. From optimization a reduction in maximum temperature of $33.69{ }^{\circ} \mathrm{C}$ was obtained.

Yutao et al. [60] conducted a numerical study on BTMS having mini-channel cold plates for cooling the battery packs. The main objective was to decrease the peak temperature and improve the temperature dissemination uniformity in the rectangular LIB cells. The 3D thermal model of the BTMS with mini channel cold plate was built using CFD code Fluent. The influence of various parameters including the number of channels, flow path, flow rate on thermal performance of battery was investigated. The authors found a decrease in the peak temperature of the battery with increase in flow rate and mini channels numbers. The influence of flow direction (Fig. 36) on thermal behaviour of the pack was more for low flow rates and decreased for high flow rates. The change of temperature (maximum) and temperature difference variation with flow direction and for constant flow rate of coolant is shown in Fig. 37. In Table 4 the details of optimization methods adopted for BTMS using mini-channels is mentioned. 


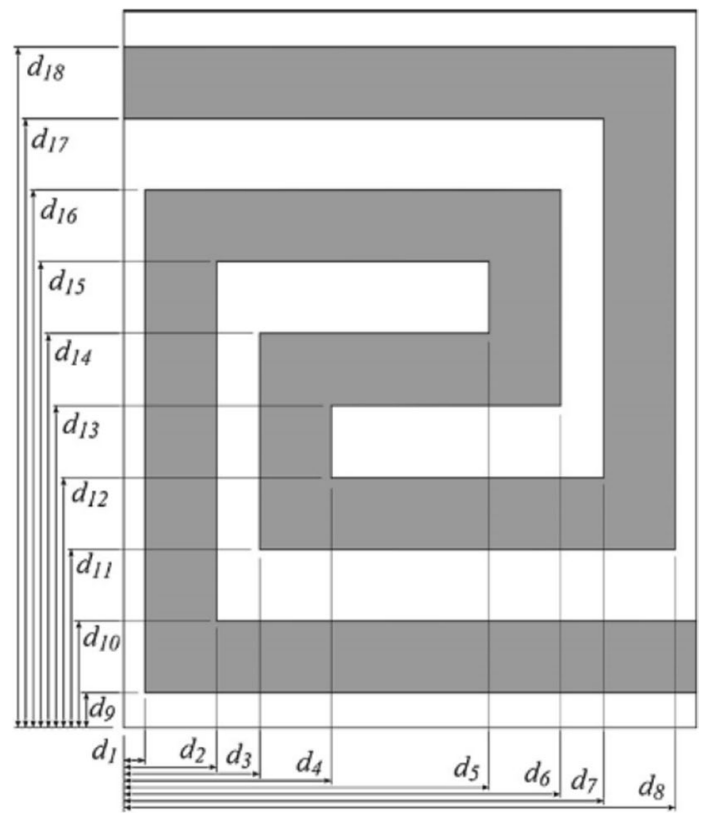

Fig. 3118 design variables of plate cooling channel adopted for optimization i.e., channel width and position [103]

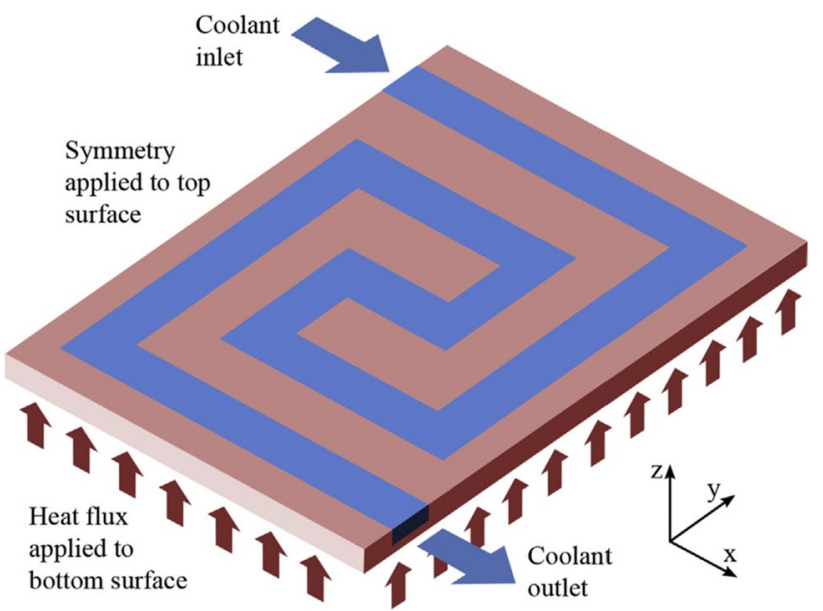

Fig. 32 Cooling plate used for the analysis [59]

\section{BTMS Investigation Based on Different Approaches}

\subsection{Hybrid Cooling}

Jaguemont et al. [110], has conducted 3D simulation of Lithium ion capacitor $(\mathrm{LiC})$ type battery cells in order to optimize the temperature, temperature uniformity and size of the battery. The thermal model for the battery module was constructed by using Multiphysics COMSOL and its equivalent electro-thermal model by using Matlab. Three different methods were adopted for cooling purpose. In the first method use of liquid cooling plate was suggested, second method uses phase change material (PCM) and finally combination of liquid cooling plate and PCM's (hybrid) were adopted to get the optimized solution. The obtained outcomes of this study show that the hybrid cooling method is an optimal choice in controlling the temperature uniformity and temperature gradient built up within the battery pack. Similarly Zhao et al. [111] conducted an experimental and numerical analysis of LIB module consisting of 40 cylindrical cell with an objective of optimizing the temperature, weight and volume of battery module. The thermal management system of battery makes use of embedded PCM, forced air cooling and combination of PCM and air cooling (hybrid) system. The Reynolds stress and renormalization group turbulent model, $\mathrm{k}-\varepsilon$ model was used to investigate the flow field of air within the battery module. The results of this study reveal that when forced air cooling was used in combination with PCM cooling (hybrid cooling) the uniformity in temperature distribution within the battery pack can be optimized. Zhao et al. [111] used an apparent heat capacity method in order to determine the temperature distribution in the battery cells surrounded by PCM region, and is given as follows:

$\sigma_{p c m} S_{p, p c m} \frac{\partial T}{\partial \tau}=\nabla \cdot(K \nabla T)$

where $\sigma$ is the density and the subscripts pcm indicates the properties for PCM, K is the thermal conductivity, and T is the temperature.

Wherein

$S_{p, p c m}=S_{s} ; T<T_{s}$, solid phase

$S_{p, p c m}=(1-\beta) S_{s}+\beta S_{l}+\frac{h_{f}}{T_{l}-T_{s}} ; T_{s}<T<T_{l}$, solid or liquid phase

$S_{p, p c m}=T_{l} ; T>T_{l}$, liquid phase

where $h_{f}$ is latent heat of phase change. $S_{l}, S_{s}$ are PCM specific heat at respective liquid and solid state,. $\beta$ is the liquid fraction of PCM and can be expressed as-

$\beta=\frac{T-T_{s}}{T_{l}-T}$ for $T_{s}<T<T_{l}$

where $T_{l}$ and $T_{s}$ are upper and lower bounds of melting range of PCM. The contour plots for temperature distribution and velocity in both the PCM embedded and original battery packs are compared and it was found that the PCM embedded battery pack gives more uniformity in temperature distribution which can be considered to be the best optimal battery pack. The contours are illustrated in the Fig. 38 .

$\mathrm{Wu}$ et al. [112] constructed a 2D thermal model for a large module batteries with high discharge rate cooled with 
Fig. 33 Optimum cooling plate designs

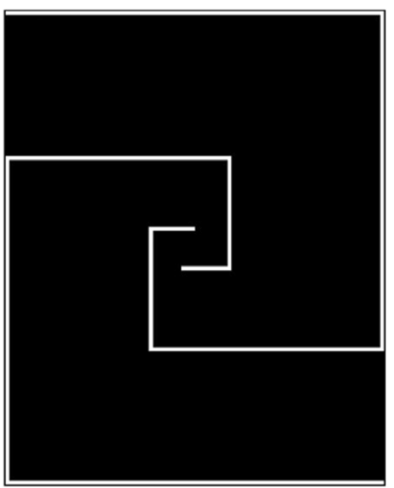

(a)

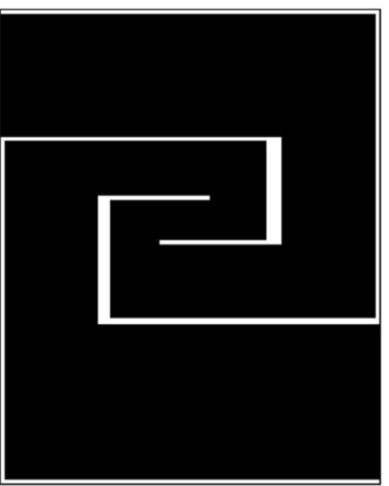

(b)

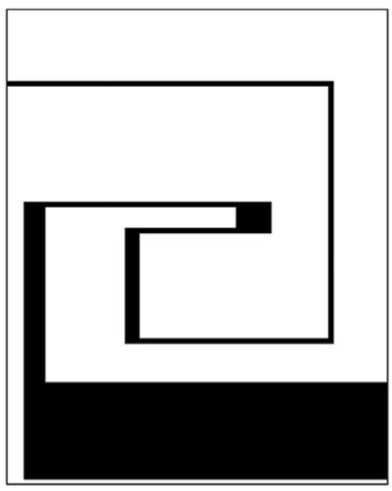

(c)
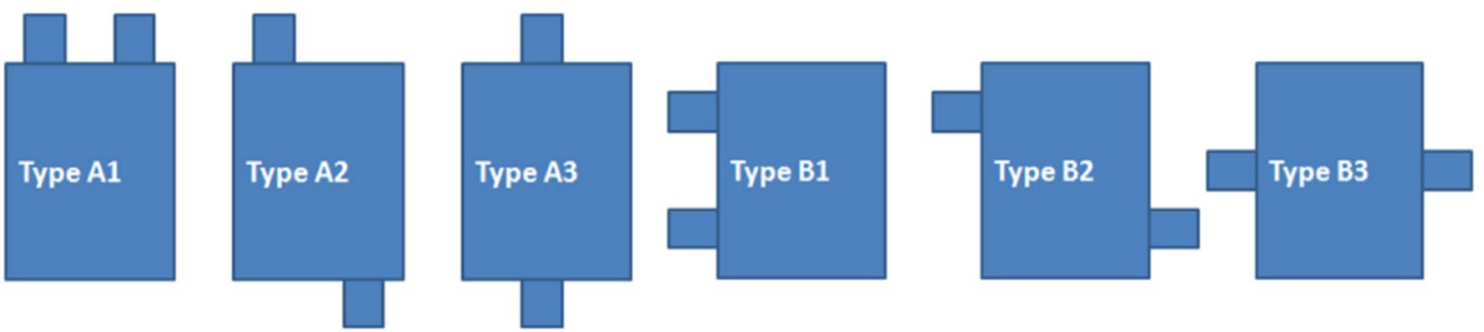

Fig. 34 Six possible tab arrangements of the battery cells [106]

Table 3 Overview of plate-cooling based optimization

\begin{tabular}{|c|c|c|c|c|c|c|}
\hline Battery & Battery type & Cooling fluid & $\begin{array}{l}\text { BTMS analysis } \\
\text { method }\end{array}$ & Objective functions & $\begin{array}{l}\text { Method of optimiza- } \\
\text { tion and tool used }\end{array}$ & References \\
\hline General & Single pack & $\begin{array}{l}\text { Water-ethylene } \\
\text { glycol }\end{array}$ & $\begin{array}{l}\text { Numerical using } \\
\text { Fluent }\end{array}$ & $\begin{array}{l}\text { Pressure drop, tem- } \\
\text { perature uniform- } \\
\text { ity, and average } \\
\text { temperature }\end{array}$ & $\begin{array}{l}\text { All possible designs } \\
\text { are selected. } \\
\text { Matlab software } \\
\text { is used }\end{array}$ & {$[103]$} \\
\hline General Motors & Single pack & Liquid coolant & $\begin{array}{l}\text { Numerical using } \\
\text { CFD solver, FLU- } \\
\text { ENT }\end{array}$ & $\begin{array}{l}\text { Temperature uni- } \\
\text { formity, average } \\
\text { temperature, and } \\
\text { pressure drop }\end{array}$ & $\begin{array}{l}\text { All possible bound- } \\
\text { ary conditions are } \\
\text { selected. Matlab } \\
\text { software is used }\end{array}$ & [59] \\
\hline General & $\begin{array}{l}\text { Pouch-type LIB with } \\
\text { higher energy den- } \\
\text { sity than cylindri- } \\
\text { cal cells }\end{array}$ & Air & $\begin{array}{l}\text { Numerical using } \\
\text { COMSOL software }\end{array}$ & $\begin{array}{l}\text { Peak temperature } \\
\text { lowering and } \\
\text { increasing the } \\
\text { battery temperature } \\
\text { uniformity }\end{array}$ & COMSOL software & [106] \\
\hline
\end{tabular}

Paraffin or expanded graphite (EG) composite based PCM and pyrolytic graphite sheet (PGS). The battery performance is optimized in terms of energy saving, temperature uniformity and thermal fluctuations within the battery module. A 2 X6 battery model was constructed by using solid-work CAD package and simulation part is carried by the AnsysFluent a commercially available CFD tool. It is observed that when PCM is used in combination with PGS the thermal performance will get improve and temperature uniformity within the battery module can be controlled to greater level. The results of this study clearly show that the combination of PCM/PGS module (hybrid module) gives the best optimal performance. Figure 39 shows the maximum temperature variation and temperature difference within the two battery modules i.e. PCM and PCM/PGS for various convective heat transfer coefficient and this figure clearly indicates that PCM/PGS module is more optimal compared to PCM module.

It was stated from the above Fig. 39 that with increase in the convective heat transfer coefficient the maximum 


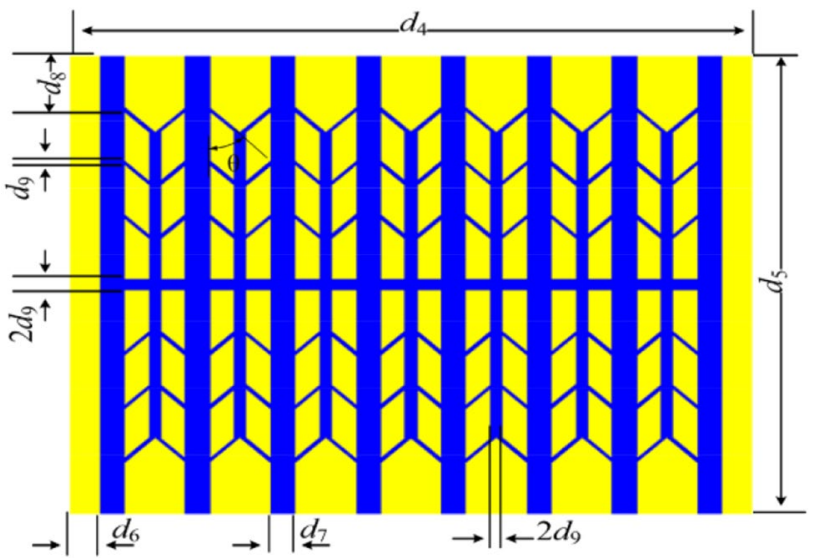

Fig. 35 Mini channel pattern (tree type) on the surface of battery showing design variables for optimization [109]

temperature in battery pack decreases and it is optimal for PCM/PGS embedded module. Ling et al.[113] used both an experimental and numerical approach to study the LIB thermal performance with 12 number of modules. The objective function of this study was to optimize the mass fraction of composite PCM, weight of the battery, compactness and maximum temperature in the battery modules. Response surface methodology (RSM) was applied as an optimizing technique. Liquid cooling in combination with different mass fractions of composite PCM/EG were used to improve the thermal management system of battery modules. Numerical simulation is performed by using Ansys-Fluent and governing equations for fluid flow are solved by using SIMPLE algorithm. The obtained results out of this study shows that the maximum temperature and temperature difference in batteries can be reduced to greater extend just by increasing the spacing between the batteries. The composite PCM/EG with high thermal conductivity and density can improve the thermal performance of the battery.
The above Table 5 gives a brief overview of different hybrid cooling strategy adopted by Ling et al.[113] and it was found that case 3 with small mass fraction of composite PCM/EG along with liquid cooling will be the optimal choice for BTMS in terms of controlling the maximum temperature, temperature distribution and temperature uniformity. Becker et al.[114] investigated numerically the performance of hybrid type LIB system consisting of different battery cell pack like prismatic, pouch type and cylindrical geometry. The purpose of using the hybrid battery system was to optimize the battery lifetime, battery weight, volume and its cost. To achieve the desired optimization a covariance matrix adaption evolution strategy (CMAES) algorithm was used. The battery system makes use of passive cooling along with active air or liquid cooling (Hybrid cooling) in order to study the BTMS. The numerical simulation of battery thermal model was carried by using Matlab Simulink vehicle model for different number of parameters such as battery format, composition of battery electrodes, power density, and energy density. The results of this study showed that using hybrid battery cooling system in electric vehicles reduces the weight, volume and cost of the whole battery model.

Figure 40 illustrate the working of optimization method adopted in this study along with vehicle model. Initially number of different parameters were defined which will be tested CMAES algorithm and this test is repeated for 1000 times or more until optimized result were obtained. Figure 41 indicates the output results obtained for single battery pack and Hybrid battery pack compared for five different electric vehicles and it is clearly observed from the figure that adopting the Hybrid battery system in compact, medium, high class and Sports utility vehicles (SUV) type will be best choice compare to single battery pack.

Kong et al. [115] performed an experimental and numerical investigation of LIBs of LiNiMnCoAlO2 (NMC) cathode

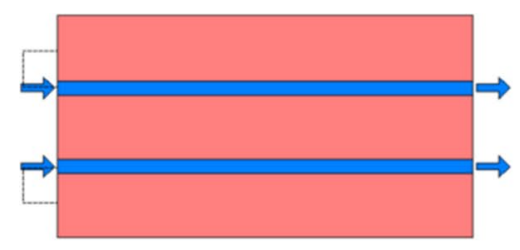

2 channels

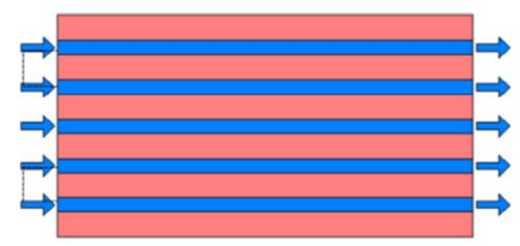

5 channels

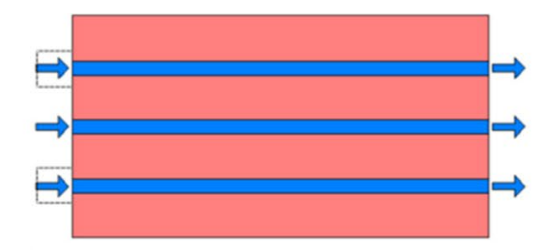

point

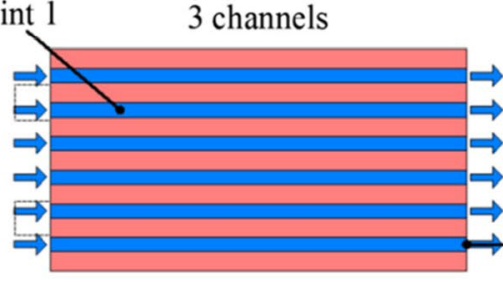

6 channels

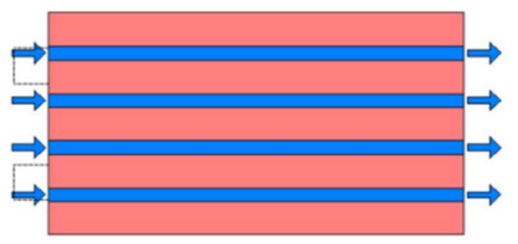

4 channels

Fig. 36 Influence of flow direction on thermal performance of BTMS [60] 


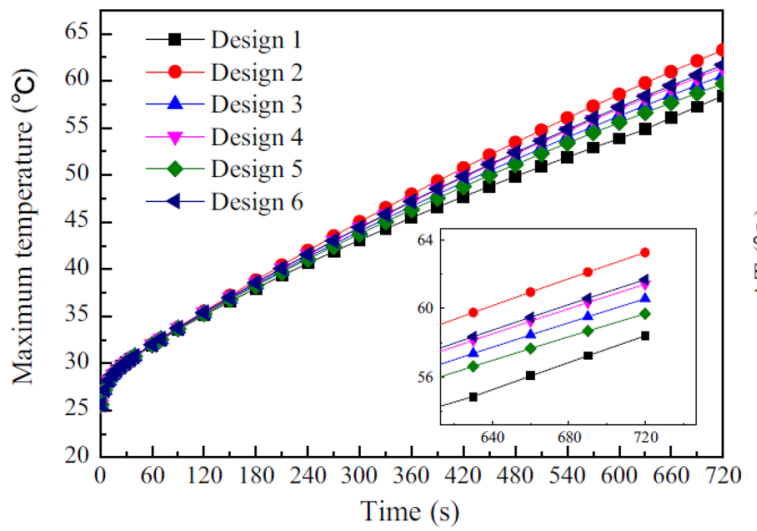

(a)

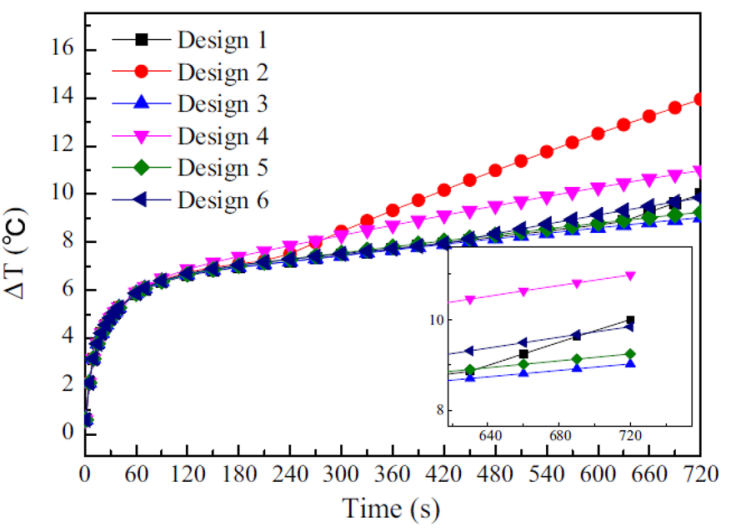

(b)

Fig. 37 Change in temperature (maximum) and temperature difference with flow direction [60]

with design optimization of cell to cell spacing, cell to tube distance, channel number and coolant velocity. A coupled PCM liquid cooling thermal battery management system (CPLS) was used to maintain the temperature of battery within the prescribed limit. The numerical simulation was carried by the COMSOL Multiphysics software and the results obtained shows that increasing the cell to cell spacing beyond $5 \mathrm{~mm}$ improves the thermal performance of battery system while the cell to tube distance beyond $2 \mathrm{~mm}$ improves the temperature uniformity. Figure 42 illustrate the temperature behaviour in battery pack for three different cooling system and it is clearly observed that the temperature drastically rises in natural convection, while drop in temperature is seen in PCM cooling while more effective temperature distribution is seen for CPLS cooling system. Table 6 is an overview of hybrid method based cooling optimization.

\subsection{Air-Cooling}

Wang et al. [116] performed a numerical simulation of LIB consisting of 36 number of prismatic cells with an objective to optimize the battery lifetime, fan power and battery volume. The BTMS in this investigation makes use of air as a cooling medium. The thermal model of battery module was simulated by means of Ansys-Fluent. The pressure based solver along with $\mathrm{k}-\varepsilon$ turbulence model is used to simulate the fluid flow conditions. The thermal radiation heat transfer effects are totally neglected in this study. The fan power can be calculated in this BTMS system is calculated as follows:

$P_{f a n}=\delta P \frac{V}{\eta}$

where $P_{f a n}$ and $\delta P$ are the fan power and the pressure difference in air at inlet and outlet, respectively. $V$ is the volume flow rate of the air. $\eta$ is the fan efficiency. The heat generated by a battery cell can be calculated by

$Q^{\prime}=I\left(V_{o}-V_{c}\right)=I^{2} R_{i}$

where $Q^{\prime}$ is heat generated in battery cell. I is flowing current in battery cell. $V_{o}$ is voltage in open circuit. $V_{c}$ is voltage of cell. $R_{i}$ is battery cell internal resistance to current.

The above Fig. 43 illustrate the Sobol sequence method the most broadly used for surrogated modelling of battery pack. The Sobol sequence method gives best possible

Table 4 Summary of optimization technique for mini-channel based cooling

\begin{tabular}{llllccc}
\hline Battery & Battery type & Cooling system & BTMS analysis method & Objective functions & $\begin{array}{c}\text { Method of } \\
\text { optimization } \\
\text { and tool used }\end{array}$ & $\begin{array}{c}\text { References } \\
\text { Li-ion }\end{array}$ \\
& Single battery & Water & $\begin{array}{c}\text { Experimental and numerical } \\
\text { using Fluent software }\end{array}$ & $\begin{array}{c}\text { Maximum temperature, temperature } \\
\text { difference }\end{array}$ & $\begin{array}{c}\text { ANOVA and } \\
\text { genetic algo- } \\
\text { rithm. Matlab } \\
\text { software }\end{array}$ & $\begin{array}{c}{[109]} \\
\text { Li-ion }\end{array}$ \\
& Rectangular & Water & Numerical using Fluent software & $\begin{array}{c}\text { Maximum temperature, uniform software } \\
\text { distribution of temperature }\end{array}$ & [60] \\
\hline
\end{tabular}


a)

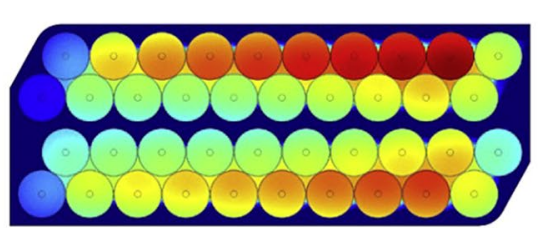

b)

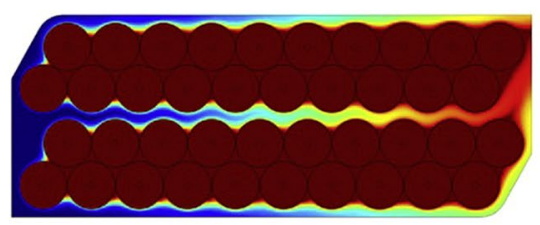

c)

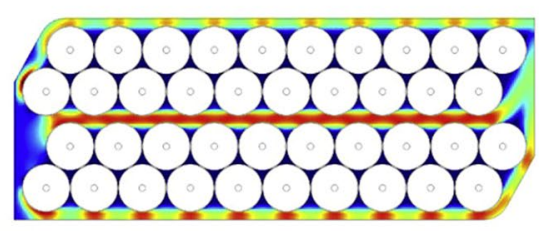

- 47.4

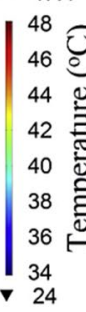

A 47.4

34.4 (3)

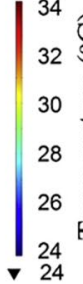

$\Delta 6.58$

$\mid \begin{aligned} & 6 \\ & 5 \\ & 4 \\ & 3 \\ & 2 \\ & 1 \\ & 0 \\ & 0\end{aligned}$

f)

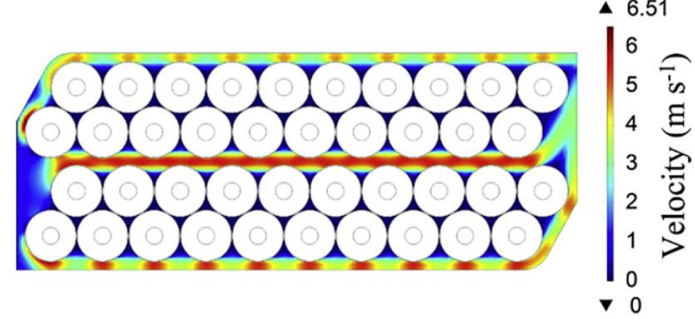

d)

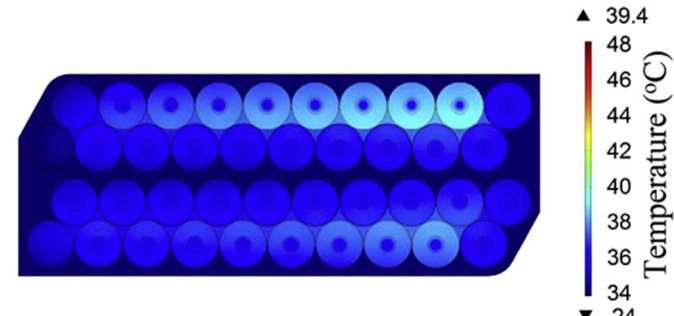

e)

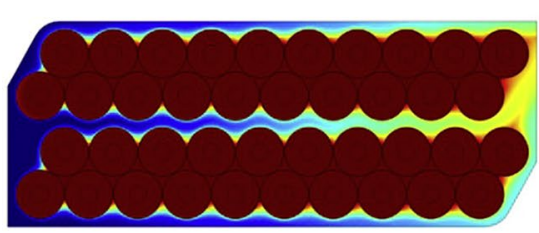

- 39.4

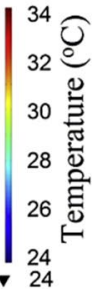

24
Fig. 38 Temperature contours in battery cell a battery pack without embedded PCM, b battery pack without embedded PCM, $\mathbf{c}$ battery pack without embedded PCM, $\mathbf{d}$ battery pack with embedded PCM (optimal battery pack), temperature contours of coolant channel, $\mathbf{e}$

uniformity and optimality in solution compared to other available methods. The study also predicts the relationship between the battery loss capacities, battery lifetime and battery temperature which is illustrated in Fig. 44. It was concluded that the LIB losses its capacity with increase in time for which battery was used and with temperature within the battery pack. There exists the critical value for used time and temperature above which the battery capacity decreases drastically.

Shahid and Chaab [117] performed an experimental and numerical analysis of LIB pack consisting of cylindrical battery cells with an objective of obtaining the best cooling arrangement to optimize the maximum temperature distribution, temperature uniformity, air mass flow rate and power required for cooling system. The authors have suggested the four different arrangements at inlet plenum of battery pack in order to find out which among the four cooling arrangements is optimal one. The numerical simulation of thermal model is carried by the help of Ansys-Fluent while the air flow simulation is made by shear stress transport (SST) k- $\omega$ model. The contours plotted for velocity of air, turbulence kinetic energy and temperature in a battery pack with most optimal arrangement among the four arrangements are shown in the Fig. 45.

battery Pack with embedded PCM (optimal battery pack), velocity contours, $\mathbf{f}$ battery pack with embedded PCM (optimal battery pack) [111]

It was quantified from the Fig. 45 that the best optimal arrangement of battery pack gives better temperature distribution uniformity, high level of flow energy of coolant which makes it the best optimal BTMS configuration. Zhang et al. [106] carried out analytical, experimental and numerical simulation of pouch type Li-ion battery subjected to flow of air acting as cooling medium. The prime objective of this study was to optimize the temperature distribution, temperature uniformity and maximum temperature in battery pouch. The study was done for different arrangements of electric current collecting battery tabs, as the location of collecting tab changes the current density and which further changes the localized heat generation rate of the battery pouch. The electrochemical-electrical-thermal coupled modelling approach was used for the analysis purpose and the obtained results are validated experimentally along with numerical simulation done by using COMSOL. The obtained results of this study show that symmetrical arrangement of tabs gives better temperature uniformity on battery pouch surface, whereas tab on opposite side along longer length of the battery pouch controls the maximum temperature more efficiently. The Heat generation rate (HGR) in a battery cell unit is given as follows: 


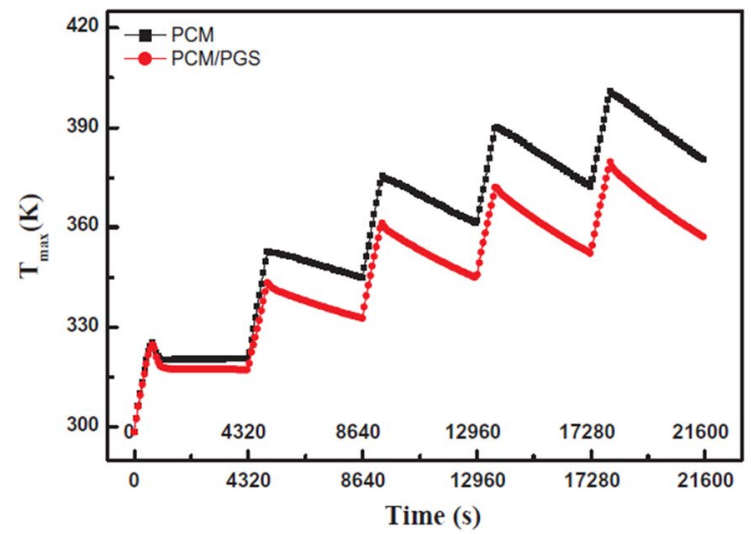

(a) $10 \mathrm{~W} \mathrm{~m}^{-2} \mathrm{~K}^{-1}$

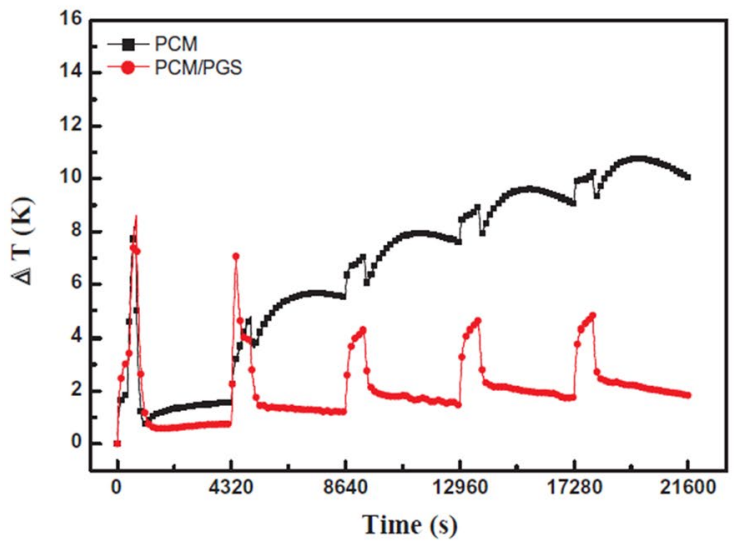

(c) $10 \mathrm{~W} \mathrm{~m}^{-2} \mathrm{~K}^{-1}$

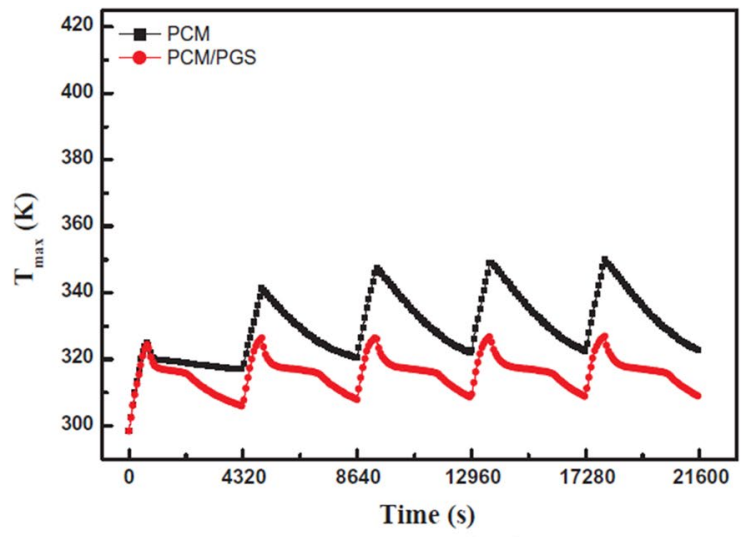

(b) $50 \mathrm{~W} \mathrm{~m}^{-2} \mathrm{~K}^{-1}$

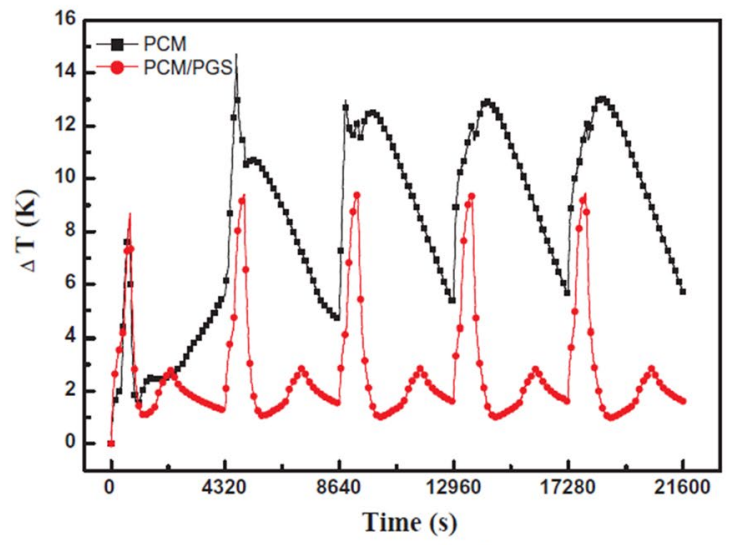

(d) $50 \mathrm{~W} \mathrm{~m}^{-2} \mathrm{~K}^{-1}$

Fig. 39 Optimized max temperature comparison between PCM module and PCM/PGS module a $10 \mathrm{Wm}^{-2} \mathrm{~K}^{-1}$, b $50 \mathrm{Wm}^{-2} \mathrm{~K}^{-1}$, temperature difference comparison between PCM module and PCM/PGS module, $\mathbf{c} 10 \mathrm{Wm}^{-2} \mathrm{~K}^{-1}$ and $\mathbf{d} 50 \mathrm{Wm}^{-2} \mathrm{~K}^{-1}$ [112]

Table 5 Optimal Choice of Hybrid cooling [113]

\begin{tabular}{|c|c|c|c|c|c|}
\hline & Parameter & Original design & $\begin{array}{l}\text { Case } 1- \\
\text { cooling from } \\
\text { side }\end{array}$ & $\begin{array}{l}\text { Case } 2-\text { cool- } \\
\text { ing from top and } \\
\text { bottom }\end{array}$ & $\begin{array}{l}\text { Case } 3 \text { - cooling from top and } \\
\text { bottom with composite PCM of } \\
\text { low PCM mass fraction }\end{array}$ \\
\hline \multirow[t]{8}{*}{ Input variables } & $\mathrm{D}(\mathrm{mm})$ & 30 & 27.4 & 20.0 & 20.1 \\
\hline & $\rho\left(\mathrm{kg} \mathrm{m}^{-3}\right)$ & 714 & 457 & 453 & 252 \\
\hline & $\alpha(\%)$ & 30 & 30 & 50 & 25 \\
\hline & $\mathrm{c}_{\mathrm{p}}\left(\mathrm{Kj} \mathrm{kg}^{-1}{ }^{\circ} \mathrm{C}^{-1}\right)$ & 2.0 & 2.0 & 1.4 & 1.2 \\
\hline & $k\left(\mathrm{Wm}^{-1}{ }^{\circ} \mathrm{C}^{-1}\right)$ & 8.3 & 5.4 & 11.6 & 10.9 \\
\hline & $\mathrm{H}(\mathrm{kJ})$ & 176 & 174 & 120 & 55 \\
\hline & $\mathrm{H}_{\mathrm{top}}\left(\mathrm{Wm}^{-2}{ }^{\circ} \mathrm{C}^{-1}\right)$ & 30 & 12 & 865.9 & 505 \\
\hline & $\mathrm{h}_{\text {side }}\left(\mathrm{Wm}^{-2}{ }^{\circ} \mathrm{C}^{-1}\right)$ & 46 & 23.4 & 12 & 12 \\
\hline \multirow[t]{7}{*}{ Output parameters } & $\mathrm{T}_{\max }\left({ }^{\circ} \mathrm{C}\right)$ & 45.2 & 46.1 & 46.7 & 44.1 \\
\hline & $\Delta \mathrm{T}\left({ }^{\circ} \mathrm{C}\right)$ & 2.3 & 3.9 & 1.4 & 0.3 \\
\hline & $\beta$ & 0 & 0 & 0 & 0 \\
\hline & $\mathrm{m}(\mathrm{kg})$ & 0.135 & 0.074 & 0.021 & 0.008 \\
\hline & Mass reduction percentage (\%) & 0 & 45.2 & 84.4 & 94.1 \\
\hline & Volume $\left(\mathrm{dm}^{3}\right)$ & 1.17 & $0.9 \mathrm{~S}$ & 0.52 & 0.52 \\
\hline & Volume reduction percentage $(\%)$ & 0 & 16.2 & 55.6 & 55.6 \\
\hline
\end{tabular}




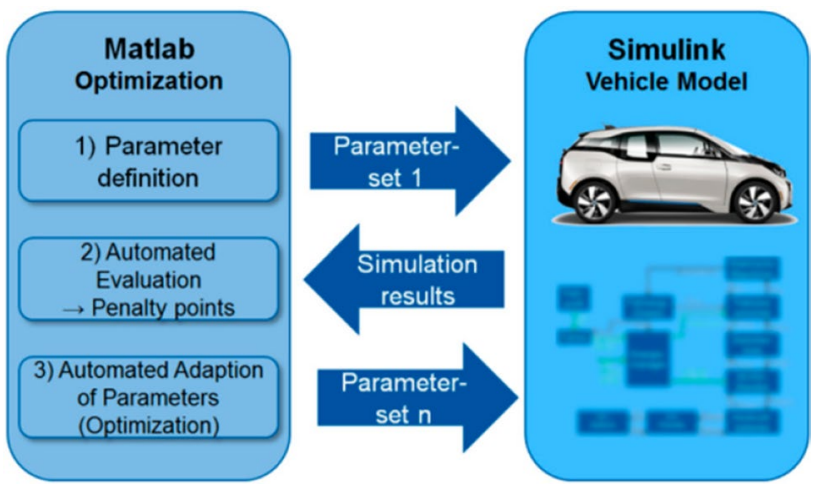

Fig. 40 Optimization method with vehicle model [114]

$H G R_{\text {total }}=C_{t}\left(V_{o c}-V_{w}\right)-C_{t} T \frac{d V_{o c}}{d T}$ where $H G R_{\text {total }}$ is the total heat generation rate in a cell, $C_{t}$ total current passing through the cell, $V_{o c}$ open circuit voltage, $V_{w}$ working voltage, $T$ is the cell temperature, and $\frac{d V_{o c}}{d T}$ is temperature- entropy fraction. The total HGR in the collecting tab can be determined by

$H G R_{t a b, i}=K_{t a b}^{2} R_{t a b, i}^{\prime} \frac{1}{2 N_{c c, i}}$

where $H G R_{t a b}$ is heat generation rate at collecting tab, $K_{t a b}$ is the current density passing through the collecting tab, $R_{t a b}^{\prime}$ resistivity of collecting tab, i denotes positive or negative electrode, $N_{c c}$ number of current collectors. Figure 46 shows the temperature distribution within the battery pouch for different collecting tab arrangement near the start and end of battery discharging process, one can easily predict that it is better to place the collecting tab at opposite side on

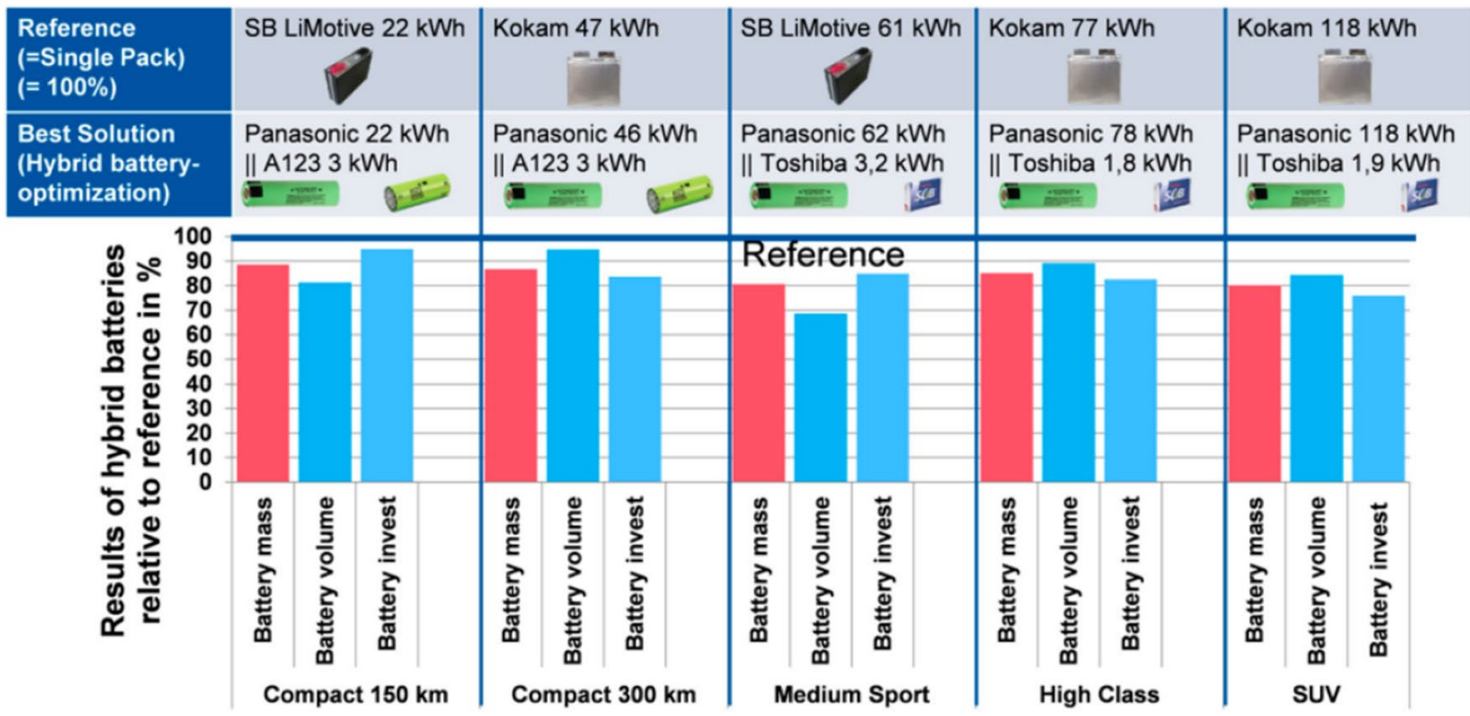

Fig. 41 Hybrid battery system optimization in five different electric vehicles [114]

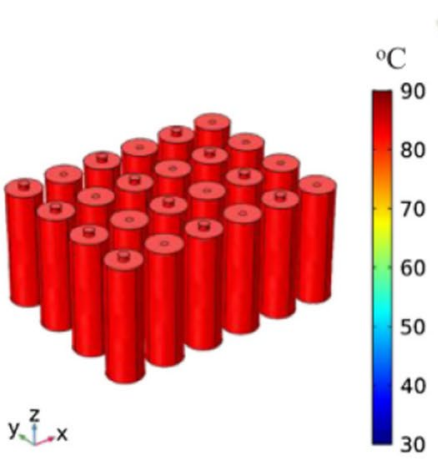

(a) Natural convection

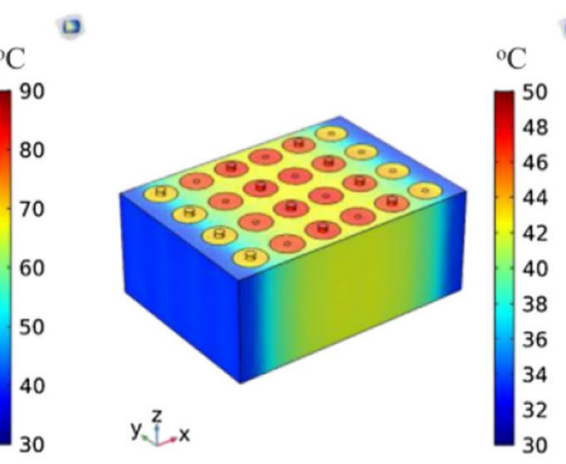

(b) PCM a

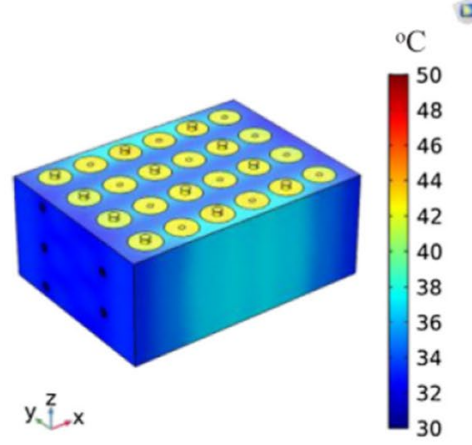

(c) CPLS

Fig. 42 Temperature profiles for a Natural convection cooling, b PCM cooling, c CPLS cooling [115] 


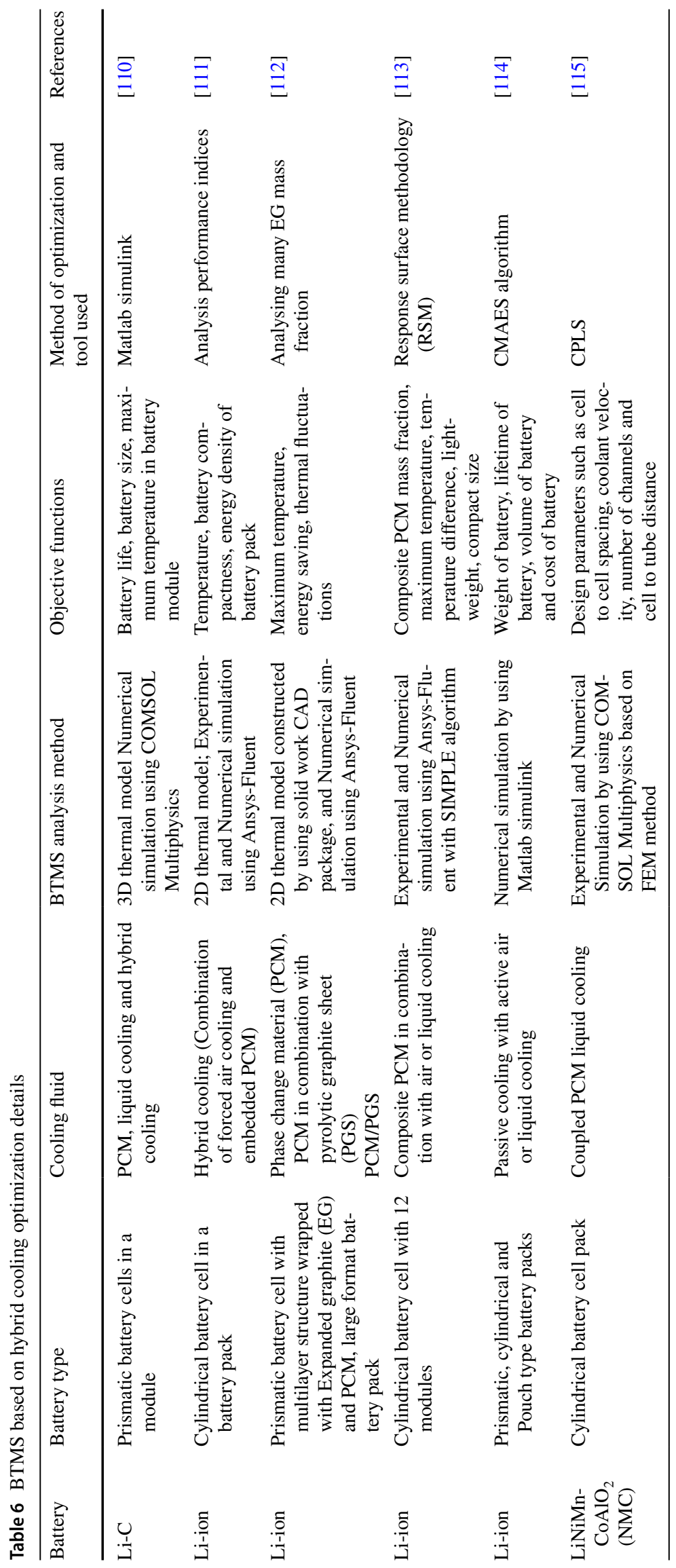




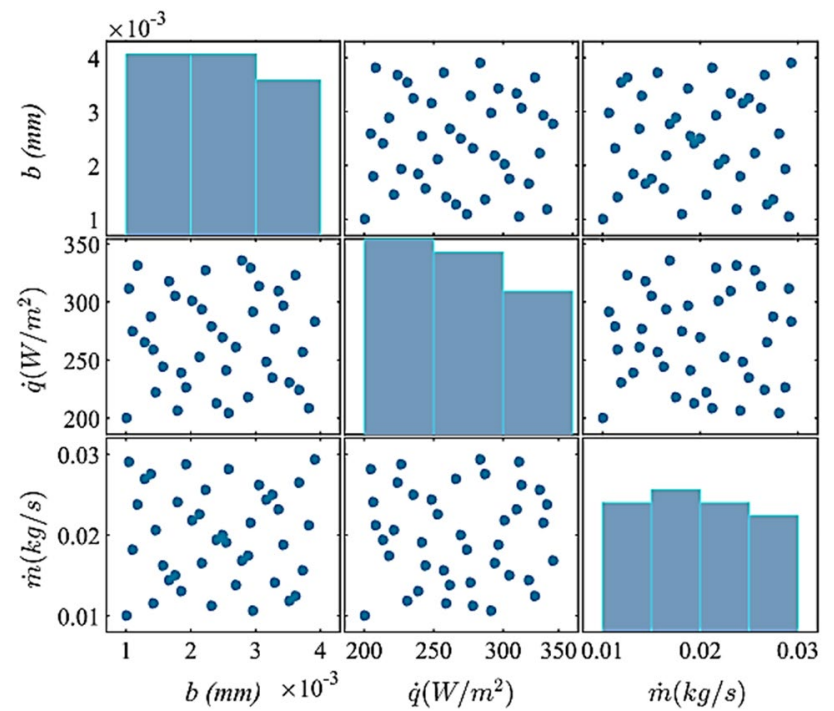

Fig. 43 Distribution of design of experiments in BTMS based on multidciplinary design optimization (MDO) [116]

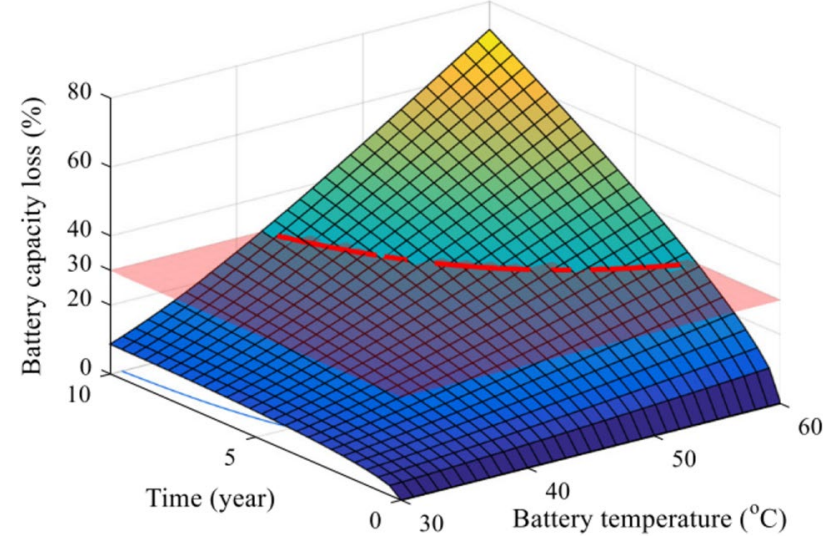

Fig. 44 Interdependency between battery temperature, battery life time and battery capacity. [116]

the longer length of the pouch symmetrically in order to get the most optimal thermal design for the LIB pouch.

Wang et al. [118] performed a 3D numerical simulation of 10 number of prismatic LIB cells cooled by air with an objective to optimize the battery life, thermal structure of battery, and its volume. The fidelity based multidisciplinary design optimization (MOD) technique was used in order to optimize the BTMS along with adaptive model switching method (AMS) to facilitate the switch between variable fidelity model. BTMS analysis was carried by using different levels of fidelity models such as three low level fidelity surrogated model and three tuned low fidelity model. The numerical simulation part of the BTMS was done by using Ansys and Abacus software. The outcome of this study suggest that the variable fidelity model proves to be good technique in determining the optimal solution to such complex multidisciplinary problems in BTMS. The lifetime of battery can be improvised to greater extent by minimizing the temperature difference between the battery cells and reducing the battery volume.

The above Table 7 shows a list of design variables considered with their initial and optimal values where b1 to b11 indicates the spacing between the battery cells for air passage and a1, a4 indicates the inlet and outlet manifold spacing for air passage. The manifold used here is tapered whose taper value is determined by a1, a2, a3, and a4. Figure 47 shows the optimization process carried on prismatic LIB cells by using variable fidelity model along with simulation part carried by CFD tool. It was concluded that the temperature distribution in each of the battery cell is optimal and thus improves the lifetime of battery system.

Ye et al. [119] suggested experimentally and numerically the structural optimization of prismatic LIB system cooled with air flow in order to improve the heat dissipation from the batteries external and internal surface. The heat dissipation optimization is achieved by using parallel ventilation method along with fluid solid conjugate thermodynamic analysis. The Simulation of thermal model of battery was carried by the help of fluent software with multiscale multi domain (MSMD) model. Form the obtained results of this study it was found that the optimized structure suggested can control the temperature distribution in battery pack very effectively by improving the heat dissipation rate during discharge process of battery. The optimized structure of battery pack in order to improve the heat dissipation from its surface is as shown below in the Fig. 48. To certify the uniformity of temperature in each cell of the battery pack a parallel ventilation with small tilt of battery is modelled.

Figure 48 comparison of temperature distribution in battery cell pre and post optimization [119]. It is very clearly seen that the temperature in each battery cell is high before using the optimized structure and after using the optimized battery structure the temperature in the battery cell reduced to greater extent. Liu et al. [120] conducted an experimental study with an objective of determining the optimal charging pattern for the Lithium iron phosphate (LiFePO4) battery so as to minimize the charging time, temperature variation and energy loss in a battery system. This study makes use of multi objective Biogeography based optimization (M-BBO) algorithm to achieve the most optimal charging pattern. The thermal model of the battery consists of heat transfer and heat generation which is dissipated to surrounding air and air will act as a cooling medium. The results obtained out of this experimental study show that among different multi objective BBO battery charging optimization algorithm the Strength Pareto BBO (SP-BBO) approach gives the best possible required optimal objectives. 
Fig. 45 a Velocity contours, b turbulence kinetic energy contours and $\mathbf{c}$ temperature contours for the optimal arrangement of cooling system [117]
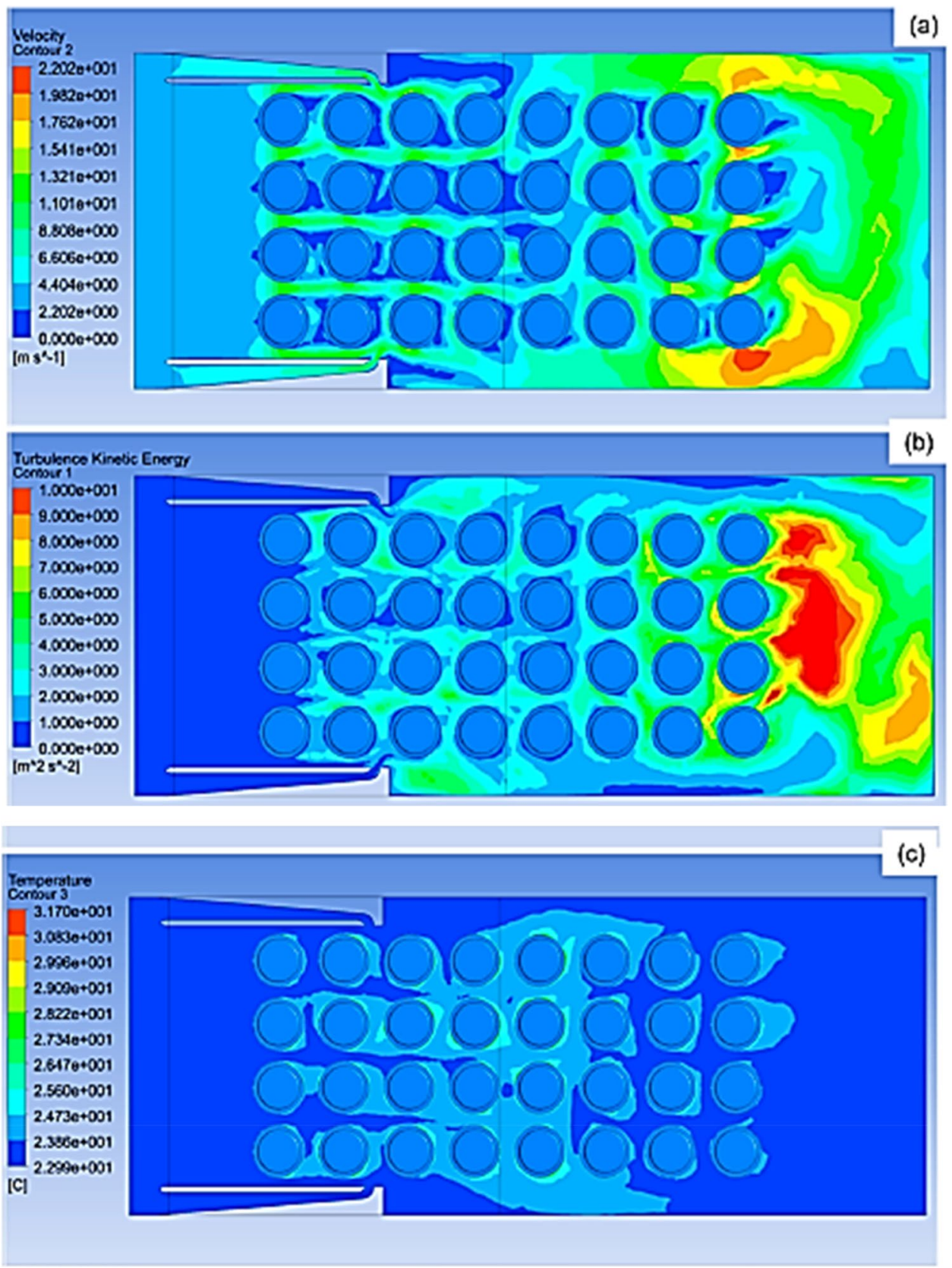

Chen et al.[121] suggested the optimization of structure design of parallel air cooled BTMS for cuboid LIB pack. Initially the air flow rate in a channel were calculated by using flow resistance network model for effective cooling, next the required plenum angle for air flow was optimized by using nested loop procedure with newton method, and finally the air inlet and outlet width were optimized by using numeration method. The validation of optimized results is done by using CFD tool with those available in the previous studies. The obtained results of this study show that by using optimized structure design in parallel U- type air cooling
BTMS the maximum temperature difference between the battery cells and power consumption can be reduced to greater extent. Power required for BTMS system was given as follows:

Power $=\left(P_{i}-P_{o}\right) a f_{o}$

where $P_{i}$ and $P_{o}$ are the average pressures at inlet and outlet cross section of air flow passage, respectively. $a f_{o}$ is air flow rate. Optimization of airflow rates in a channel was determined as follows: 


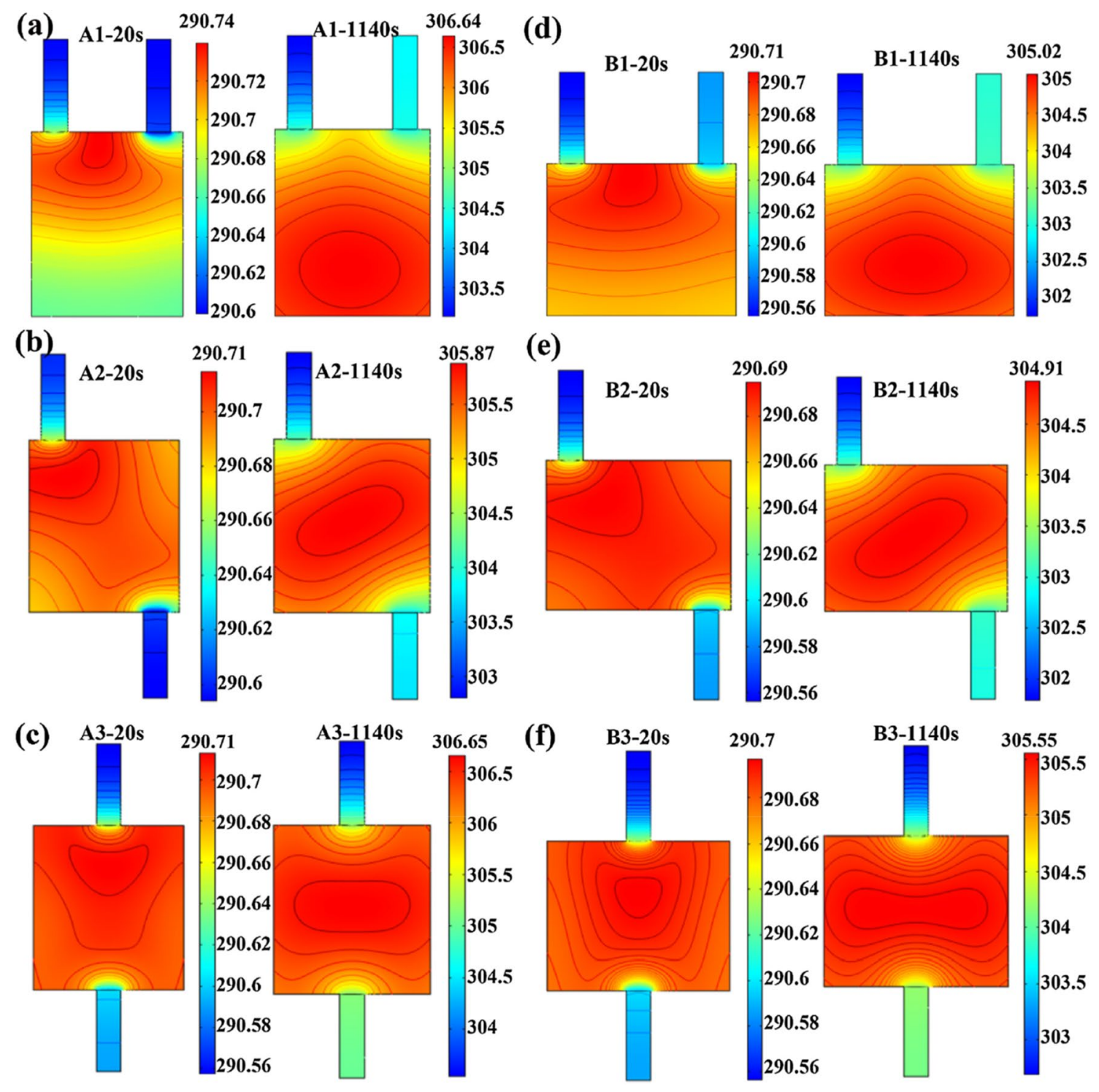

Fig. 46 Temperature distribution in battery pouch for different collecting tab arrangement. e- B2 an optimal arrangement of collecting tab in terms of thermal design of the battery pouch [106]

$S_{a f}=\sqrt{\frac{\sum_{j=1}^{M+1}\left(a f_{j}-a f^{\prime}\right)^{2}}{M+1}}$

where $S_{a f}$ is air flow rate standard deviation in a channel, M is number of batteries column, $\mathrm{M}+1$ number of air cooling channels, $a f_{j}$ is the flow rate of air in jth cooling channel, af' is the average value of air flow rate in all the cooling channels.

Mei et al. [122] proposed an optimal solution for structural design of tab dimensions for a nickle, cobalt, manganese (NCM111)/ graphite Li-ion battery pouch cell. A coupled electrochemical-thermal model was used to find out the optimal dimensions of battery tabs both experimentally and numerically. The Numerical simulation for 3D battery pouch was carried by the help of COMSOL Multiphysics software. Air based cooling system was used by considering the effect of both convection and radiation heat transfer. The results obtained in this study plainly shows that by calculating the appropriate dimensions i.e. by increasing the width and thickness of battery tab in pouch type cell one can control the temperature distribution on battery surface with improved performance.

Arrhenius equation was used to describe the interaction between the electrochemical and thermal model and is described as follows: 
Table 7 Optimal outcomes for different design variables considered in the study of Wang et al. [118]

\begin{tabular}{lcc}
\hline Design variable (unit) & Initial value & Optimal solution \\
\hline$b_{1}(\mathrm{~mm})$ & 3.00 & 2.46 \\
$b_{2}(\mathrm{~mm})$ & 3.00 & 1.95 \\
$b_{3}(\mathrm{~mm})$ & 3.00 & 2.88 \\
$b_{4}(\mathrm{~mm})$ & 3.00 & 2.39 \\
$b_{5}(\mathrm{~mm})$ & 3.00 & 0.75 \\
$b_{6}(\mathrm{~mm})$ & 3.00 & 1.74 \\
$b_{7}(\mathrm{~mm})$ & 3.00 & 0.72 \\
$b_{8}(\mathrm{~mm})$ & 3.00 & 4.58 \\
$b_{9}(\mathrm{~mm})$ & 3.00 & 4.11 \\
$b_{10}(\mathrm{~mm})$ & 3.00 & 4.96 \\
$b_{11}(\mathrm{~mm})$ & 3.00 & 3.98 \\
$a_{1}(\mathrm{~mm})$ & 7.00 & 8.83 \\
$a_{1}(\mathrm{~mm})$ & 7.00 & 12.09 \\
$a_{3}(\mathrm{~mm})$ & 7.00 & 12.82 \\
$a_{4}(\mathrm{~mm})$ & 7.00 & 14.81 \\
$\dot{m}(\mathrm{~kg} / \mathrm{s})$ & 0.0150 & 0.0149 \\
$\dot{q}\left(\mathrm{~W} / \mathrm{m}^{2}\right)$ & 213.64 & 203.98 \\
Objective function & 0.6162 & 0.1699 \\
\hline
\end{tabular}

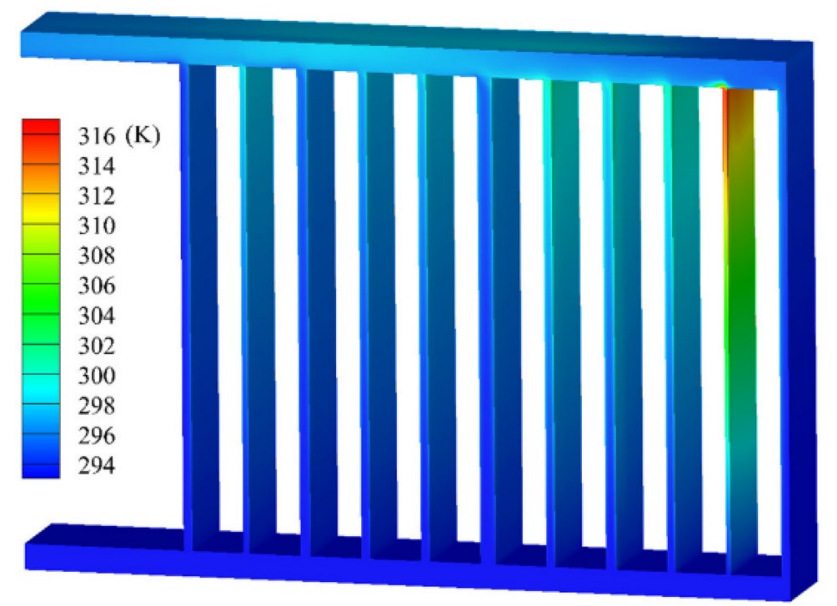

Fig. 47 Optimal temperature distribution in battery cells based on variable fidelity model [118]

$\Psi=\Psi_{\text {ref }} \exp \left[\frac{U_{a}}{R_{g}}\left(\frac{1}{T_{r e f}}-\frac{1}{T}\right)\right]$

where $\Psi$ is parameter dependent on temperature. $U_{a}$ is activation energy. $\Psi_{\text {ref }}$ is the reference value. $R_{g}$ is gas constant. $\mathrm{T}$ is the battery temperature. $T_{r e f}$ is battery temperature reference value.

Figure 49 depicts the isotherms and temperature distribution in battery pouch both for physical tab dimension and optimized tab dimension and it was found that using optimal dimensions of tab can reduces the chance of heat accumulation thereby increases the energy density of battery and also improves the level of safety in battery system. Lei et al. [123] proposed an optimal solution for charging LIBs based on degradation capacity speed and loss of energy from the battery. A first order equivalent experimental battery model under different state of charge (SOC) was established and by making use of dynamic programming algorithm the optimal value for current was obtained. The experimental results were further validated by conducting simulation with the help of Simulink software. The results of this study show that compare to traditional method of charging, the proposed optimal method of charging improves drastically the battery life with reduced loss of energy and capacity degradation. Li et al. [124] performed 3D numerical and experimental thermal behaviour investigation of prismatic type LIB module so as to optimize the temperature difference between the battery cells, temperature standard deviation and space required for battery accommodation in electric vehicle. A MOGA scheme was used to get the optimization of design parameters and numerical simulation was carried by the help of Ansys-Fluent. Air was used as a cooling fluid which will flow through the passage available between the battery cells. The outcomes of this study suggest that by using the proposed air-cooling optimized design for a battery module can reduce the temperature difference, temperature deviation and the volume required for the battery module as compare to conventional air cooling method. Figure 50 illustrate the temperature difference, temperature deviation and volume occupied by the battery cells in an air cooling BTMS. The blue points are the feasible point and red points are selected points based on MOGA optimization technique which will give the best suitable volume required for the battery cells which may tend to reduce the cost of the battery.

Figure 51 shows a 3D temperature distribution in battery module consisting of 8 number of cells it is clear from the figure that the temperature in battery module has reduced drastically after optimization in comparison to before optimization along with reduction in the volume. Li et al. [125] experimentally and numerically investigated the thermal performance of LIB module consisting of 36 number of prismatic cells with an objective of optimizing the maximum temperature difference between the battery cells, maximum temperature between the cooling air between adjacent passages, uniformity in temperature distribution and pressure drop at inlet and outlet manifolds. Two approaches were used to achieve the optimization of the problem one was by assuming density and velocity constant and second is extracting the density and velocity from CFD simulation results. The numerical simulation was done by using AnsysFluent and pressure velocity were linked by SIMPLEC algorithm. The results of this study prove that three basic design parameters i.e., air mass flow rate, heat flux at battery cell 

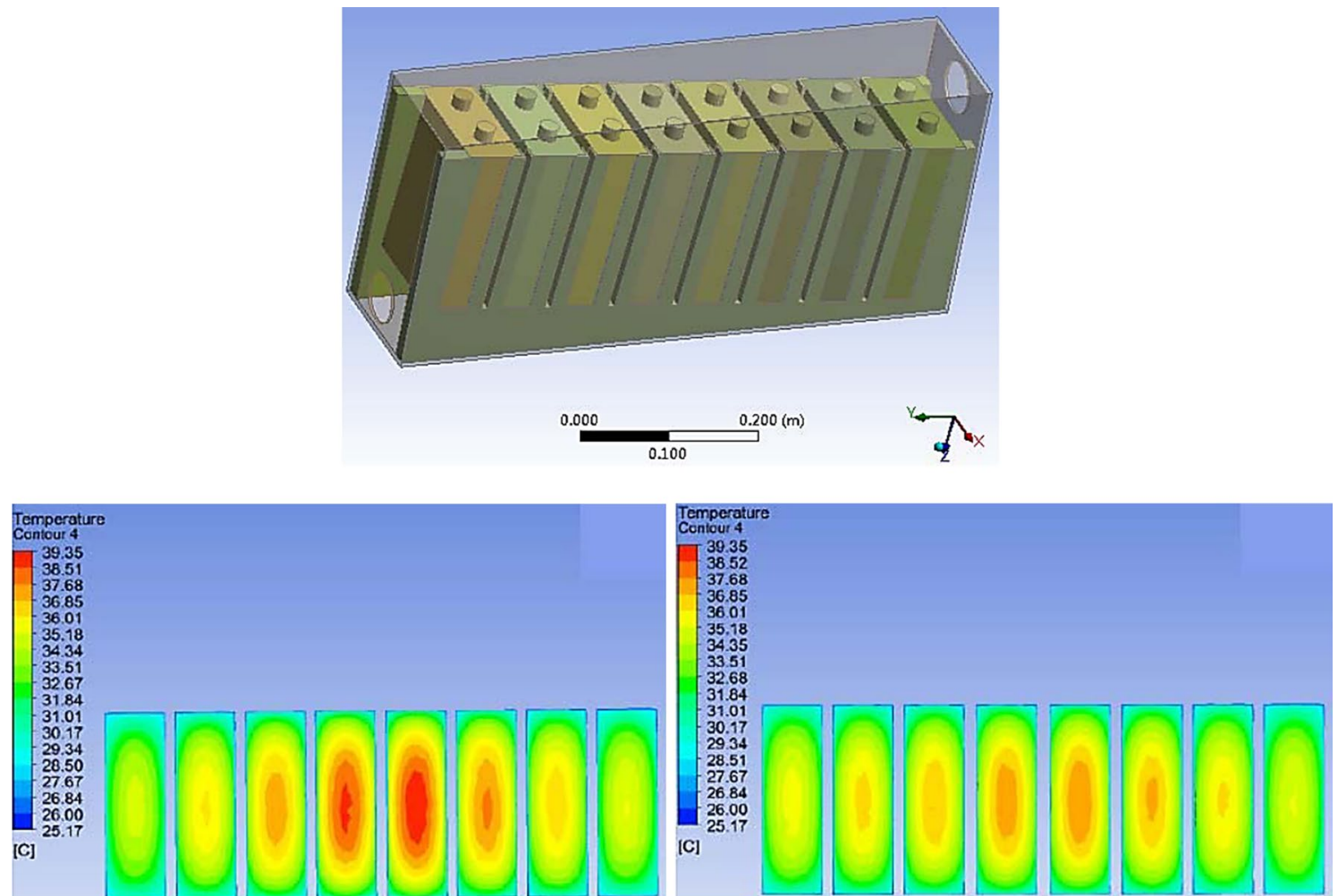

Fig. 48 Optimized battery structure for maximum heat dissipation [119]

(a)

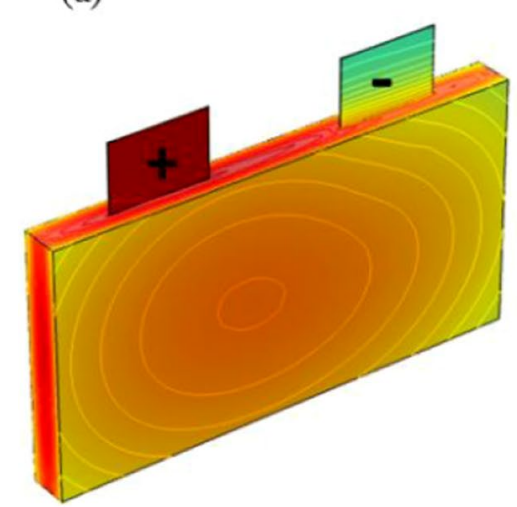

$\Delta 352.89$

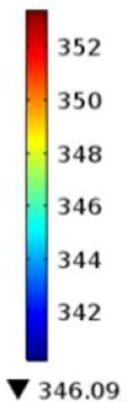

(b)

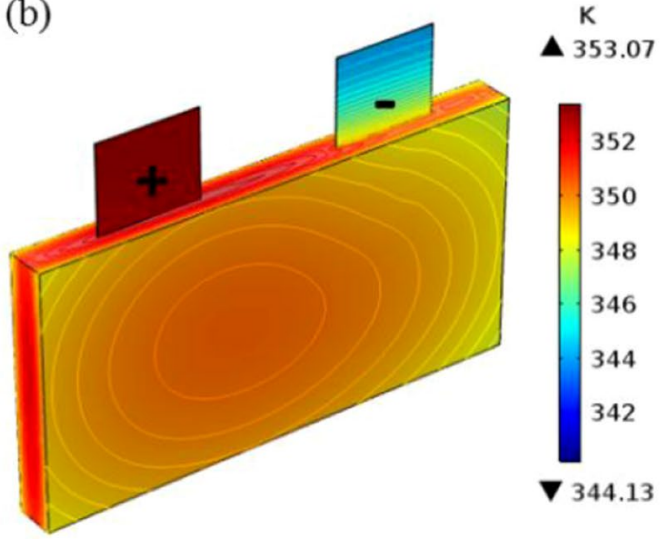

Fig. 49 Isotherms and Temperature distribution on battery surface at the end of discharge a physical tab dimensions, b optimized dimensions of tab [122]

and passage spacing between the adjacent battery cells plays a vital role in deciding the temperature distribution in a module. The fan power used to supply the required mass flow rate in battery module was determined as follows:
$P_{\text {fan }}=P_{\text {drop }} \frac{m_{a}}{\rho_{a} \beta_{\text {fan }}}$

where $P_{d r o p}$ is drop in pressure of the air at inlet and outlet. $m_{a}$ mass rate of flow of air. $\rho_{a}$ is air density. $\beta_{f a n}$ is fan efficiency. 


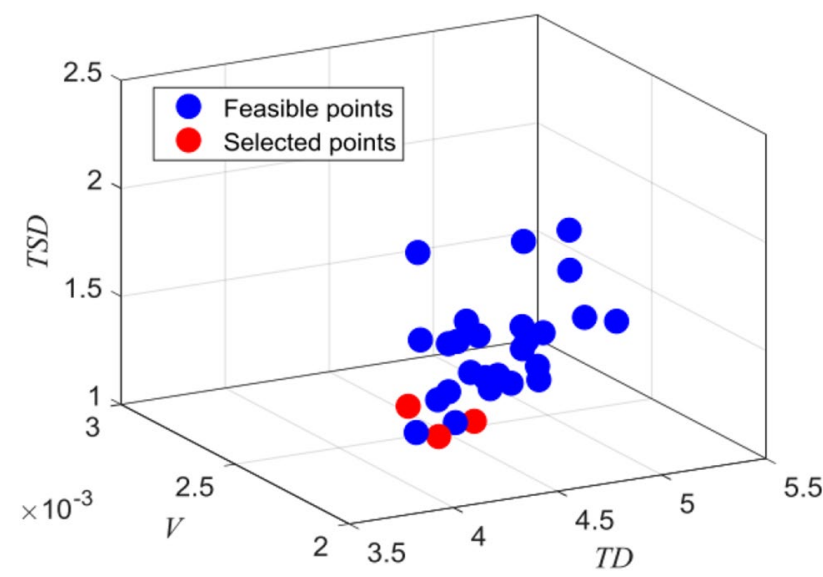

Fig. 50 Selection of feasible points based on MOGA optimized scheme[124]

The above Table 8 shows a comparison between the basic model of BTMS and proposed optimal models in this study. It was found that the proposed optimized model will be better choice in controlling the temperature uniformity in the battery module as well as improves the life of the battery.

Liu and Zhang et al. [126] conducted experimental and numerical analysis of LIB with prismatic cell pack with an objective of optimizing the design structure of battery to minimize the maximum temperature in battery pack, to have temperature uniformity and energy saving. A surrogated model based on GA was used for obtaining the optimization objectives. A J-type air cooling BTMS system was proposed and compared with conventional $\mathrm{Z}$ and $\mathrm{U}$ type channel. Numerical simulation was done by Ansys-Fluent with $\mathrm{k}-\varepsilon$ model for turbulent flow of coolant. The results of this study show that the J-type configuration for air passage proves to be more significant when the manifolds are tapered at their section. Figure 52 depicts CFD simulation of three different channels namely U, Z and J type. The careful comparison between these three channels shows that in terms of temperature uniformity and pressure drop the J-type channel is more efficient. Figure 53 illustrate the temperature distribution and pressure drop for the J-type optimized channel design under benchmark and comparative condition with different resampling and it was concluded that the results of benchmark condition were more concentrated in relative to comparison condition.

Ji et al. [127] tested both experimentally and numerically the thermal performance of Li-ion (LiNiCoMnO2) cylindrical cells by using different arrangement of batteries in a module to achieve the required optimal uniformity in temperature distribution. Air is used as a coolant for carrying the heat from the battery module. Two different arrangements were used namely the arithmetic and geometric ratios to determine the optimal physics for the module. Numerical simulation is carried by the help of COMSOL Multiphysics software based on finite element scheme. The major take back from this study were (i) the arithmetic arrangement ratio gives better uniformity in temperature distribution in battery module compare to geometric ratio (ii) the maximum temperature difference between the battery's cells reduced to greater level by using arithmetic arrangement ratio. Figure 54 depicts the temperature behaviour within the battery module at its centre section when the discharge rate of the battery comes to an end. It was concluded that the more uniformity of temperature distribution is achieved in the arithmetic ratio compare to geometric ratio arrangement.

Qian et al. [128] experimentally and numerically optimized the spacing between the battery cell without changing the volume of the battery pack consisting of cylindrical li-ion cells subjected to flow of air. The objective is to minimize the maximum temperature difference and maximum temperature in the battery cells. Bayesian neural network technique was used to obtain the optimal spacing. The numerical simulation was carried out by Ansys-Fluent and the results obtained out of simulations are used to train the neural network. The flow fields were solved by using SIMPLE algorithm. The results of the investigation show that the front to back spacing have negligible effect while the left to right spacing have adverse effects on temperature within the battery pack. With increase in the left to right spacing the temperature uniformity at middle section of the battery pack improved a lot. Figure 55a-c shows the optimal spacing combination effect on minimum temperature, maximum temperature and temperature difference respectively. In Fig. 55d depicts the effect of optimal spacing combination on temperature contours within the battery pack. It is clearly seen that with increase in the spacing from left to right the temperature at the middle section of the battery pack reduced to greater extent. The temperature difference can be used to obtain the heat dissipation from the battery pack.

Li et al. [129] conducted an experimental and numerical simulation of electro chemical thermal coupled 3D model of li-ion prismatic battery cells to optimize the parameters like average temperature rise in battery, thickness of positive electrode, inlet ambient temperature, solid phase volume fraction and solid particle diameter. The optimization was done by the help of response surface methodology (RSM) along with analysis of variance (ANOVA) and the simulation was done by using COMSOL Multiphysics software. The results obtained out of this study suggests the suitable range of optimal parameters such as the thickness of positive electrode was $40-70 \mu \mathrm{m}$, diameter of positive electrode8-10 $\mu \mathrm{m}$, and solid phase volume fraction was in the range of $0.5-0.7$. Figure 56a shows the effect of battery thickness on the temperature contours within the battery pack and the battery thickness with $22 \mathrm{~mm}$ gives the minimal temperature rise. 
Fig. 51 a Temperature distribution in battery module a before optimization, b after optimization [124]
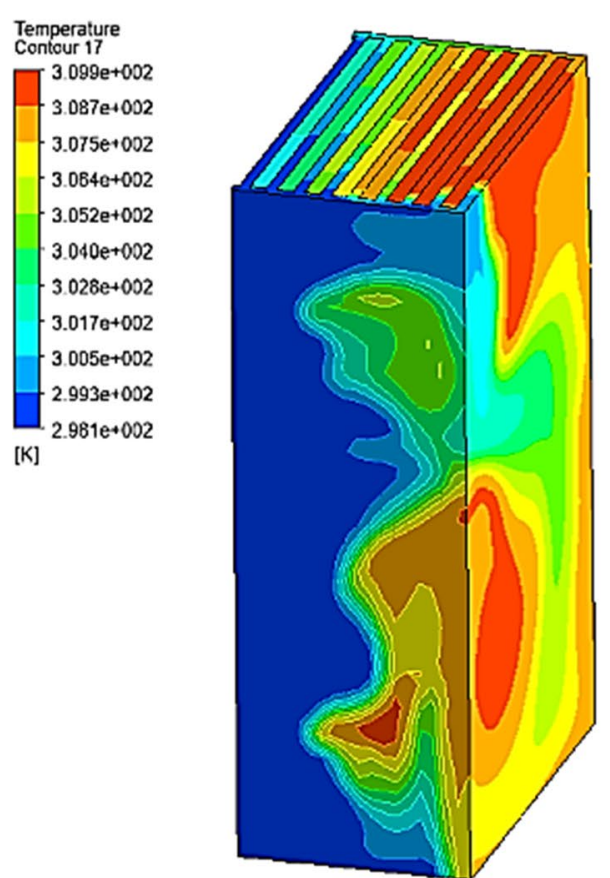

二

Temperature
Contcur 17

3.005e+002

$3.037 \mathrm{e}+002$

- 3.075 e.002

$-3.054 \mathrm{e}+002$

$-3.052 \mathrm{e}+002$

- $3.040 e+002$

- $3.028 \mathrm{e}+002$

- $3.017 \mathrm{e}+002$

$3.005 \mathrm{se}+002$

$2.993 \mathrm{e}+002$

2.931e+002

[K]

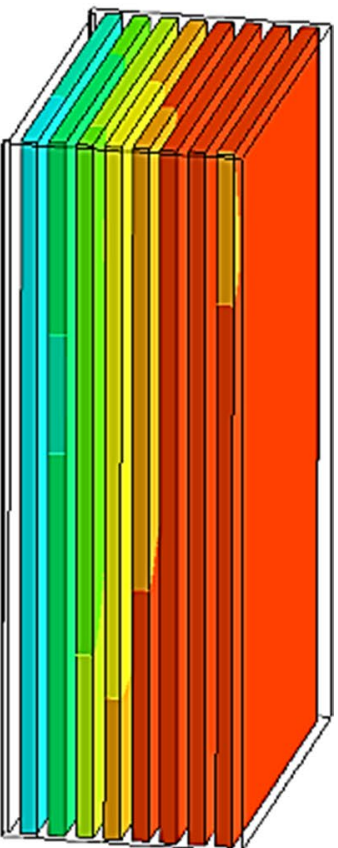

(a)
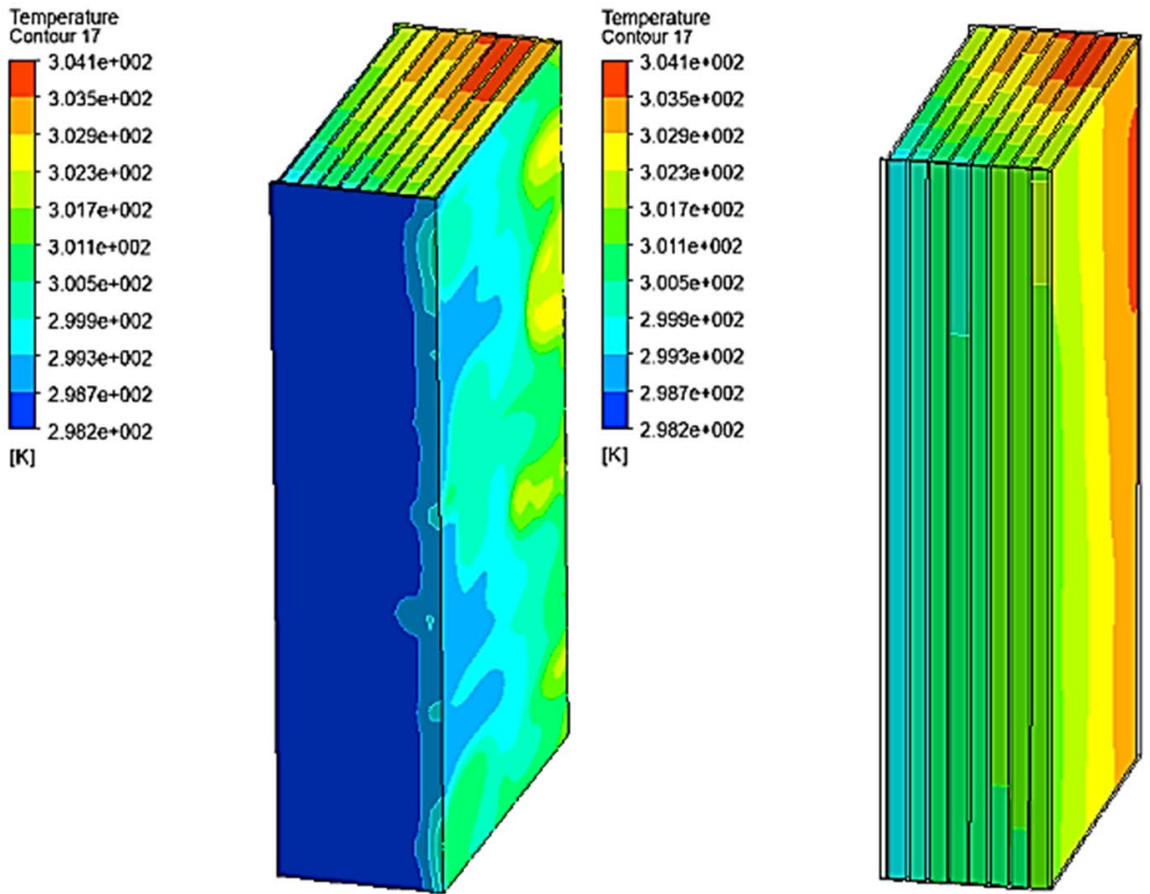

(b)

Figure 56b shows the optimal point of interaction for charging rate, ambient inlet temperature, and average temperature rise in battery.
Liu et al. [130] presented a comparison study on U-type, Z-type and J-type cooling channel in LIB pack so as to optimize the maximum temperature in battery, temperature uniformity, pressure drop, and power to weight ratio (Table 9). 
Table 8 Optimized model values of maximum temperature difference between the cooling air in passages, maximum temperature difference between the battery cells, and air pressure drop

\begin{tabular}{lccl}
\hline Case & $\Delta T_{\text {amax }} / \mathrm{K}$ & $\Delta T_{\max } / \mathrm{K}$ & Pressure drop/Pa \\
\hline M0 & 23.9 & 25.3 & 212.08 \\
M1 & 85.4 & 100.6 & 245.35 \\
M2 & 10.1 & 16.1 & 229.37 \\
M3 & 4.9 & 10.5 & 230.82 \\
M4 & 2.1 & 7.6 & 229.43 \\
\hline
\end{tabular}

The surrogated model based on concurrent surrogate model selection (COSMOS) was used to achieve the optimization. The numerical simulation was carried by the help of AnsysFluent with k- $\varepsilon$ turbulence model. The results of the study conclude that the proposed J-type channel design gives better cooling performance in terms of reducing the maximum temperature, temperature difference, better temperature uniformity and reduced pressure drop.

Where Tmax is maximum battery temperature, $\Delta \mathrm{T}$ is temperature difference, and $\Delta \mathrm{P}$ is pressure drop. The above Table 9 gives a comparison between the three different cooling schemes utilized in the this investigation and it was clearly observed from the above table that the J-type cooling scheme will be a better choice over $\mathrm{U}$ and $\mathrm{Z}$ type cooling scheme. Hence it was concluded that J-type cooling method was optimal choice. In Table 10 the details of optimization carried on air cooling based BTMS are provided.

\subsection{PCM and Composite PCM}

Li et al. [131] illustrated experimental and a numerical simulation of cylindrical LIB embedded with EG/PA composite PCM. The main objective of this numerical study is to optimize the mass of PCM in battery system, maximum temperature in battery, and time to keep the battery within

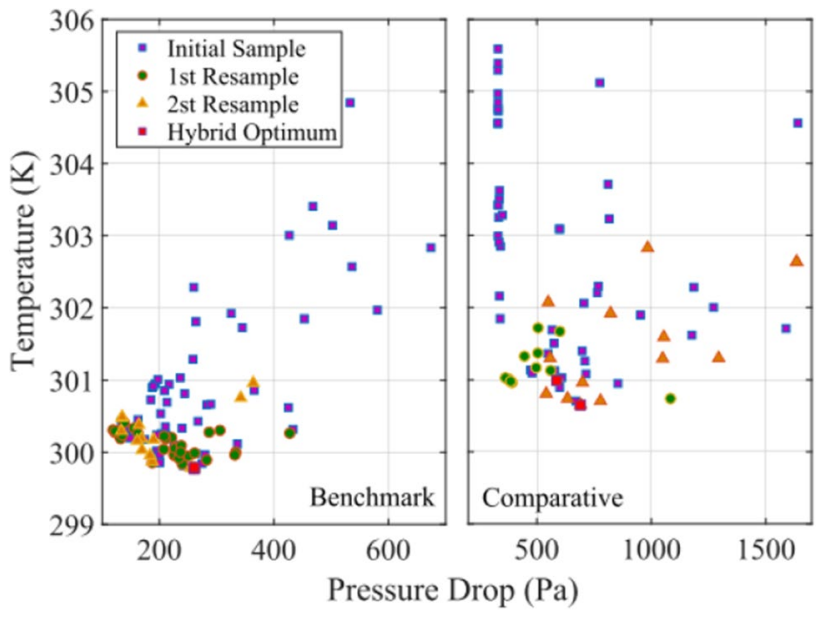

Fig. 53 The optimized J-type channel with tapered manifolds [126]
Fig. 52 Optimal design simulation of a U-type channel, $\mathbf{b}$ Z-type channel, c J-type channel [126]

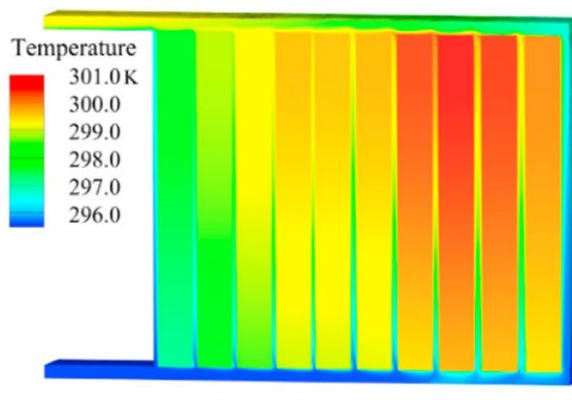

(a) U-type

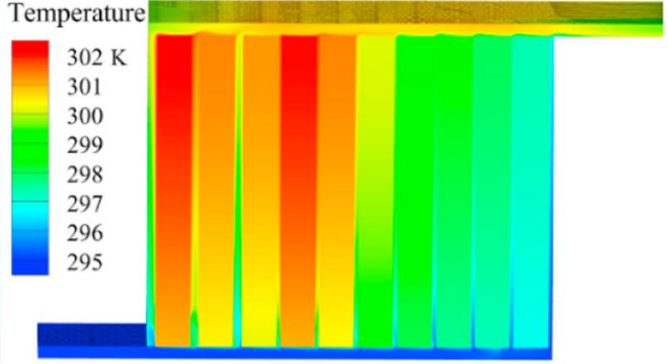

(b) $Z$-type

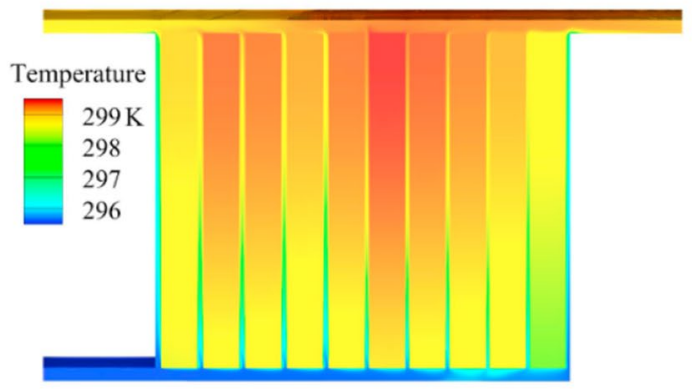

(c) J-type 


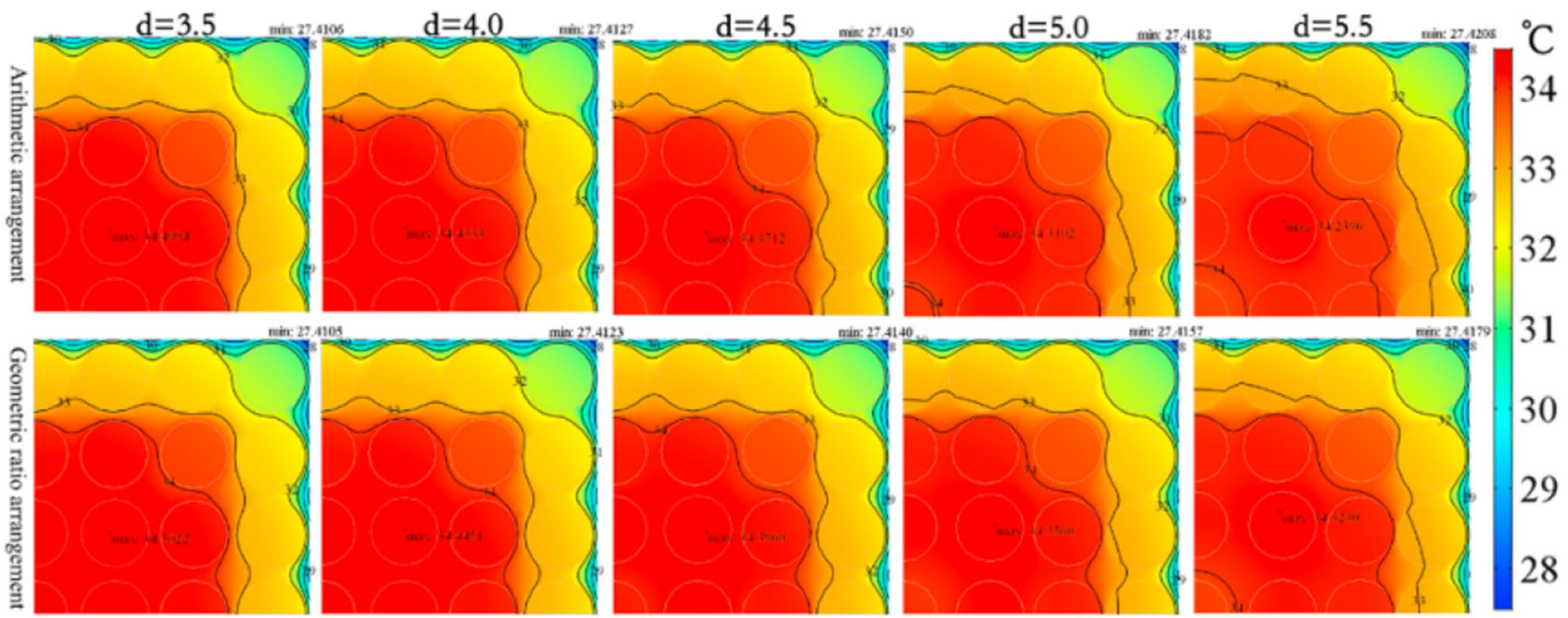

Fig. 54 Temperature contours in battery module for arithmetic and geometric ratio arrangement at the end of discharge [127]

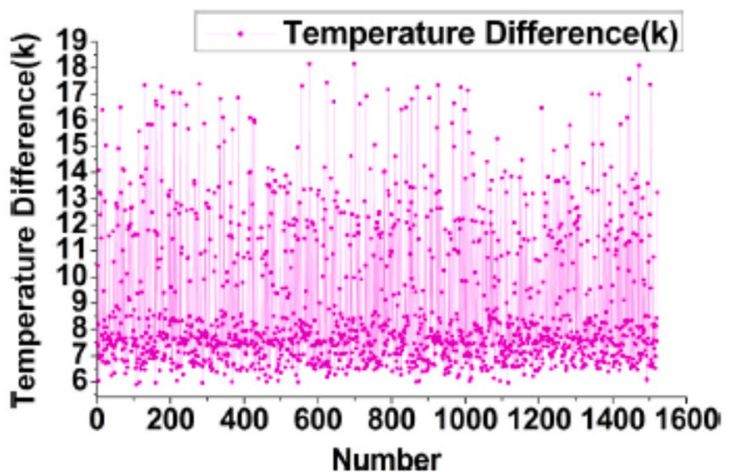

(a)

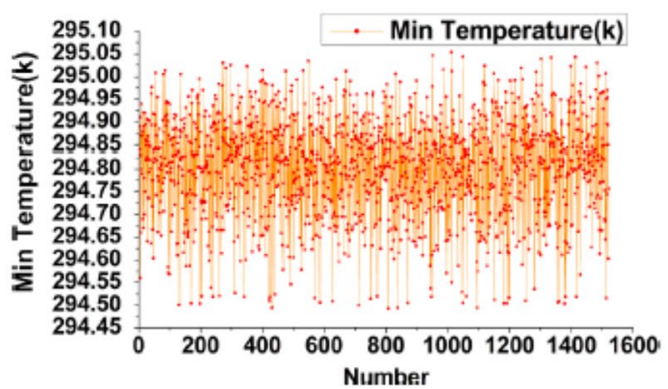

(c)

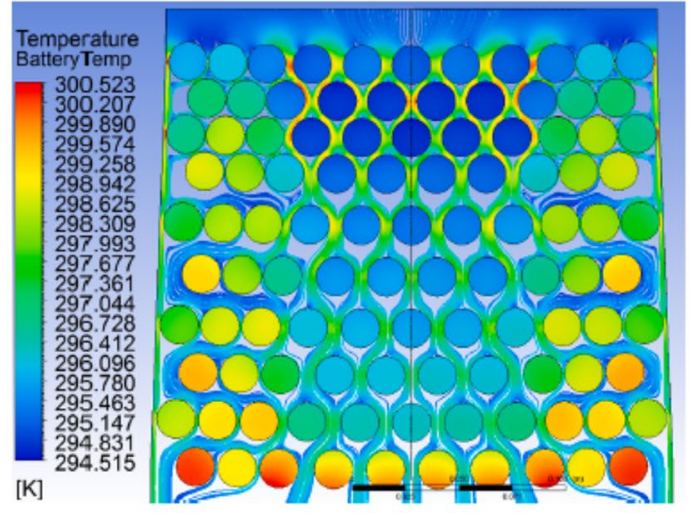

(b)

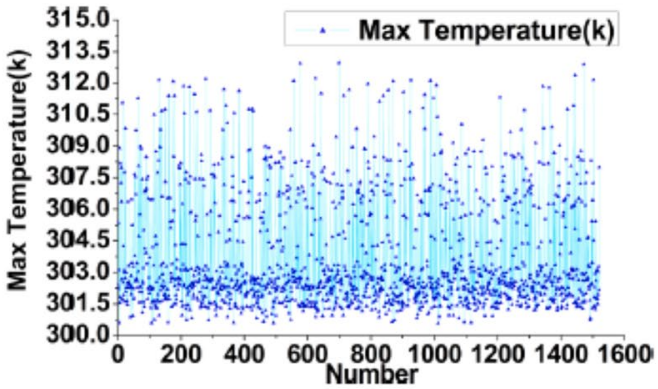

(d)

Fig. 55 Optimal spacing combination a minimum temperature, $\mathbf{b}$ maximum temperature, $\mathbf{c}$ temperature difference, and $\mathbf{d}$ temperature contours [128]

the safe operating temperature. Evaluation index optimization method was used in order to find out the optimal mass of PCM in BTMS. Numerical simulation was done by using commercial CFD Fluent software while governing equations are solved by Finite element method (FEM) whereas heat transfer equations are solved by using enthalpy method.
Four different BTMS arrangement were used by varying the number of batteries from 1 to 4 . The possible outcomes of this study suggest that the battery radius, gap between the adjacent batteries, and thickness of PCM at top and bottom of the batteries will influence the PCM mass, maximum 
(a)

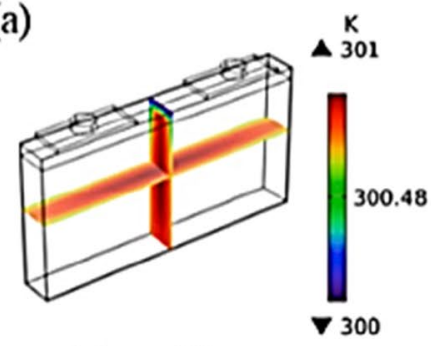

$T h_{b a t}=22 \mathrm{~mm}$

$\underset{\mathbf{S}}{\mathrm{K}}$
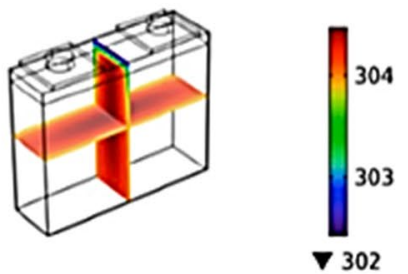

$T h_{b a t}=34 \mathrm{~mm}$
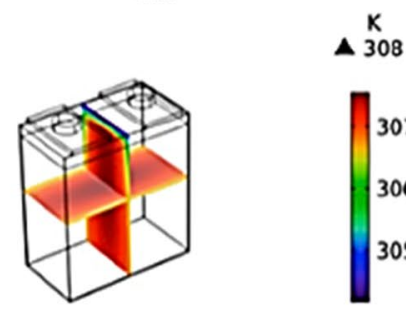

$T h_{b a t}=46 \mathrm{~mm}$

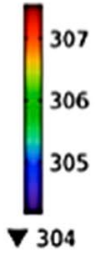

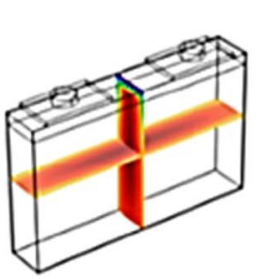

$T h_{b a t}=26 \mathrm{~mm}$

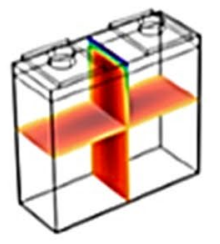

$T h_{b a t}=38 \mathrm{~mm}$

$\underset{402}{x}$

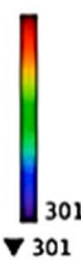

$\underset{306}{x}$

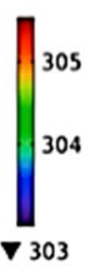

$\underset{409}{K}$

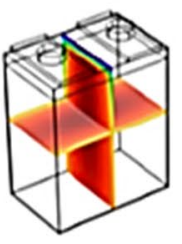

$T h_{b a t}=50 \mathrm{~mm}$

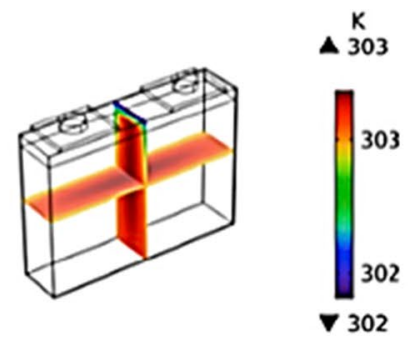

$T h_{b a t}=30 \mathrm{~mm}$

$\mathrm{K}$
$\mathbf{3} 307$

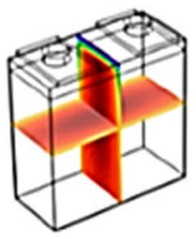

$T h_{b a t}=42 \mathrm{~mm}$
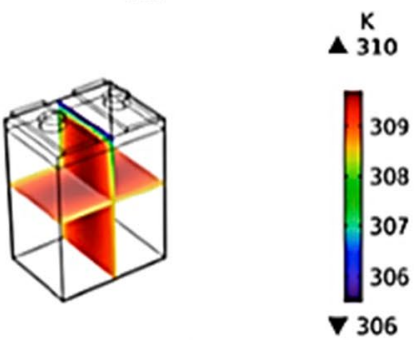

$T h_{b a t}=54 \mathrm{~mm}$

(b)

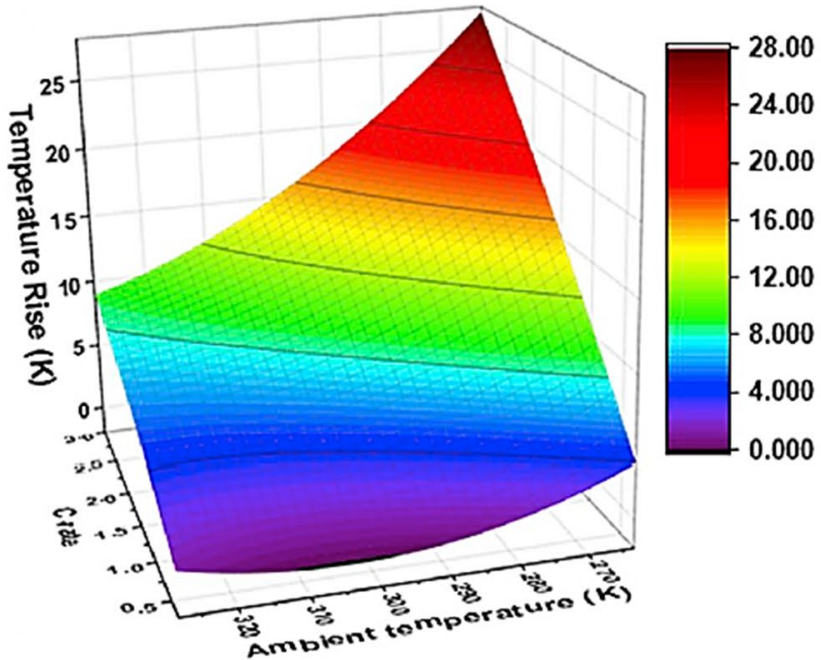

Fig. 56 a Temperature contours with different battery thickness, b optimal interaction point [129] 
temperature and time to maintain the safe temperature limit. The mass of the PCM in BTMS is expressed as follows:

$M_{p c m}=\sigma_{p c m} X_{B T M S}\left(P i . r_{p c m}^{2}-N_{b} P i . r_{b}^{2}\right)$

where $M_{p c m}$ and $\sigma_{p c m}$ are mass and density of PCM, respectively. $X_{B T M S}$ is length of BTMS. $r_{p c m}$ is radius of PCM unit. $N_{b}$ is number of batteries in BTMS.

Figure 57 depicts the minimum mass in BTMS with respect to number of batteries and heat generation rate in the battery. It was found that with increase in heat generation and number of batteries in a battery system the minimum mass of PCM increases. Here the prime objective of this study was to optimize the mass of the PCM. Parhizi and Jain [132] presented an analytical modelling approach for optimization of surface and core temperature of the LIB cell in a battery pack by using PCM based thermal management system. The study makes use of perturbation analytical method in order to arrive at optimal solution to the problem of this conjugate PCM cooling of LIB. Further to validate the solution obtained by analytical method a numerical simulation is performed by using Ansys CFX based on finite element approach. The results of this analytical approach give some of the useful output in terms of designing an efficient PCM cooling method with energy and power saving benefits. The temperature at the interface of the PCM and battery cell is described as follows: improvement of thermal performance and reduction in size and cost of BTMS consisting of prismatic Li-ion iron oxide battery cell. The Hybrid pulse power characterization (HPPC) method along with enthalpy method was employed to determine the best optimal results. Both experimental and numerical study was performed by making use of AnsysFluent. A 3D thermal model of battery with three different shape stabilized PCM plate (PCMP) were used in order to find out the best PCMP configuration in battery system. The outcome of this study purely suggests the use of wrapping the PCMP around the battery cell in order to control the temperature distribution within the battery cell as well as to improve the thermal performance of battery. Further the study also gives the critical value for thickness of PCMP and convective heat transfer coefficient above or below which the temperature distribution in battery cell get greatly influenced. Figure 59 elucidate the temperature distribution in prismatic battery cell considering three different cases of PCMP arrangement during discharge time of battery. It was found that case 3 will be a better choice in terms of thermal performance of battery and energy consumption.

Yang et al.[134] investigated numerically the thermal performance of Lithium cobalt oxide ( $\mathrm{LiCoO} 2)$ stretchable type of battery cell to optimize the maximum temperature and temperature difference between the cells. The optimization was carried by using multiple objective particle swarm optimization (MOPSO), Non dominating sorting genetic algo-

$T_{i f}(t)=\frac{\beta_{c}}{K_{c} B} \int_{0}^{t} h^{\prime \prime}(t) d t+\sum_{n-1}^{\infty} \frac{-2 \beta_{c}}{K_{c} B} \cos ^{2}\left(\sigma_{n} B\right) \int_{0}^{t} h^{\prime \prime}(t) \exp \left[-\beta_{c} \sigma_{n}^{2}(t-\pi) d t\right]+\frac{H^{\prime \prime \prime}}{\rho C_{p}} t$

where $T_{i f}$ is interface temperature between PCM and battery cell. $\beta_{c}$ is cell thermal diffusivity. $K_{c}$ is cell thermal conductivity. B is half the thickness of cell. $h^{\prime \prime}$ is heat flux. $H^{\prime \prime \prime}$ is volumetric heat generation in cell. $\rho$ is mass density of PCM. $C_{p}$ is specific heat of PCM. $\sigma_{n}$ is eigen values, and $\tau$ is time step for transient analysis. Figure 58 shows that when the discharge rate of a battery get increases the core temperature in a cell increases which finally increases the mass of PCM required and thus reduces the energy density level in the battery pack. Therefore, an optimal choice of discharge rate quantifies the optimal core temperature and energy density in a battery cell.

Wu et al. [133] makes use of shape stabilized PCM to optimize the temperature distribution, rise of temperature,

Table 9 Comparison of U, Z and J type flow channel [130]

\begin{tabular}{lrrr}
\hline Evaluation Index & $U$-type & $Z$-type & $J$-type \\
\hline$T_{\max }(\mathrm{K})$ & 322.3 & 323.5 & 311.5 \\
$\Delta T(\mathrm{~K})$ & 18.2 & 20.1 & 6.3 \\
$\Delta P(\mathrm{~Pa})$ & 406.1 & 356.4 & 199.4 \\
\hline
\end{tabular}

rithm type III (NSGA-III), and strength Pareto evolutionary algorithm-II (SPEA-II). The CPCM was used in the BTMS with different arrangement on the surface of the battery cell. The obtained results of this study show that the maximum temperature in battery cell depends on thickness, radius and position of CPCM on surface of the battery cell while the maximum temperature difference depends on mass fraction of expanded graphite, density of CPCM and thickness of CPCM. The heat generation in the stretchable battery cell is given as-

$\rho C_{p c} \frac{\partial T}{\partial \tau}-\gamma \nabla^{2} T=q_{\text {reaction }}+q_{a}+q_{\text {ohmic }}$

where $\rho$ is density. $C_{p c}$ is specific heat capacity. T is temperature. $\gamma$ is thermal conductivity. $q_{\text {reaction }}$ is heat generation due to chemical reaction in battery. $q_{a}$ is active polarization heat. $q_{\text {ohmic }}$ is ohmic heat. The variation in temperature distribution on the surface of the battery cell is as shown in the Fig. 60 for different discharge time. It is clear from the Fig. 60 with increase in the discharge time the uniformity of 


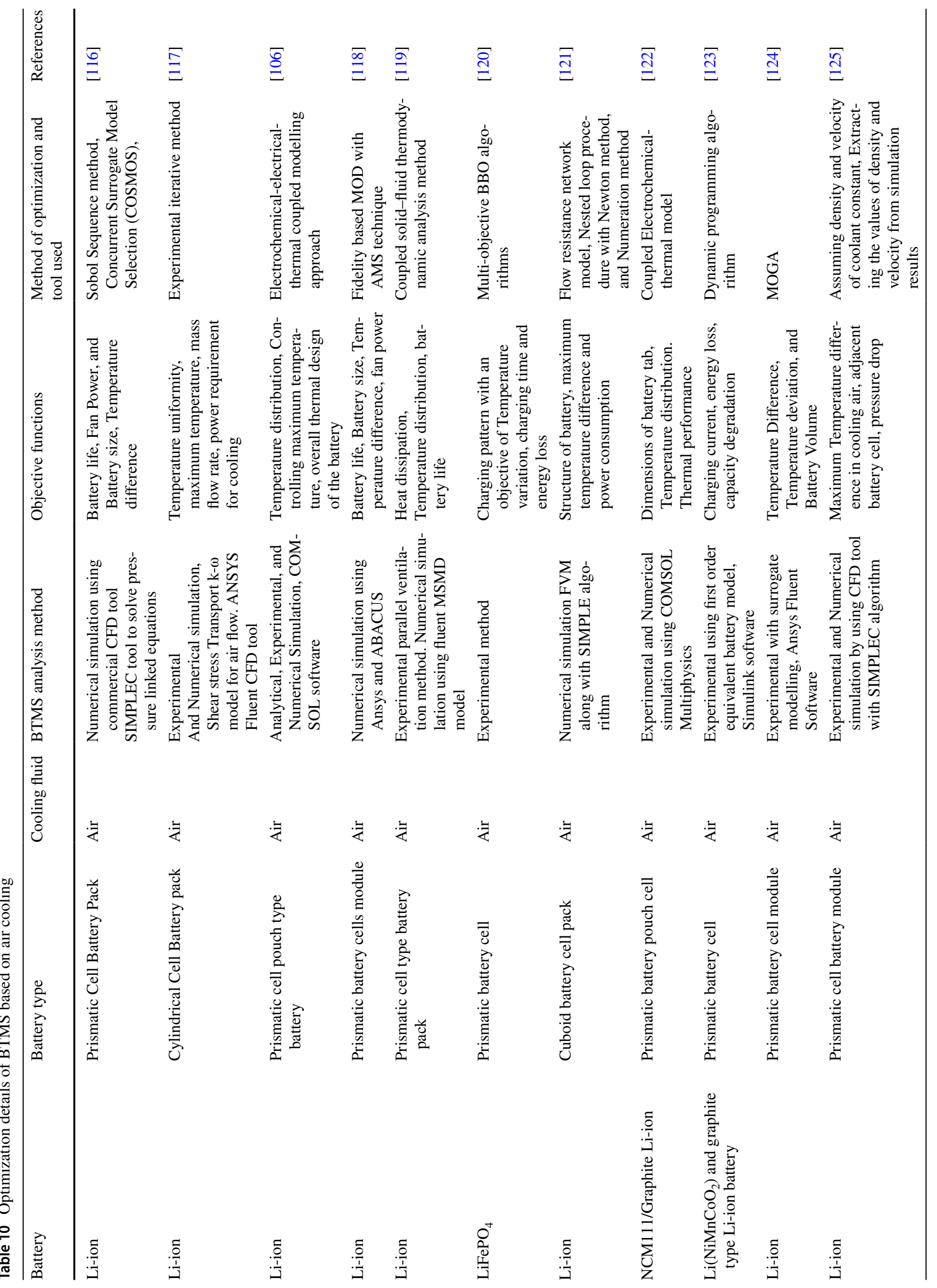




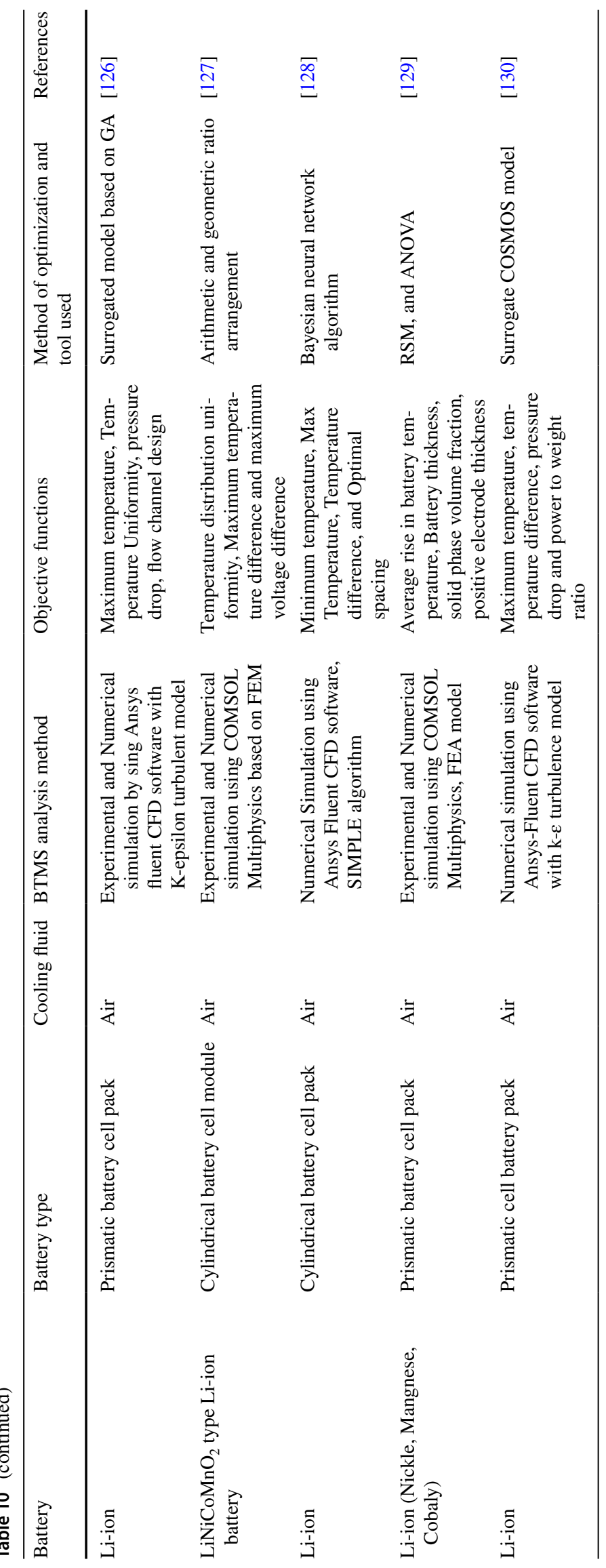

照 Springer 


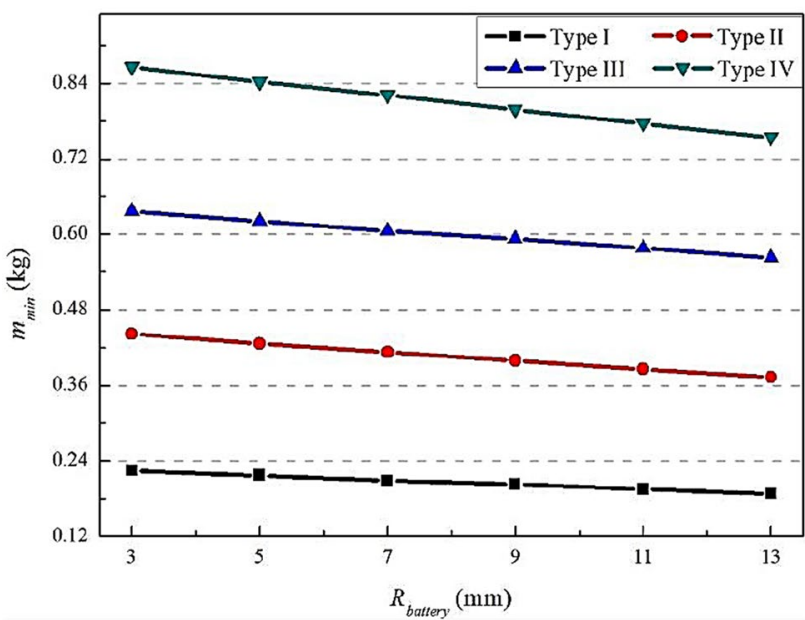

Fig. 57 Minimum mass $\left(M_{\min }\right)$ of PCM V/s Heat generation $\left(Q_{b}\right)$ in battery [131]

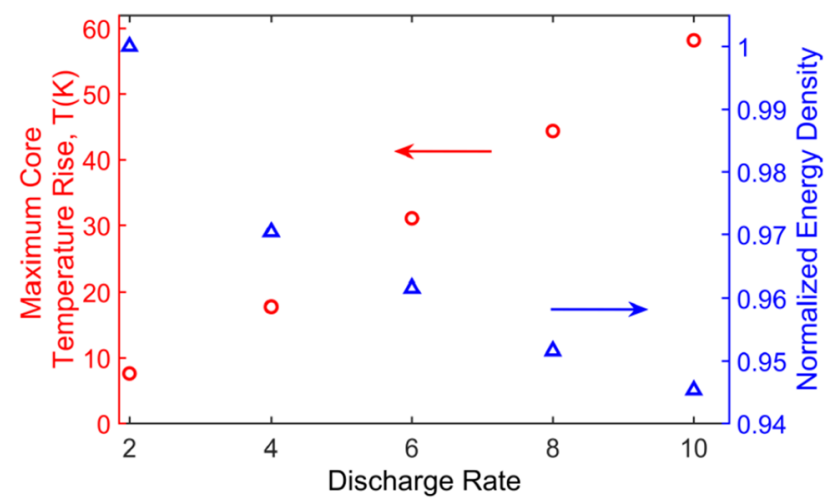

Fig. 58 Optimization of cell core temperature and energy density with respect to discharge rate [132]

temperature in battery with optimal CPCM design is better compared to original design without CPCM.

Weng et al.[135] conducted an experimental study on cylindrical Li-ion battery cell with PCM layer to determine the optimal thickness of PCM layer, the phase change temperature (PCT) of PCM and laying aside time during dynamic cycling. The experiments were carried out at constant current and constant voltage condition with different discharge rates. The results of this study show that the thickness of PCM layer plays important role in the cooling performance of battery, increasing the lying aside time improves the cooling efficiency of battery. Figure 61 depicts the influence of PCM layer thickness on the temperature variation in battery and it is found that there exists an optimal thickness of PCM layer $(10 \mathrm{~mm})$ which gives best efficient cooling effects.
The above Fig. 62 shows the different cycles in a battery with variation in temperature and voltage when the rest time was of $5 \mathrm{~min}$.

Curve A-B: Due to heat generation at constant current the temperature rises.

Curve B-C: At constant voltage due to heat generation the drop in temperature is seen.

Curve C-E: Temperature increases during discharging process.

Curve: E-F: Fall in temperature during rest time.

Ling et al. [136] performed an experimental, numerical and thermal network optimization of PCM properties so as to warm up the battery module during the cold start. The thermal management system consists of Li-ion battery pack fixed with Paraffin/ expanded graphite PCM. The optimization was achieved by using thermal network model which was solved by electric circuit model integrated with Simulink. The output attained from this study shows that the melting point of PCM should be around $40{ }^{\circ} \mathrm{C}$, with thermal conductivity of $5.4 \mathrm{~W} / \mathrm{mK}$, and latent heat of storage density less than $0.0145 \mathrm{~kJ} / \mathrm{m} 3$. For PCM and their compositions the relationship between various thermal properties were determined by using the following equations:

$L_{H}=m^{\prime} E^{\prime}$

$E^{\prime}=\beta E^{\prime \prime}$

$K=\rho_{\text {cpem }}(1-\beta) \frac{K_{e g}}{\rho_{e g}}$

where $L_{H}$ is latent heat of capacity PCM. $m^{\prime}$ is mass of PCM. $E^{\prime}$ is specific phase change enthalpy. $\beta$ is paraffin mass fraction. $E^{\prime \prime}$ is specific phase change enthalpy of paraffin. $\mathrm{K}$ is thermal conductivity of composite PCM. $\rho_{\text {cpem }}$ is composite PCM density. $K_{e g}$ and $\rho_{e g}$ are thermal conductivity and density of expanded graphite, respectively.

Figure 63 illustrate the three cooling schemes utilized to study its effect on average battery temperature, average temperature difference, maximum temperature difference, minimum depth of discharge and difference in depth of discharge. It was concluded that the usage of paraffin/EG intense active cooling scheme proves to be very efficient for thermal management of the battery module.in Table 11 the details of BTMS using composite PCM optimization is provided.

\subsection{Water Coolant with Mini-Channel}

An et al.[137] Numerically tested a 3D thermal model of pouch type LIB cells in order to get an optimal temperature distribution, maximum temperature difference between the 

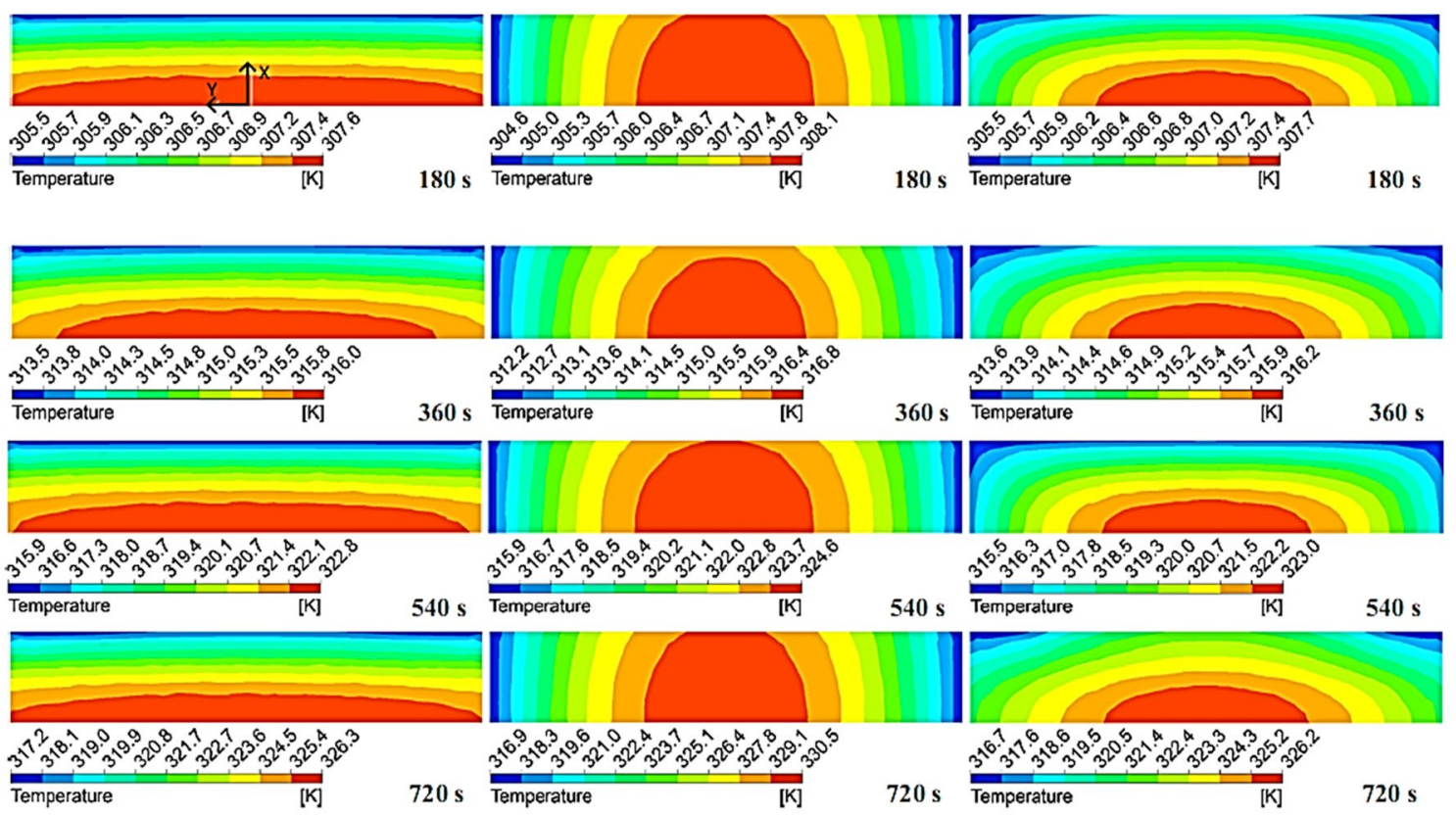

Case 1

Case 2

Case 3

Fig. 59 Comparison between different cases of PCMP for temperature distribution in prismatic cell (Case 3 is optimal choice) [133]

cells and high energy density in a battery pack. A simplified numerical model based on effective convective heat transfer boundary condition was used to develop the optimal solution under conjugate heat transfer condition at the interface of battery cell and water coolant. An Ansys CFX software based on finite volume method was used to solve the governing equations for the given problem. The results of this study indicate that using mini channel cooling technique in a BTMS can reduce the maximum temperature difference between the cells and increases the energy density of battery system. The drop in pressure within the mini channel was calculated by

$\delta P=f^{\prime} \frac{L_{b}}{d_{h}} \frac{\partial_{w} U^{2}}{2}$

where $\delta P$ is pressure drop in mini-channel. $f^{\prime}$ is Darcy friction factor. $L_{b}$ is length of the battery. $d_{h}$ is hydraulic diameter. $\partial_{w}$ is water density. $\mathrm{U}$ is mean velocity of water in mini channel.

Figure 64 shown above implies that when the width of the mini channel tubes increases the maximum temperature in the battery cell drops and also the pressure loss within the channel part can be minimized hence the pumping power required can also be minimized. In another study Tang et al. [138] also adopted the combination of water coolant and mini channel to manage thermally the Li-ion prismatic battery cells with an objective of optimizing the maximum temperature, uniformity in temperature distribution and to reduce the maximum temperature difference between the battery cells. This study makes use of Bernardi heat generated thermal model to achieve the optimized design for the battery. Three different arrangements were used for BTMS, in the first arrangement mini channel cold plates were kept only at the bottom of the battery cell, in the second cold plates were kept on both sides of battery, and in the final arrangement cold plates were kept on sides as well as at bottom of the battery cells. The obtained experimental results were validated by numerical simulation carried by the help of Ansys-Fluent FVM based solver. From the results of this study it was found that when the mass flow rate of water increases in the mini channel the uniformity in temperature distribution gets improved, maximum temperature reduces also difference in maximum temperature get reduced. The arrangement of mini-channel cold plates at bottom and both the sides of the battery cells gives the best optimal design and cooling effects. The proposed Bernardi thermal model is represented by

$Q^{\prime}=\frac{1}{V_{o l}}\left(I^{2} R_{i}+I T \frac{\partial V_{o c}}{\partial T}\right)$

where $Q^{\prime}$ is heat generated in battery. $\operatorname{Vol}_{b}$ is the battery volume. $\mathrm{I}$ is discharge current. $R_{i}$ is internal resistance. $\mathrm{T}$ is battery temperature. $V_{o c}$ is open circuit voltage. $I^{2} R_{i}$ is joule heat. $I T \frac{\partial V_{o c}}{\partial T}$ is chemical reaction heat. 

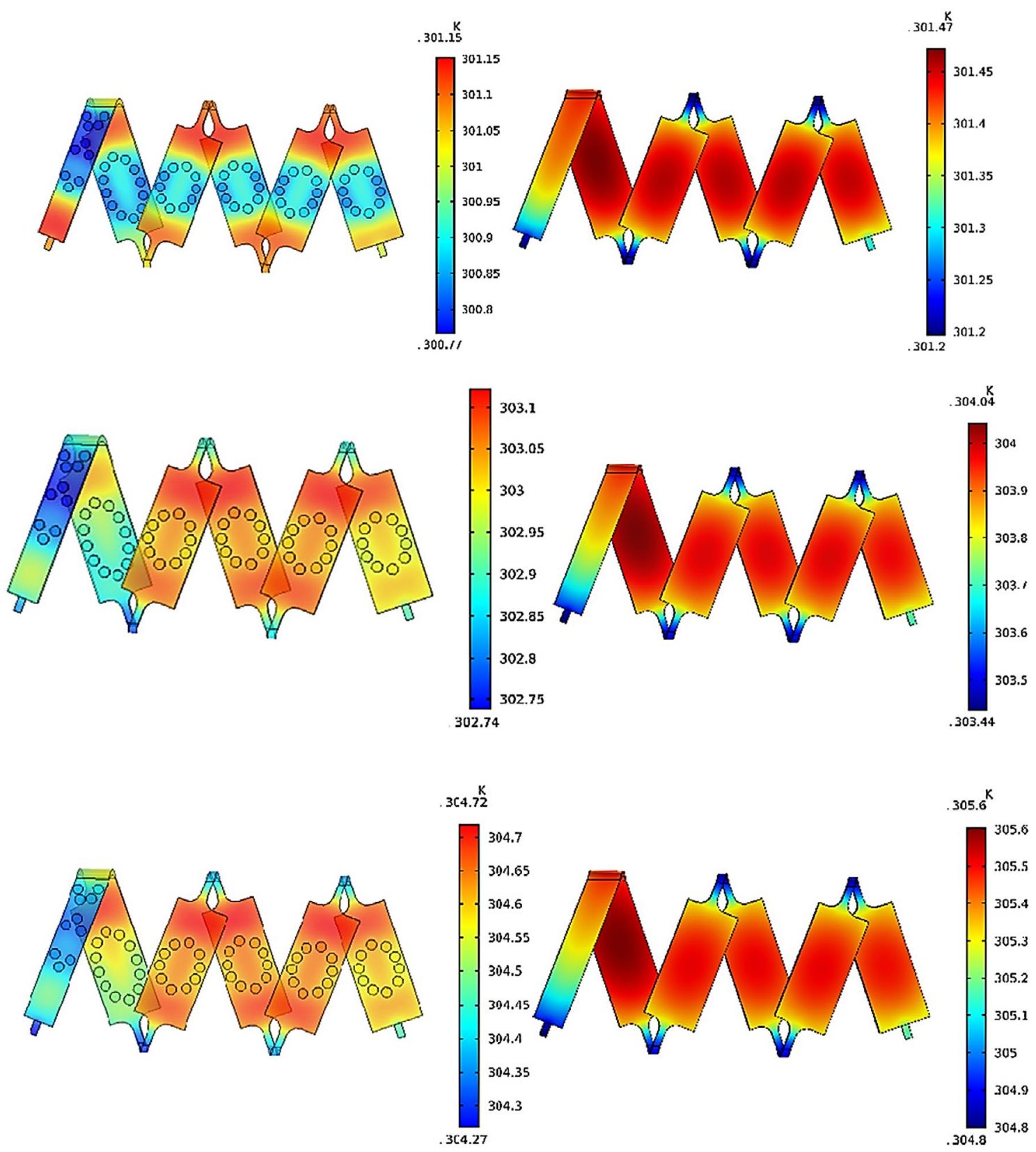

Fig. 60 Thermal behaviour of stretchable battery cell with optimal design and original design [134]

From the above Fig. 65, it is clear that for same discharge rate the temperature distribution in the battery pack and cell at its centre section is more uniform with reduced maximum temperature for design ' $c$ ' compare to other two design ' $a$ ' and ' $b$ '. Li et al. [139] proposed a numerical solution to optimize the temperature distribution and to maintain the maximum temperature within the prismatic LIB cell and module under safe operating conditions. Similar to Tang et al.[138] in this study also Bernardi heat generation thermal model was used to optimize the desired objectives. The BTMS used in this investigation is based on water coolant flowing through the channel mounted in between the two neighbouring battery cells. A $3 \mathrm{D}$ numerical simulation is performed by the help of Ansys-Fluent, convective terms were solved by using QUICK scheme and pressure velocity coupling was done by SIMPLE algorithm. This study suggest that it was inlet temperature of water which counts more rather than flow rate which controls the maximum temperature in the battery module. Figure 66 above shows that with decrease in the inlet temperature of water flowing through the channel the average temperature of battery surface also decreases while the discharge rate of battery and 


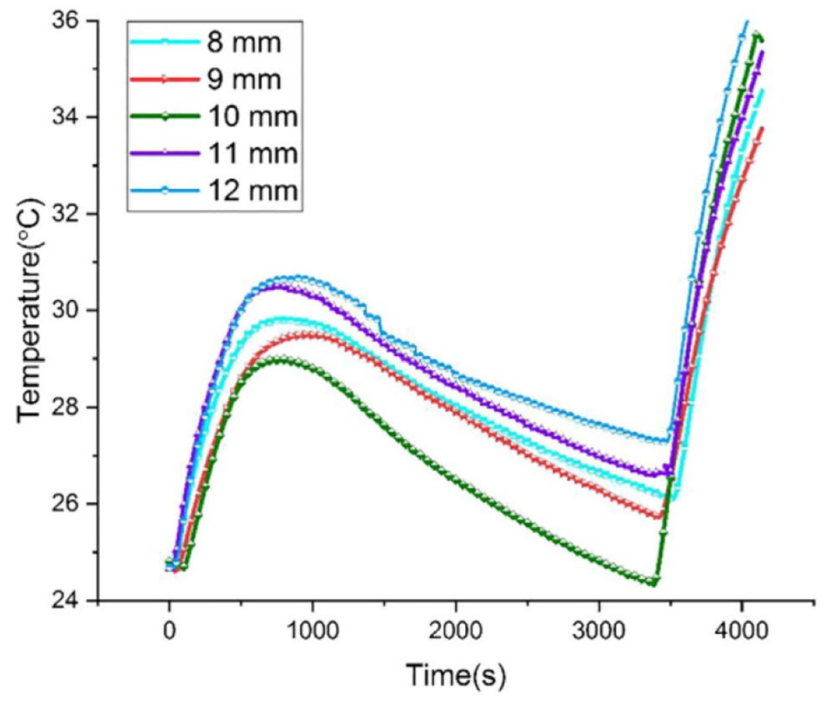

Fig. 61 Effect of PCM layer thickness on temperature of battery surface [135]

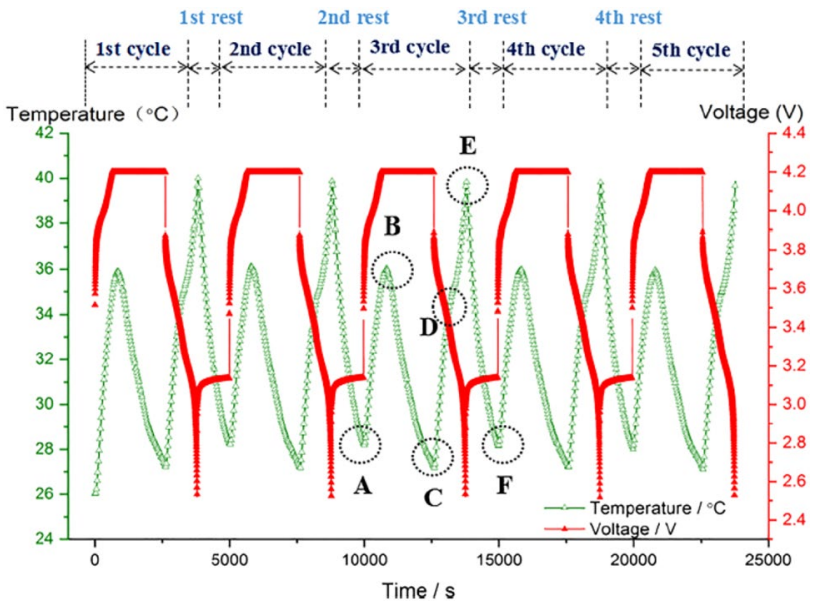

Fig. 62 Voltage and temperature Variation for different cycles with rest time of 5 min [135] mass flow rate of water were kept constant. Such behaviour clearly indicates that water inlet temperature is much more significant compare to its mass flow rate.

Li et al. [140] demonstrated a numerical and experimental study of Li-ion prismatic battery cell with an objective of optimizing the temperature distribution in battery pack, pressure drop and thermal performance and structural design of the battery. A mini channel is inserted in between the two adjacent battery cell through which water as a coolant is flowing. A MODO optimization technique along with multi objective genetic algorithm (MOGO) was employed in order to attain the desired optimization results, whereas mini channel based BTMS system was optimized by using Surrogate model. The Ansys-Fluent software was used so as to obtain the numerical simulation of 3D thermal battery model. The results of this study show that by using the new proposed optimization design the temperature difference, maximum temperature, power consumption and battery volume can be reduced to satisfactory range. Figure 67 indicates the distribution of temperature within the battery pack before and after optimization and it was found that by using the proposed optimization technique the temperature in a battery pack can be kept under desirable safe limit. Figure 68 shows the pressure contours in mini-channel before and after the optimization and it was observed that by employing the proposed surrogate model to optimize the BTMS system the pressure loss in mini channel can be reduced hence the power consumed by the cooling system also get reduced.

Similar type of numerical study was carried by Ye et al. [141] to optimize the temperature distribution, maximum temperature in LiFePO4 battery cell and pressure distribution in mini channel cooling plates in which the water is used as a coolant. The mini channel cooling plates were installed on top and bottom parts of the battery cells which are arranged in series connection. The orthogonal experimental design strategy was used to obtain the optimal

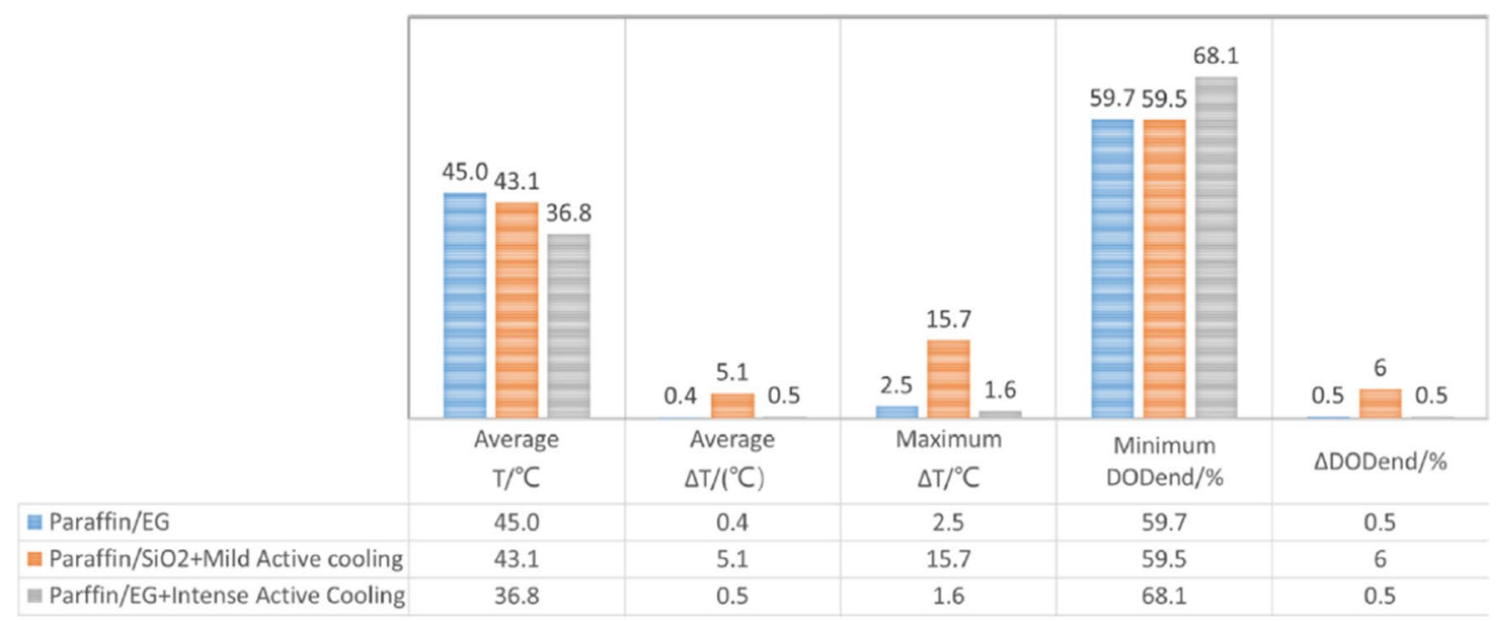

Fig. 63 Temperature and battery capacity fade comparison under three different cooling conditions [136] 
configuration and battery module parameters and surrogate model was used to catch the optimal geometry of cooling plates. Further the 3D thermal battery model was built by using CATIA CAD package and analysis was done by using Ansys Fluent software. The output of this study shows that by increasing the number of channels and cross section of cooling plates the temperature distribution and pressure drop can be reduced to greater extent by keeping flowrate of water constant at the channel inlet. The temperature rise in the battery module was verified theoretically and numerically by using following equation-

$\Delta T_{c}=\frac{M \alpha}{2 f_{i} S_{p}}$

where $\Delta T_{c}$ is difference in temperature of the coolant. $\mathrm{M}$ is number of batteries. $\alpha$ is heat generated per unit time in the cell. $\mathrm{fi}$ is the flow rate of water at inlet. $\mathrm{Sp}$ is specific heat of water.

The above Figs. 69, 70 and 71 indicates the temperature distribution on the battery module surface, cooling plates and Pressure distribution in cooling plates when surrogate optimal design model was used. The contours of temperature and pressure clearly shows that the proposed optimal design of the BTMS reduces the temperature in battery module and decreases the pressure loss. One more type of experimental and numerical study related to BTMS based on mini channel with water as a coolant was conducted by Liu et al. [109]. In this study a tree shape mini channel is used to manage the thermal performance of prismatic LIB cell with an objective of optimizing the maximum temperature, temperature difference, and battery life by making use of single and multi-objective genetic algorithm (GA).The numerical simulation of the battery cell was carried by the help of Ansys-Fluent, pressure velocity coupling was performed by SIMPLE algorithm and second order upwind discretizing scheme was used to solve the fluid flow governing equations. The results obtained out of this study shows that by adopting the tree like mini channel the thermal performance of battery cell can be improved compare to straight mini channel. The parameters like inlet width and oblique angle of the tree type mini channel has significant role in heat transfer enhancement with marginal increase in the pumping power.

Figures 72a elucidates the experimental apparatus used to study about the tree type mini channel heat sinks while Fig. 72b illustrate one of the type of mini-channel tree used in this study with $\mathrm{d}$ as inlet width of inclined channel and $\theta$ is inclination angle or oblique angle. Both the parameters $d$ and $\theta$ will have a significant effect on heat transfer. Figure $73 \mathrm{a}$ illustrate the results obtained for maximum temperature in battery cell by multi-objective GA in comparison with CFD results and it was found that maximum temperature of battery cell has decreased with optimal algorithm. Figure 73b, 


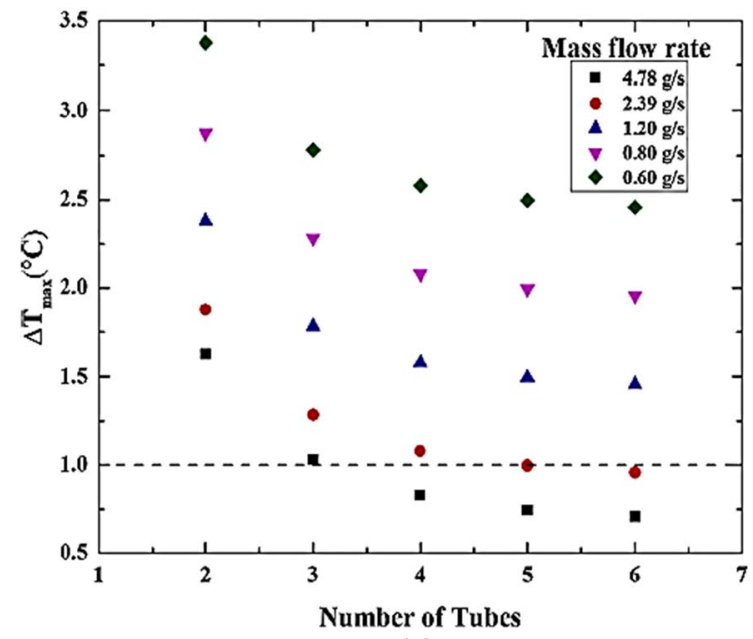

(a)

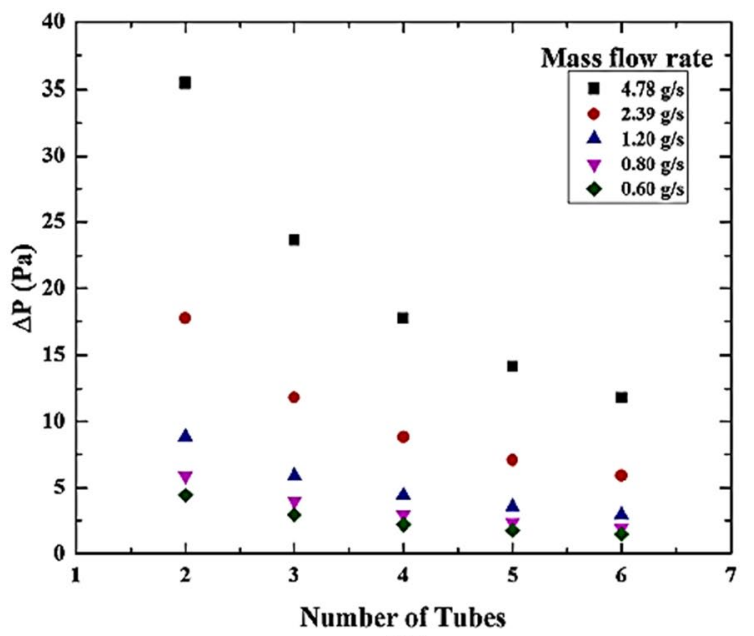

(b)

Fig. 64 Influence of mini channel width on a maximum temperature in battery cell, b Pressure drop in mini channel [137]

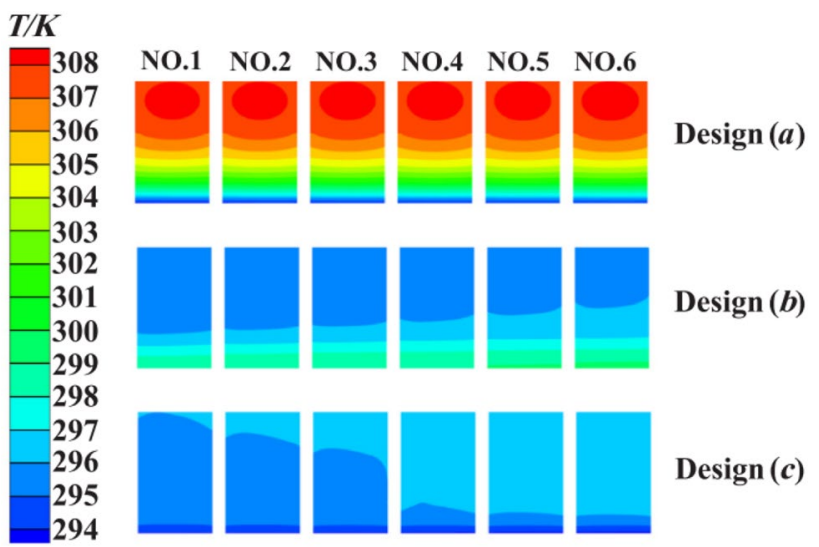

Fig. 65 Temperature distribution in battery cells with three different configuration of mini-channel cold plates and design $\mathrm{C}$ is optimal configuration [138]

c indicate the optimal results for temperature difference and pressure drop respectively.

Chen et al. [142] conducted an experimental and numerical investigation on LIB cells to optimize the temperature deviation, uniformity in temperature distribution and pumping cost with structural design. The optimization is achieved by using MMDO algorithm. A water cooled mini channel cooling plate is sandwiched between the two battery cells. The numerical simulation was done by using ICEM CFD software and Fluent. The results of this study imply that by keeping same input power to the battery one can easily control the temperature deviation and temperature reduction.

The above Fig. 74 shows how one can minimize the maximum temperature in battery module, minimize the deviation in temperature difference, and minimize the pressure loss in a mini channel cooling plate. The optimization method

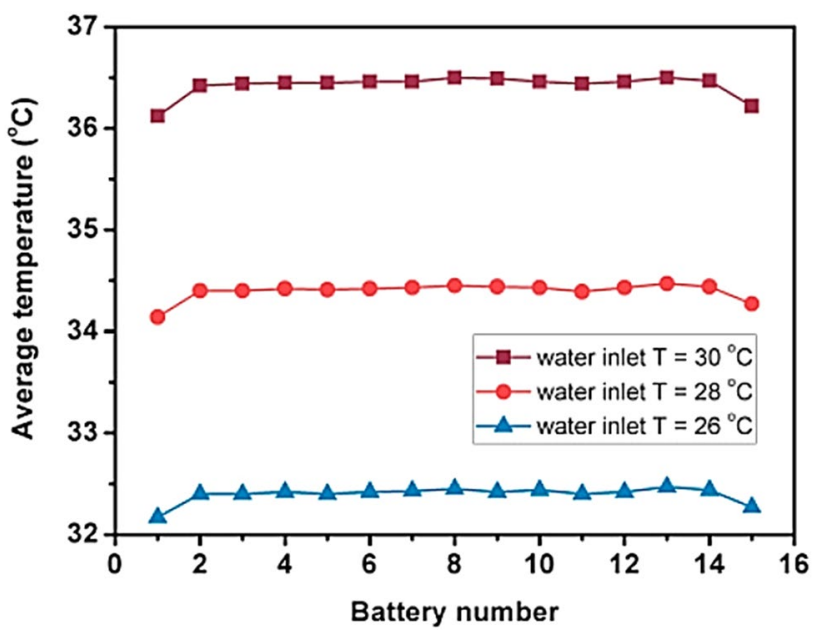

Fig. 66 Effect of water inlet temperature on average temperature of battery [139]

used in this study gives a better and easy way of improving the thermal performance of BTMS. Deng et al. [143] performed a numerical simulation of prismatic type LIB to achieve the optimization of multi-objective functions such as maximum temperature, temperature deviation at the surface and pressure drop in a flow channel along with design of the BTMS. To fulfil these above stated goals a multi-objective optimization method based on genetic algorithm was used. A bifurcated network of double layered type cooling plate was used in which water is flowing as a coolant. The numerical simulation was carried by STAR CCM + software and design optimization were done by using a response surface approximation (RSA) surrogate model. Finally, out of this study it was concluded that by using reverted double bifurcated cooling plate in LIB can reduce the maximum 


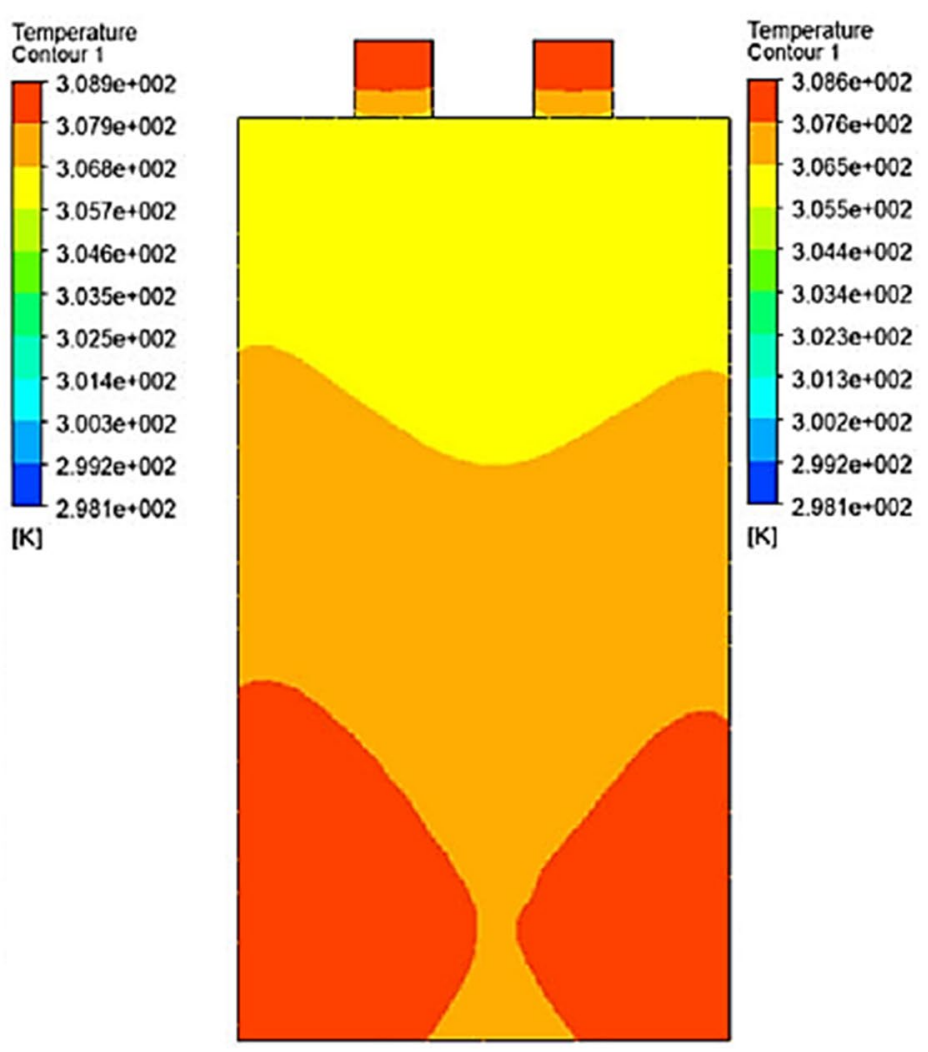

(a)

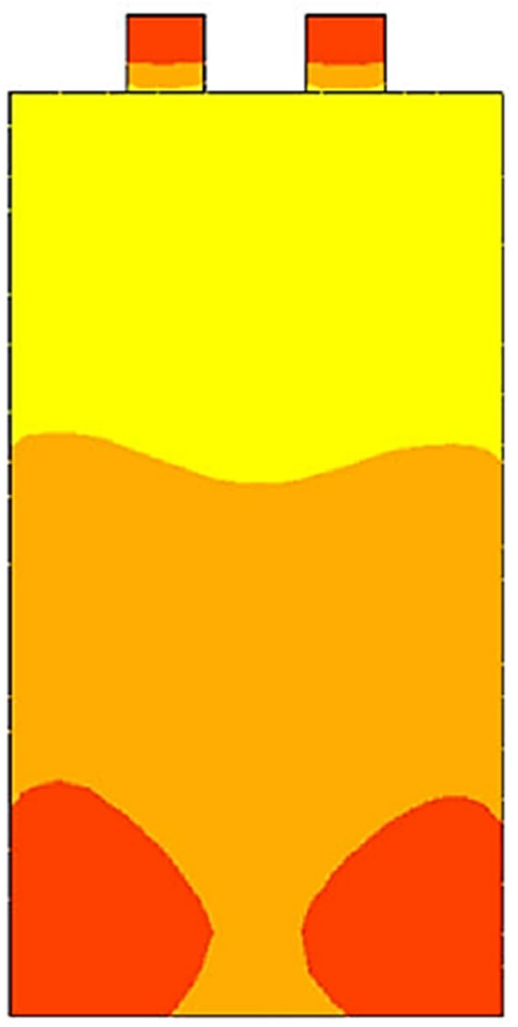

(b)

Fig. 67 a Temperature distribution in battery pack before optimization, b temperature distribution in battery pack after optimization [140]

Fig. 68 Pressure variation in mini channel a before optimization, $\mathbf{b}$ after optimization [140]
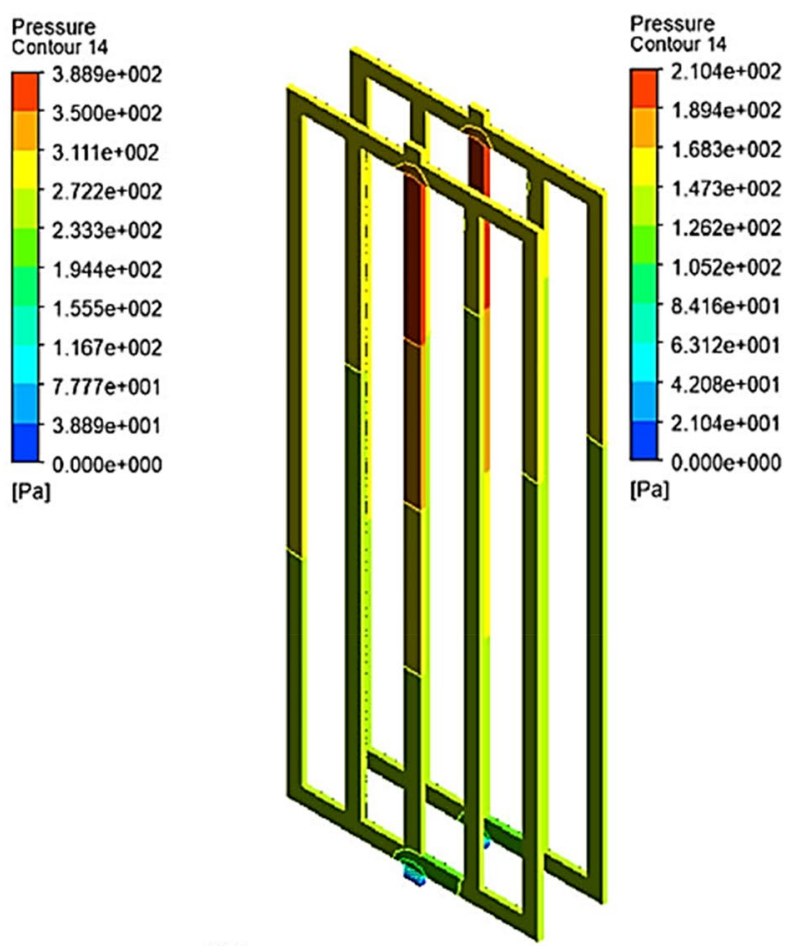

(a)

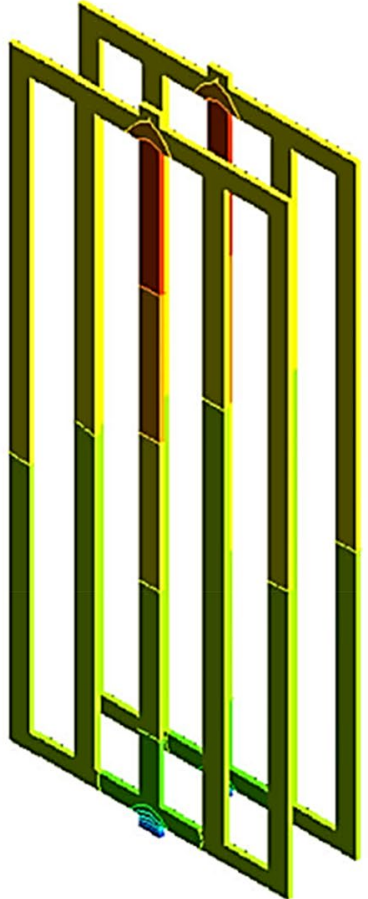

(b) 
Fig. 69 Optimized battery module temperature distribution [141] contour-1

Total Temperature

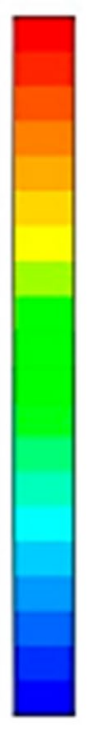

$3.22 \times 10$

$3.19 \times 10$

$3.16 \times 10$

$3.12 \times 10$

$3.09 \times 10$

$3.06 \times 10$

$3.03 \times 10$

$2.99 \times 10$

$2.96 \times 10$

$2.93 \times 10$

$2.90 \times 10$

$2.86 \times 10$

$2.83 \times 10$

$2.80 \times 10$

$2.77 \times 10$

$2.73 \times 10$

$2.70 \times 10$

$2.67 \times 10$

$2.63 \times 10$

$2.60 \times 10$

$2.57 \times 10$

\section{contour-1}

Tolal Temperalure

[141]

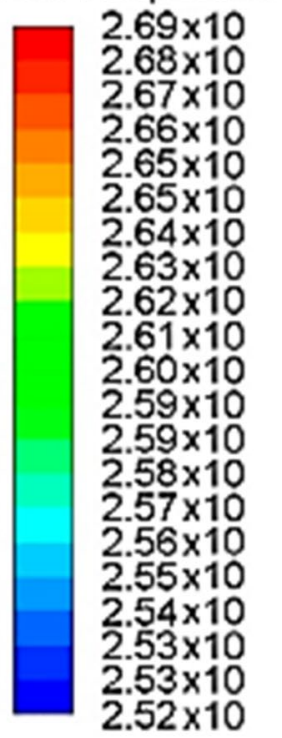

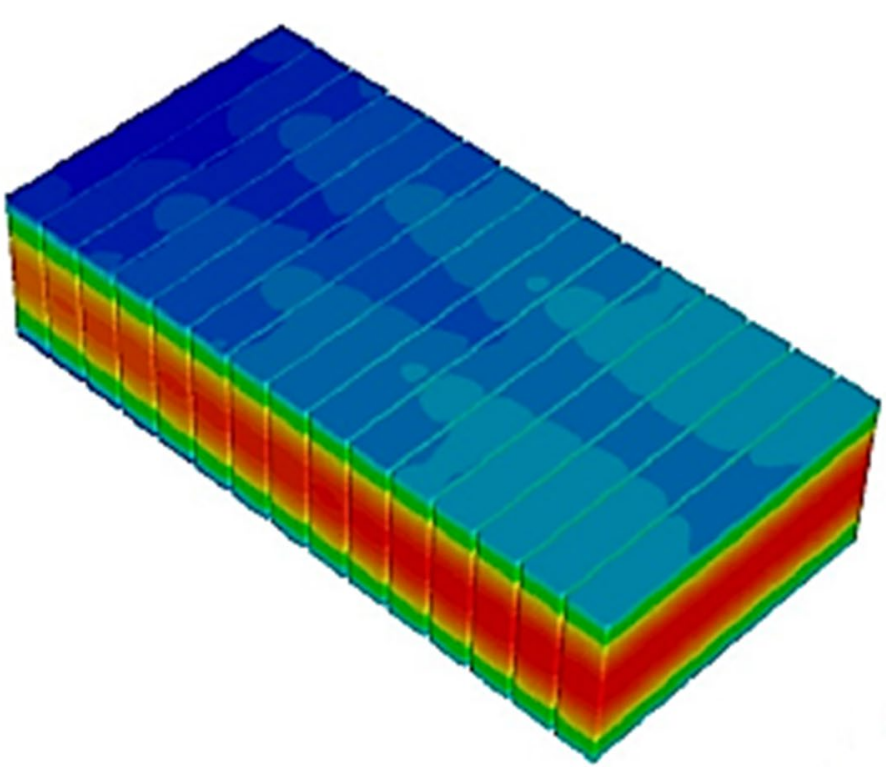

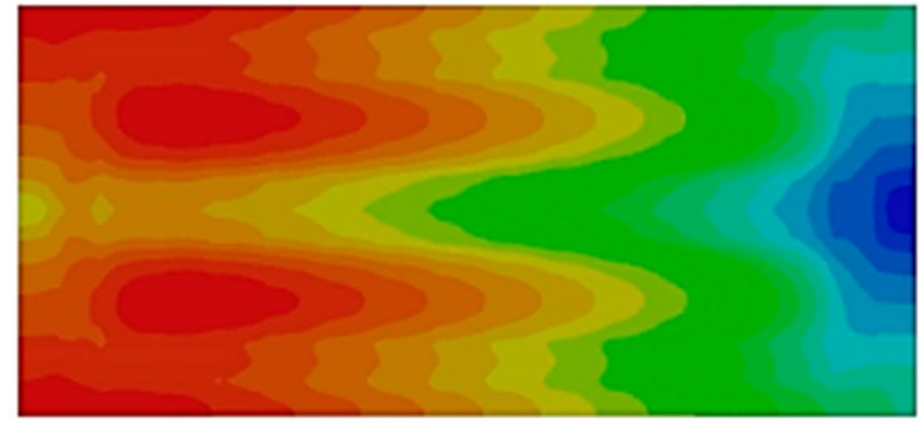

temperature of battery surface, reduces the deviation in temperature and pressure drop of fluid within the channel part simultaneously.

By determining the standard deviation in bottom surface temperature of the battery one can easily predict the uniformity in the surface temperature of the battery which is one of the optimizations objectives. Therefore, the standard temperature deviation at the bottom surface of the battery is given as follows
$T_{\alpha t}=\sqrt{\frac{\int A_{b}\left(T-T_{a v g}\right)^{2} t A^{\prime}}{\int A_{b} t A^{\prime}}}$

where $T_{\alpha t}$ is bottom surface temperature deviation of cold plate, $A_{b}$ bottom surface area of the cold plate, $T$ is temperature, $T_{\text {avg }}$ is temperature average value at bottom surface, $\mathrm{t}$ is thickness of cols plate, $\mathrm{A}^{\prime}$ is contact surface area between the cold plate and battery surface. The pressure drop in the flow channel part is given by 
Fig. 71 Optimal Pressure distribution in cooling plates [141] contour-1

Total Pressure

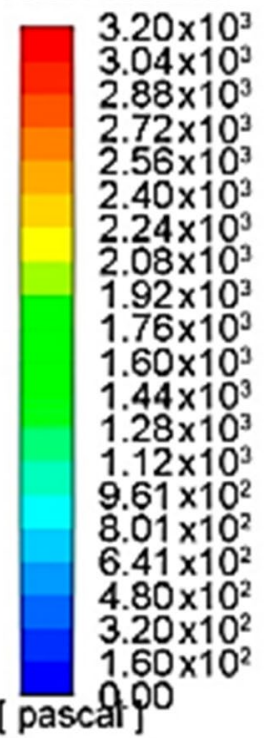

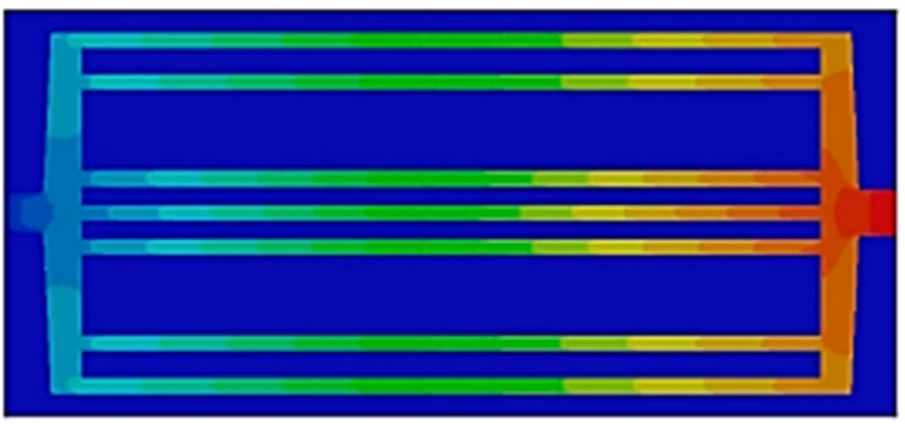

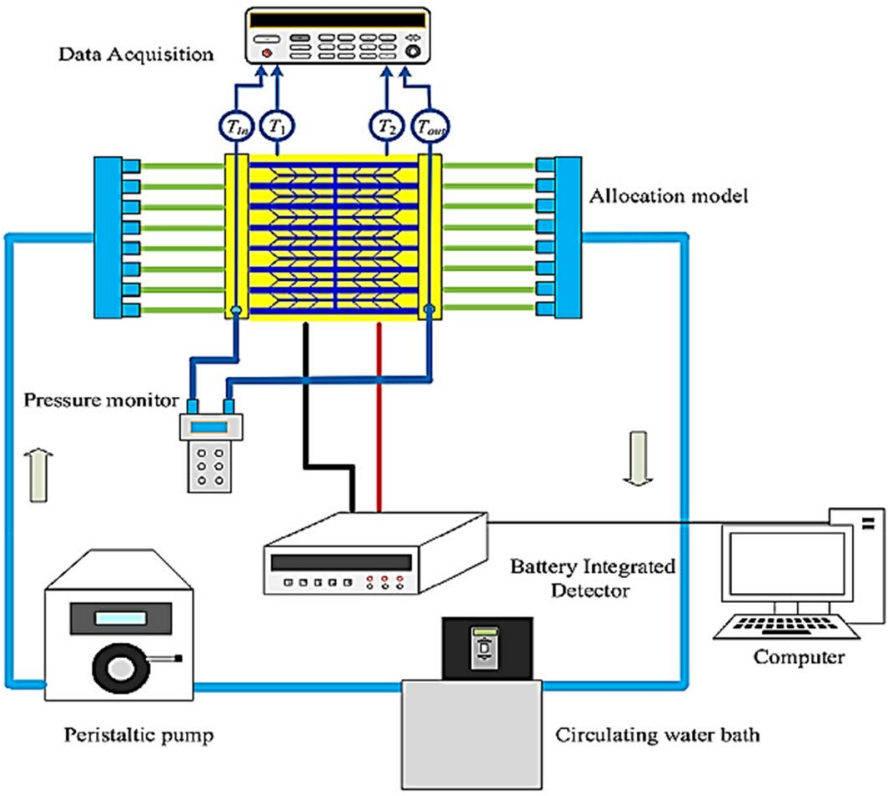

(a)

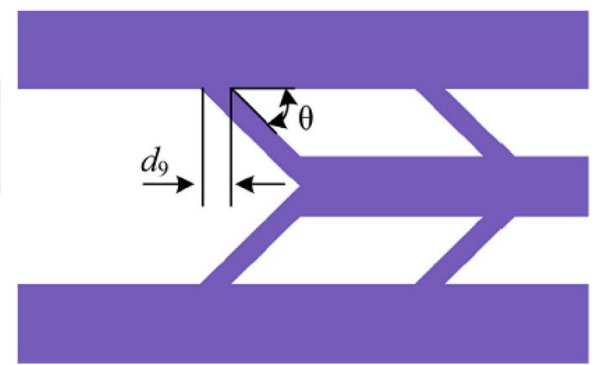

(b)

Fig. 72 a Experimental set up for tree type mini channel heat sink, b tree type mini channel $d$ inlet width of the oblique mini channel, $\theta$ is the oblique angle [109]

$$
P_{\text {drop }}=P_{\text {longitudinal }}-P_{\text {local }}
$$

where Pdrop is pressure drop at inlet and outlet of the channel, Plongitudinal pressure drop in longitudinal direction of the channel, Plocal local pressure drop in turning sections and variable cross sectional areas of the channel. The longitudinal pressure drop can be determined as follows:
$P_{\text {longitudinal }}=\sum P_{j}=\frac{128}{\pi} \frac{\gamma l_{j}}{d_{h}^{4}} m_{j}$

where $P_{j}$ is pressure drop of channel $\mathrm{j}, \gamma$ is Kinematic viscosity of liquid. dh is hydraulic diameter, $\mathrm{mj}$ is mass flow rate. $l_{j}$ is length of the channel $\mathrm{j}$.

Figure 75 indicates a comparison of surface temperature and velocity of coolant flowing in the channel. It was clearly 


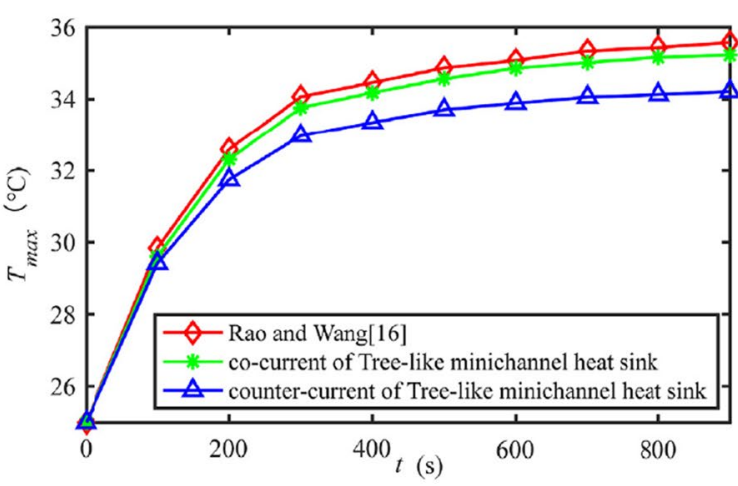

(a)

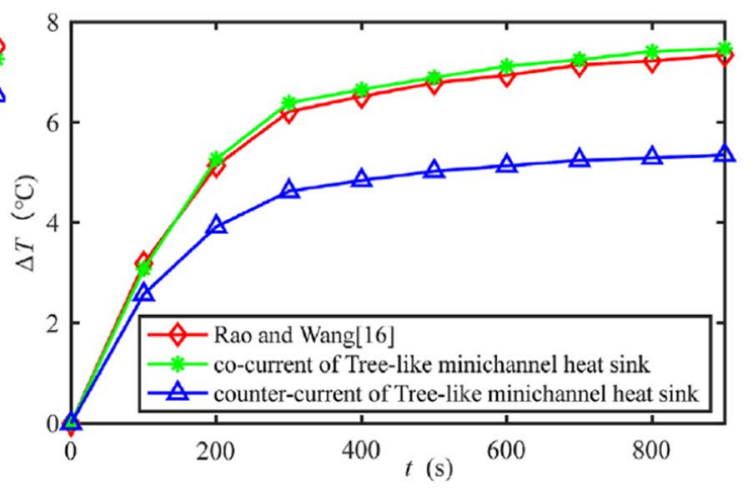

(b)

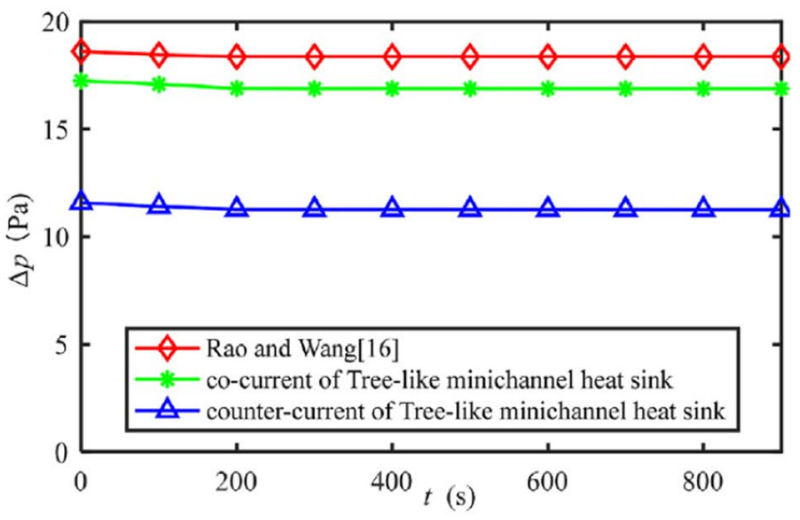

(c)

Fig. 73 a Optimization of maximum temperature of battery cell, $\mathbf{b}$ optimization of temperature difference, $\mathbf{c}$ optimization of pressure drop [109]

mentioned that the hot spot concentration at the channel outlet is more for serpentine channel as well as for reverting double layer cold plate, but the double layer bifurcated channel design can be easily changed to avoid the temperature concentrating areas. While from the velocity profiles it was concluded that using bifurcated network of channel leads to less pressure drop as compared to serpentine and straight channels. In one more study Deng et al. [144] conducted numerical simulation of rectangular battery cell with cooling plates embedded with leaf like bifurcated network mini-channel to optimize the design of cooling plates and to reduce the maximum temperature, temperature deviation and pressure drop. The multi objective optimization based on genetic algorithm was used whereas the simulation was carried by the help of STAR CCM+ software. The mini channel with leaf like network through which water is flowing was used for improving the thermal performance of battery. The results of this study show that the design parameters like, main channel width, number of feeds out channel, mass flow rate and width ratio of symmetric bifurcation channel have significant effect on the heat dissipation from the cooling plate. The pressure drop at the $\mathrm{j}$ channel in turbulence form for bifurcated symmetric leaf network channel was obtained as follows:

$P_{(d r o p) j} \sim \frac{m_{(i n) j}^{2} l_{j}}{d_{j}^{5}}$

where $P_{(d r o p) j}$ pressure drop in j channel, $m_{(i n) j}$ inlet mass flow rate in $\mathrm{j}$ channel, $l_{j}$ is the length of the channel $\mathrm{j}$, $\mathrm{dj}$ is the hydraulic diameter of channel $j$. The turbulent dynamic viscosity is given by

$\mu_{\text {turb }}=\frac{\rho_{l} C_{\mu} K_{i}^{2}}{\varepsilon}$

where $\mu_{\text {turb }}$ is dynamic turbulent viscosity, $\rho_{l}$ is liquid density, $\varepsilon$ is turbulent dissipation rate, $\mathrm{Ki}$ is turbulent kinetic energy, and $C_{\mu} i$ s empirical coefficient.

Figure 76 shows the layout of bifurcated leaf type network channel with inlet and outlet sections. Figure 77 illustrate the temperature contours in leaf shaped bifurcated network channel for various width ratio. With decrease in the channel path the hotspot region area expands. The pressure drop in 


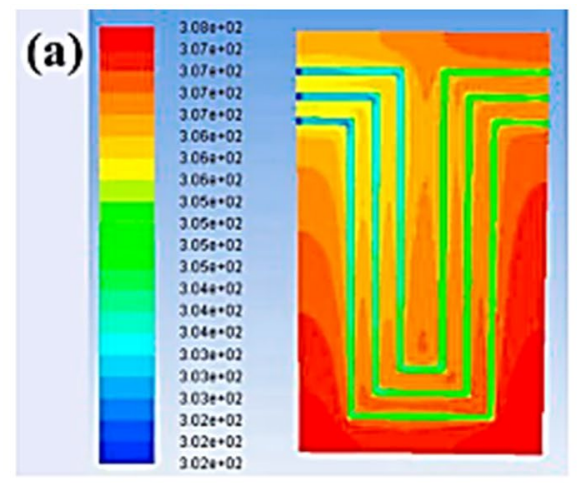

(a) Temperature distribution for the symmetric face of the cooling plate.

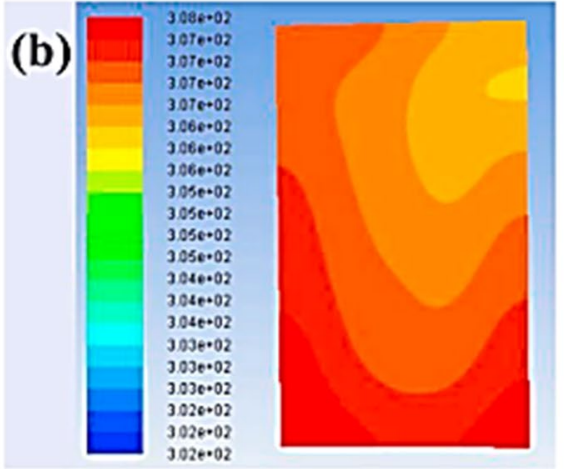

(b) Temperature distribution for the back side of the battery.

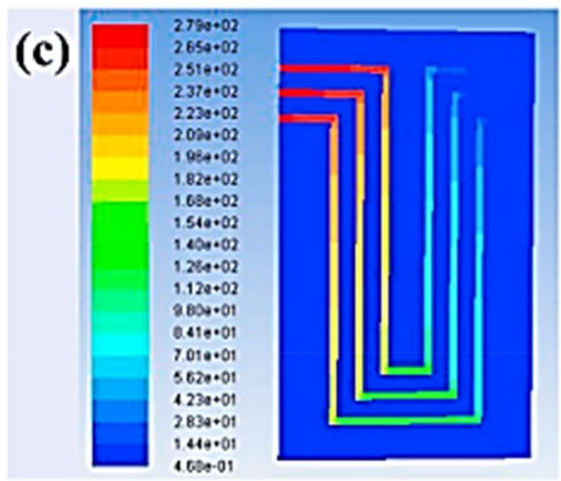

(c) Pressure distribution for the symmetric face of the cooling plate.

Fig. 74 Optimized design a temperature contours at symmetric face of mini channel and battery cell, b temperature contours at back face of battery cell, c pressure distribution in mini channel [142]

the channel part decreases with decrease in the width ratio. Shang et al. [145] optimized experimentally and numerically the structural design of the LIB module in order to achieve multi objectives such as reduced maximum temperature, temperature difference between the battery cells, and pumping power. An orthogonal testing scheme has adopted to achieve the design parameters (inlet temperature of coolant, mass flow rate and width of cooling plate) optimization. The cooling plates are placed at the bottom side of the battery cell through which a mixture of glycol and water will flow. The numerical simulation based on finite volume scheme is carried out by using commercially available CFD software. The results obtained shows that there exists an optimal value for coolant inlet temperature, width of cooling plate and mass flow rate at which the maximum temperature, pumping power can be reduced with better temperature uniformity in battery module.
As the battery cell bottom surface and thermal conductive pad comes in contact, therefore, the temperature at this contact surface is determined as:

$T=\frac{q_{v o l}}{C_{z}}\left(W_{c}^{2}-z^{2}\right)+T_{i 1}$

where $\mathrm{T}$ is the temperature at cell and conductive pad interface, $q_{v o l}$, volumetric heat in the cell, $C_{z}$ thermal conductivity in $\mathrm{z}$ direction, $\mathrm{Wc}$ is half width of cell, $\mathrm{z}=0, T_{i 1}$ boundary temperature between the cell and cooling pad. The temperature distribution in the direction perpendicular to the cooling plate is given by -

$T=\frac{q_{v o l}}{2 C_{z}}\left(W_{c}^{2}-z^{2}\right)+q_{v o l}\left(r_{c}+\frac{t_{p}}{C_{p}}+\frac{1}{h}\right)+T_{\text {inlet }}+\frac{q_{v o l} w_{c} y}{\rho_{k} V L_{h a l f}}$

where $\mathrm{T}$ is temperature distribution perpendicular to cooling plate, $r_{c}$ is thermal contact resistance, $t_{p}$ is thickness of cooling plate, $C_{p}$ is thermal conductivity of cooling plate, $T_{\text {inlet }}$ 

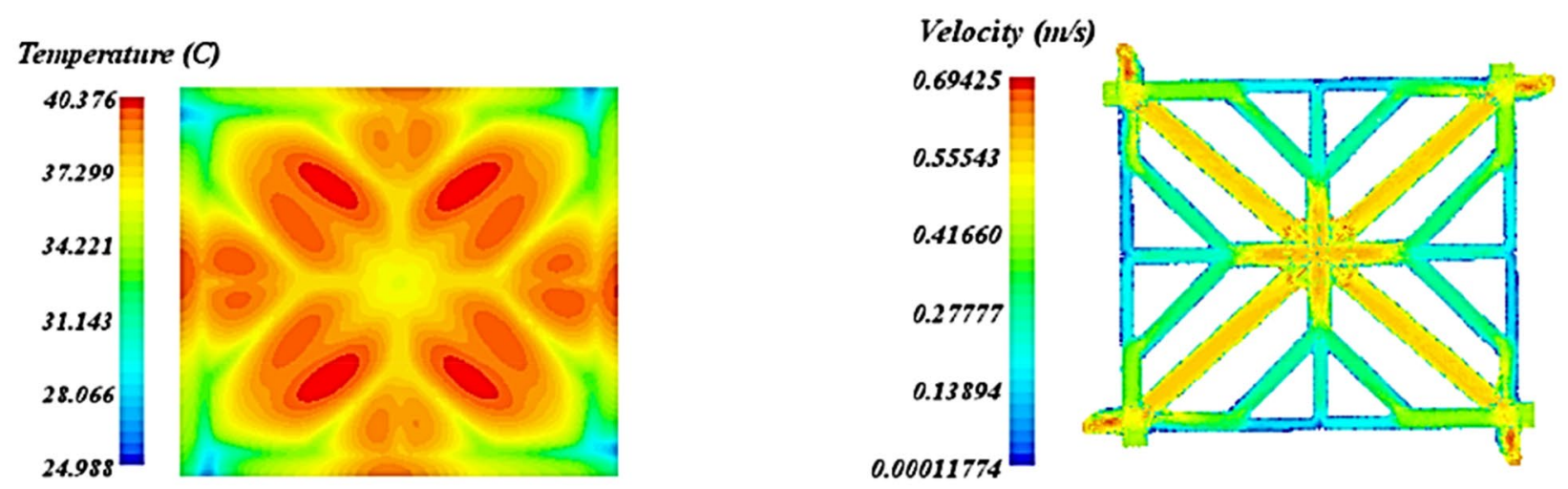

(a) Temperature and flow velocity profiles of double-layered bifurcation channel

\section{Tempernture (C)}
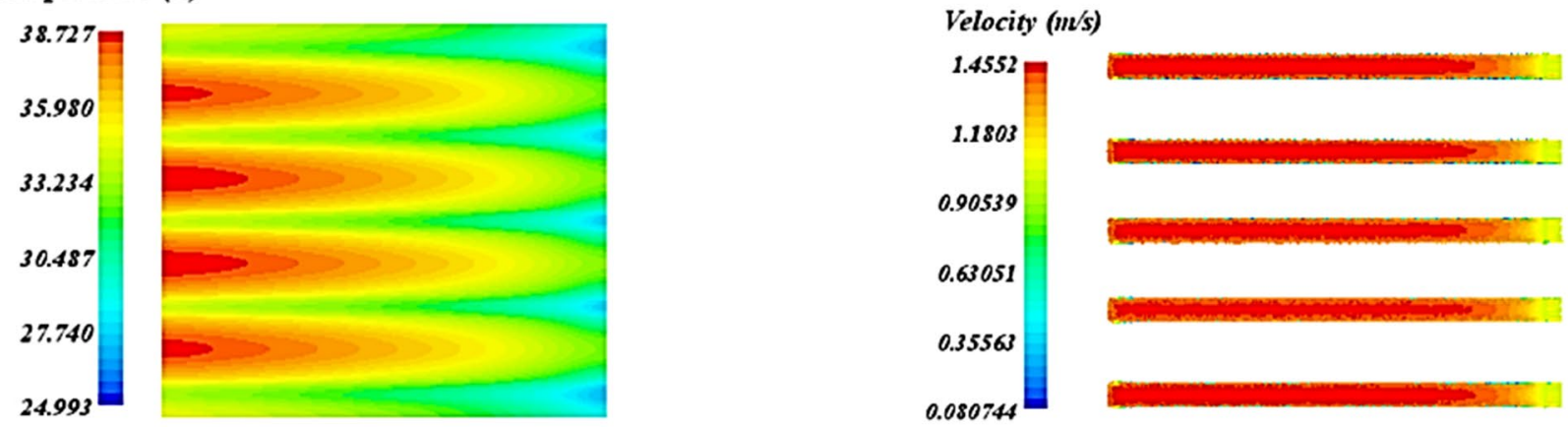

(b) Temperature and flow velocity profiles of serpentine channel

\section{Temperature (C)}
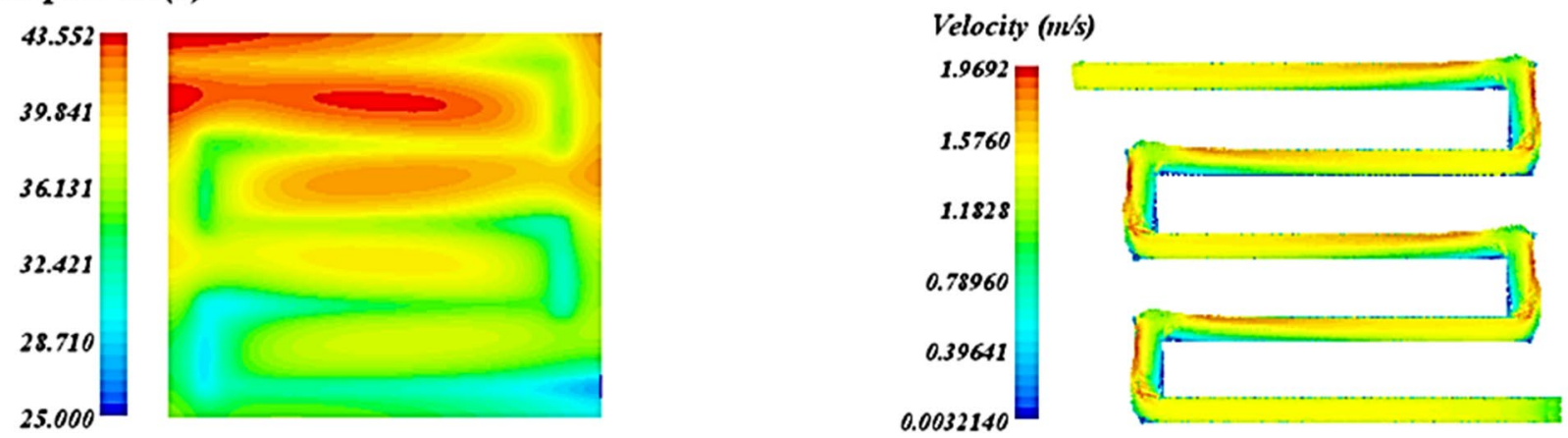

(c) Temperature and flow velocity profiles of parallel straight channel

Fig. 75 a Temperature and velocity contours in double layered bifurcated channel network, b temperature and velocity contours in serpentine channel, $\mathbf{c}$ temperature and velocity contours in straight channel [143]

inlet temperature of the coolant, $\rho_{k}$ is density of the coolant, $V$ is velocity vector of the coolant, $L_{\text {half }}$ is half the width of cooling channel.

Figure 78 shows the temperature profiles in the battery module for different inlet coolant temperature and fixed width of cooling plate and it was observed that with increase in the inlet temperature the maximum temperature in battery module decreases but there exist an optimal value of inlet temperature which is $21^{\circ} \mathrm{C}$. In one more study Shang et al. [145] suggested a multiple factors which plays a very important role in thermal management of LIB module with liquid cooling. The focus was given to optimize the structure design parameters such as coolant inlet temperature, cooling plate width and mass flow rate. The optimization was carried by using orthogonal testing scheme. The results obtained from this study shows that the temperature within the battery module is directly proportional to inlet temperature of coolant but inversely proportional to the cooling plate width. 


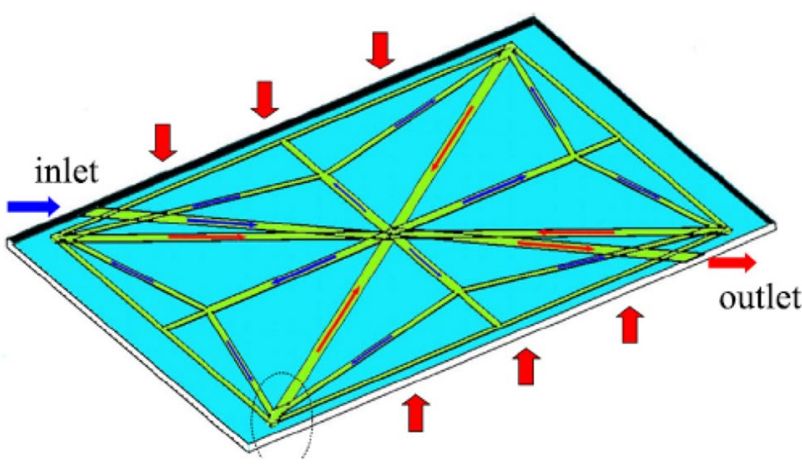

Fig. 76 Bifurcated leaf network mini channel [144]

The above Fig. 79 shows that with change in inlet temperature of the coolant the temperature in the battery module also changes and there exists an optimal value of inlet temperature $\left(18{ }^{\circ} \mathrm{C}\right)$ at which the temperature within the battery module get reduced. Wang et al. [146] conducted an experimental and numerical study on cylindrical LIB cells forming a large module for optimization of structural design parameters in liquid (water) cooling such as inlet velocity of coolant, contact angle and number of channels. The main objective is to determine the influence of these design parameters on the maximum temperature of battery module and maximum temperature difference in module. The optimization of these parameter was carried by single factor analysis in combination with orthogonal test. The numerical simulation was done by using Ansys-Fluent. The results of this study show that the contact angle plays a very major role in controlling the maximum temperature and temperature difference in battery module while the inlet velocity have the nominal effects and number of channels have least influence. Figure 80 shows the effect of different contact angle $(\phi)$ on temperature behaviour in battery module and it was found that with increase in the contact angle the temperature in the battery module decreases due to increase in the contact surface area. Figure 81 shows the effect of contact angle on the maximum temperature and temperature difference in battery module and it is clear from the figure that with increase in the contact angle both the maximum temperature and temperature difference in a module get reduced.

$\mathrm{Xu}$ et al. [147] utilized an experimental and numerical method to optimize the maximum temperature and temperature difference in a LIB pack fixed with a cooling plate at its bottom section. The cooling plate structure is modified by fixing the number of splitters in the flow path of the coolant. The optimization is achieved by using orthogonal

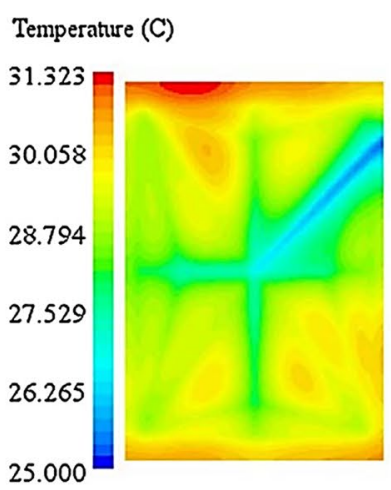

(a) $a^{\prime}=1$

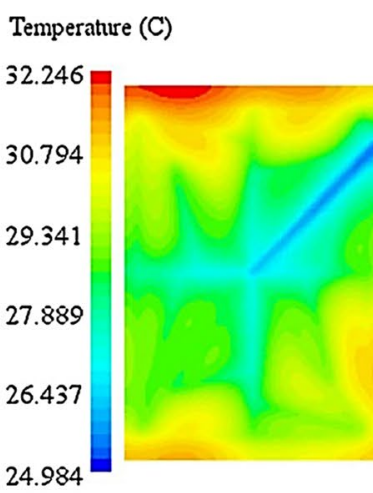

(b) $a^{\prime}=7 / 8$

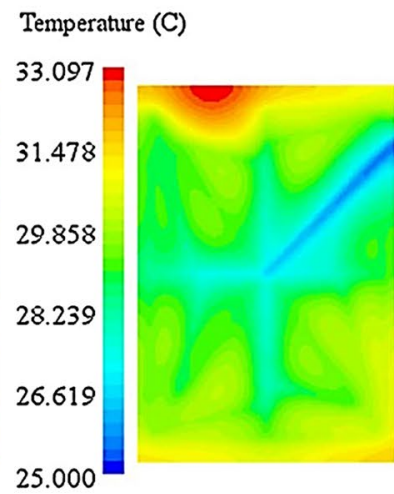

(c) $a^{\prime}=5 / 6$

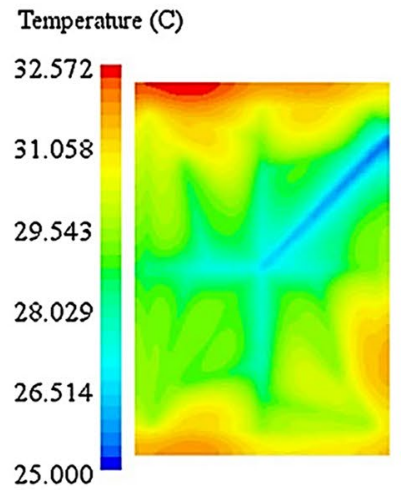

(d) $a^{\prime}=3 / 4$

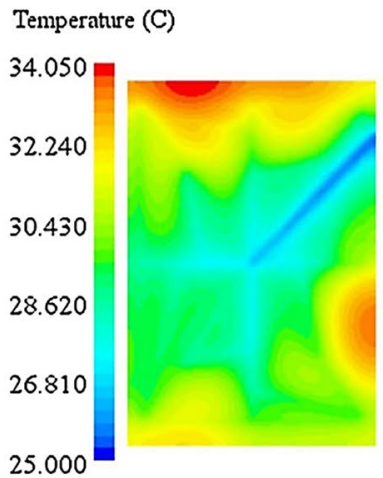

(e) $a^{\prime}=2 / 3$

Fig. 77 Temperature profile in leaf network channel for different channel width ratio [144] 


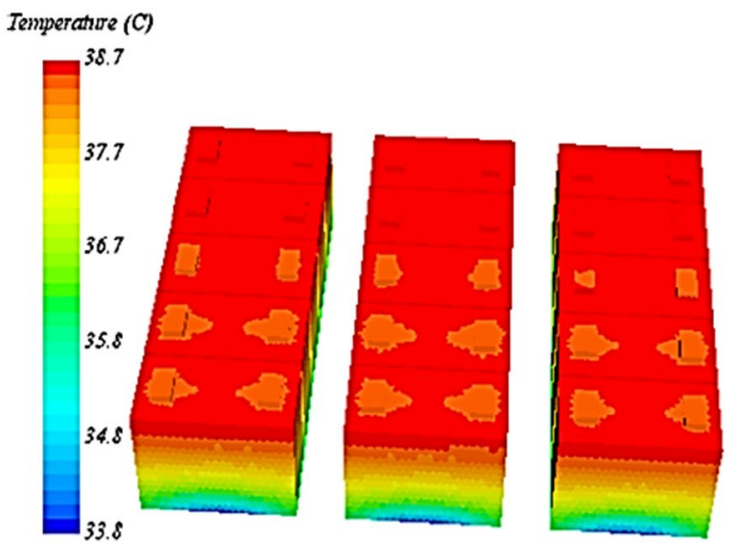

(a) Inlet temperature $=15^{\circ} \mathrm{C}$

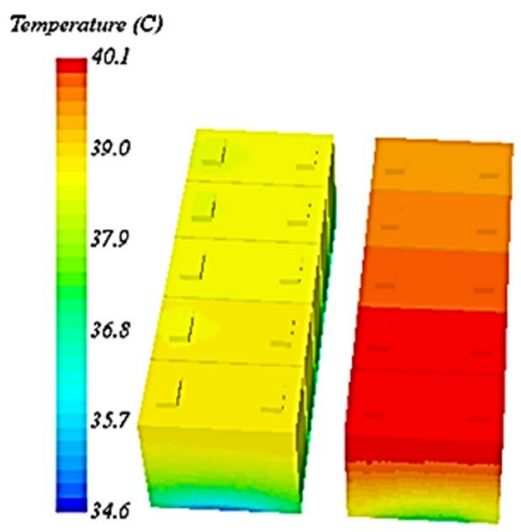

(c) Inlet temperature $=21^{\circ} \mathrm{C}$

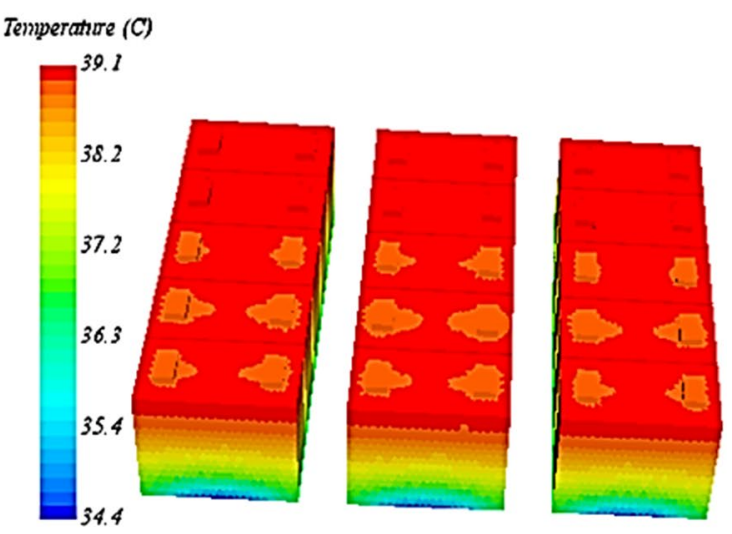

(b) Inlet temperature $=18^{\circ} \mathrm{C}$

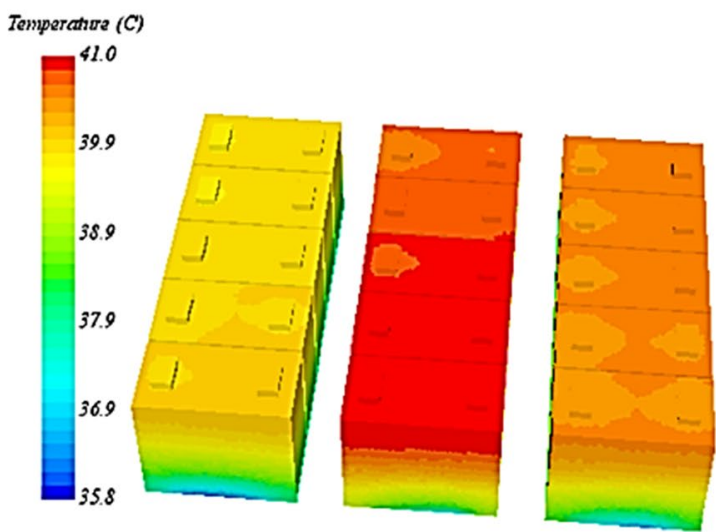

(d) Inlet temperature $=24^{\circ} \mathrm{C}$

Fig. 78 Temperature contours in battery module at constant cooling plate width and varying inlet temperature $\mathbf{a}$ inlet temperature $=15^{\circ} \mathrm{C}, \mathbf{b}$ inlet temperature $=18{ }^{\circ} \mathrm{C}, \mathbf{c}$ inlet temperature $=21^{\circ} \mathrm{C}, \mathbf{d}$ inlet temperature $=24^{\circ} \mathrm{C}[145]$

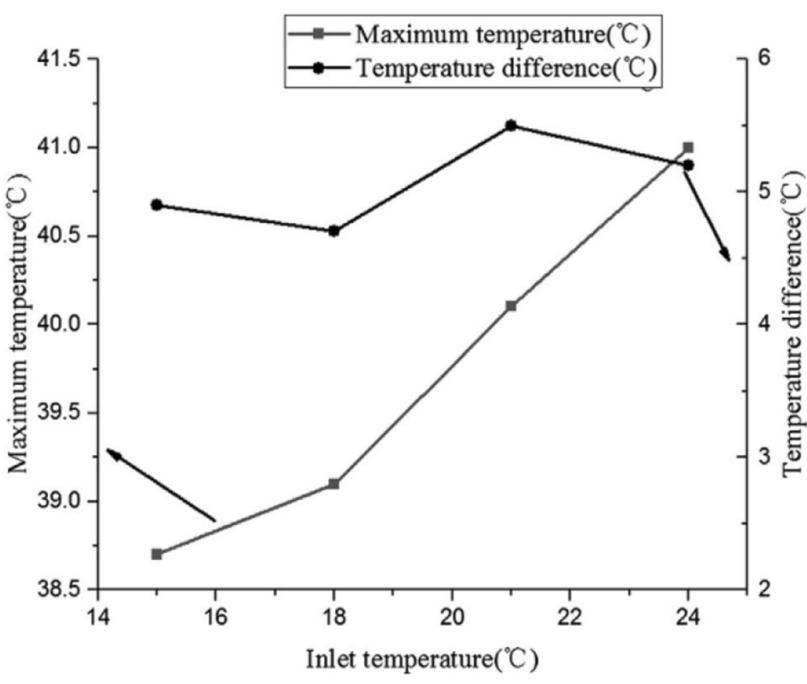

Fig. 79 Variation in maximum temperature and temperature difference with inlet temperature of coolant [145] test design procedure and numerical simulation is carried by the help of FloEFD simulation software. Five design parameters of the splitter were changed such as number of splitters, acute angle of splitter, length of splitter, distance between two splitters and offset distance. The output results of this study show that with increase in the number of splitters the temperature difference between the battery cell becomes more uniform. Figure 82 shows the arrangement of splitters within the cooling plate channel through which the water coolant flows where $\mathrm{N}$ indicates the number of splitters, $\alpha$ is acute angle, $\mathrm{L}$ is length, $\mathrm{d} 1$ is distance between splitters, and $\mathrm{d} 2$ is offset distance. Figure 83 illustrate the temperature behaviour within the battery pack fixed with a cooling plate having number of splitters. It is observed that the temperature at the rear end of the battery pack rises due to decrease in the heat carrying capacity of the coolant in this region.

Deng et al. [148] performed and experimental and numerical simulation of prismatic LIB cell pack with cold 


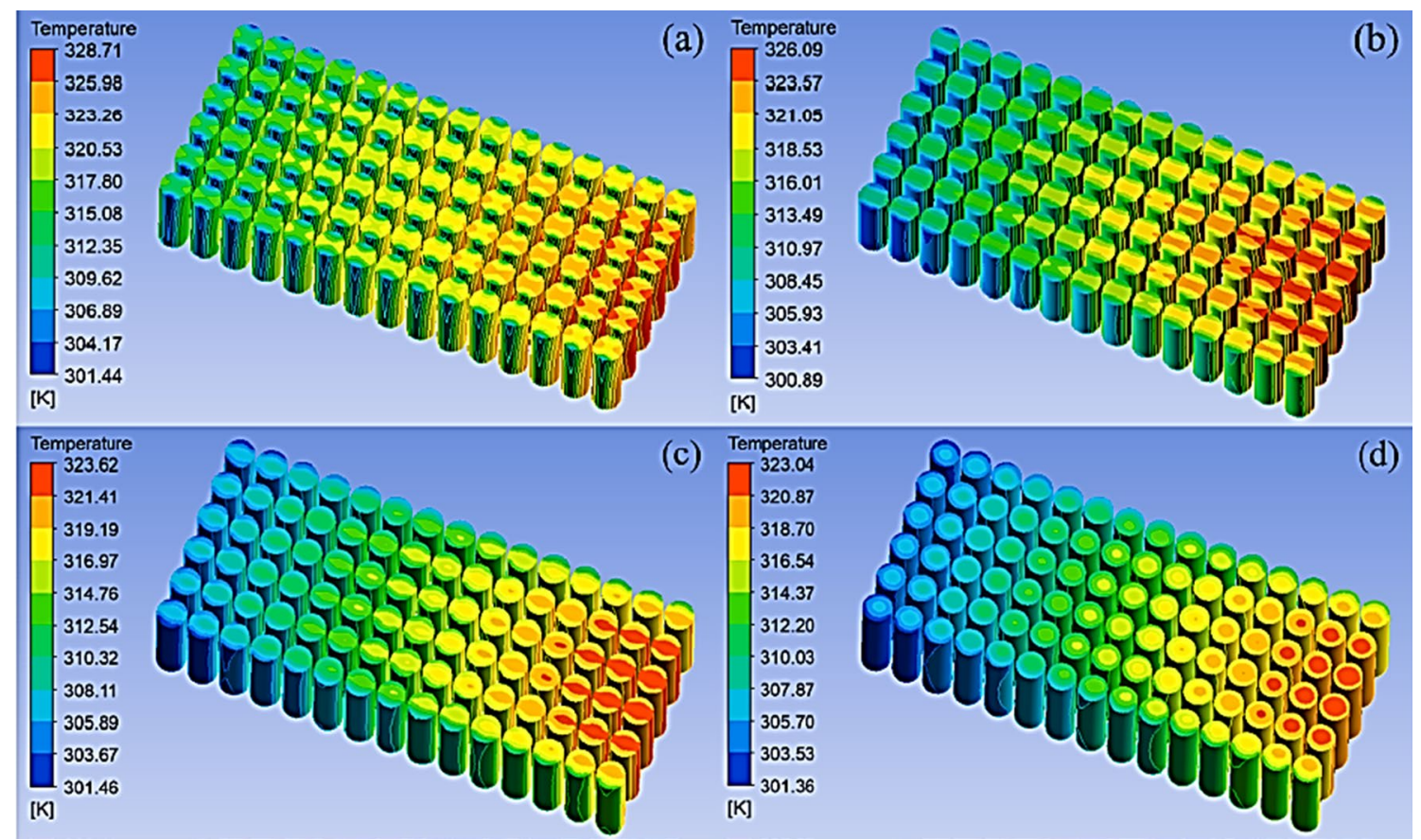

Fig. 80 Influence of Contact angle on temperature behaviour of battery module when $\mathbf{a} \phi=20^{\circ}, \mathbf{b} \phi=40^{\circ}, \mathbf{c} \phi=60^{\circ}, \mathbf{d} \phi=80^{\circ}[146]$

Fig. 81 Variation of maximum temperature and temperature difference for different contact angle [146]
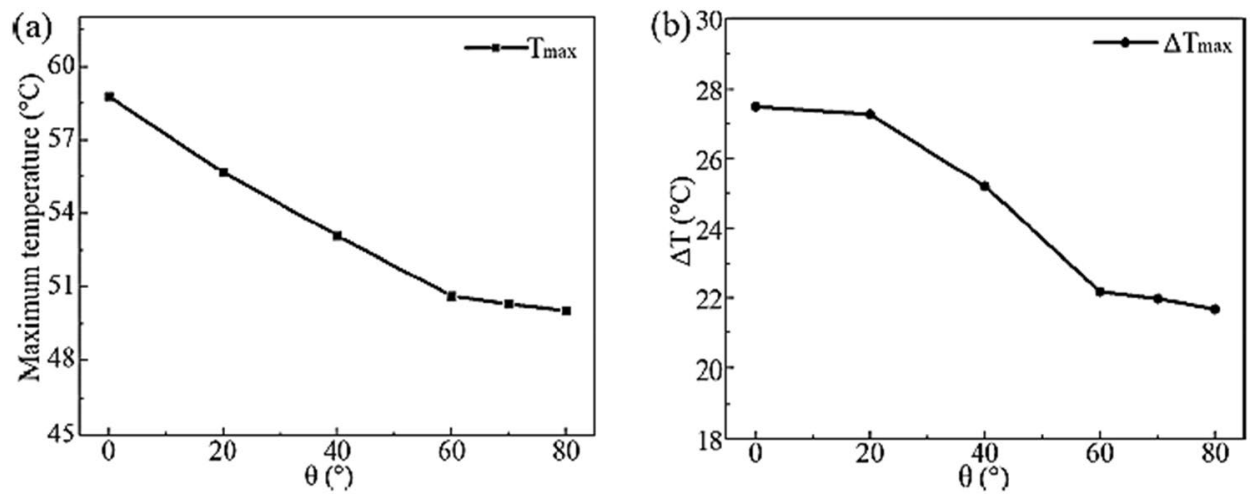

plates placed in between the two adjacent battery cell in order to optimize the maximum temperature, maximum temperature difference and pressure drop. The multi-objective non dominated sorting genetic algorithm-II (NSGA-II) was used to obtain the optimization. A commercial hydrodynamic STAR-CCM + software was used for solving the governing equations numerically. The cold plate used in this study was of type symmetrical double layer reverting bifurcation channel. Finally, it was concluded from the results of this study that with increase in channel thickness and their length ratio greatly influence the thermal performance of the battery pack. In Table 12 all the details of optimization and BTMS using mini-channel water based cooling is provided.

\section{Conclusion}

The prime objective of this review paper is to highlight the role played by the optimization technique and selected thermal, structural design parameters in order to achieve better thermal performance, less maintenance cost, less power to weight ratio and life span of LIBs. The optimization schemes used for LIBs are considered under different BTMS heads such as hybrid cooling, air cooling, liquid cooling, and PCM cooling. Most of the researchers used different optimization algorithms such as GA, MODO, MMDO, MOGO, NSGA-II, while some of them utilized iterative type of optimization technique like, evaluation index method. Perturbation iterative method, enthalpy method, and HPPS method. Various battery geometries were studied by the researchers such as 
Fig. 82 Design parameters of splitter within a cooling plate [147]
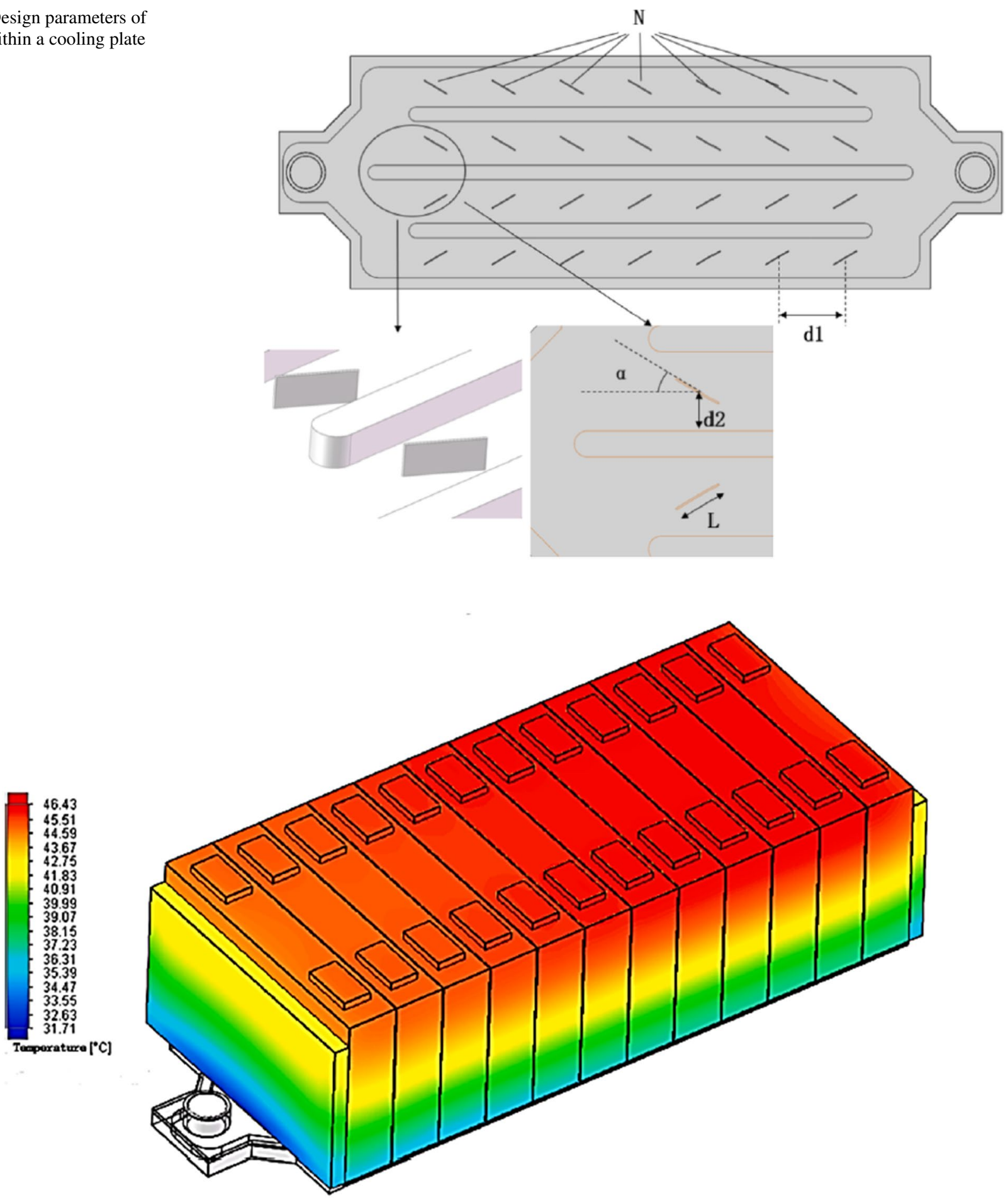

Fig. 83 Temperature contours in battery pack [147]

prismatic cell, cylindrical cell, pouch type cell and stretchable battery cells. The important concluding remarks made out of above review are as mentioned below:
- In Hybrid cooling BTMS, the combination of PCM/ PSG along with forced air cooling proves to be a better choice for optimizing the battery pack temperature and uniformity in temperature throughout the pack thus 


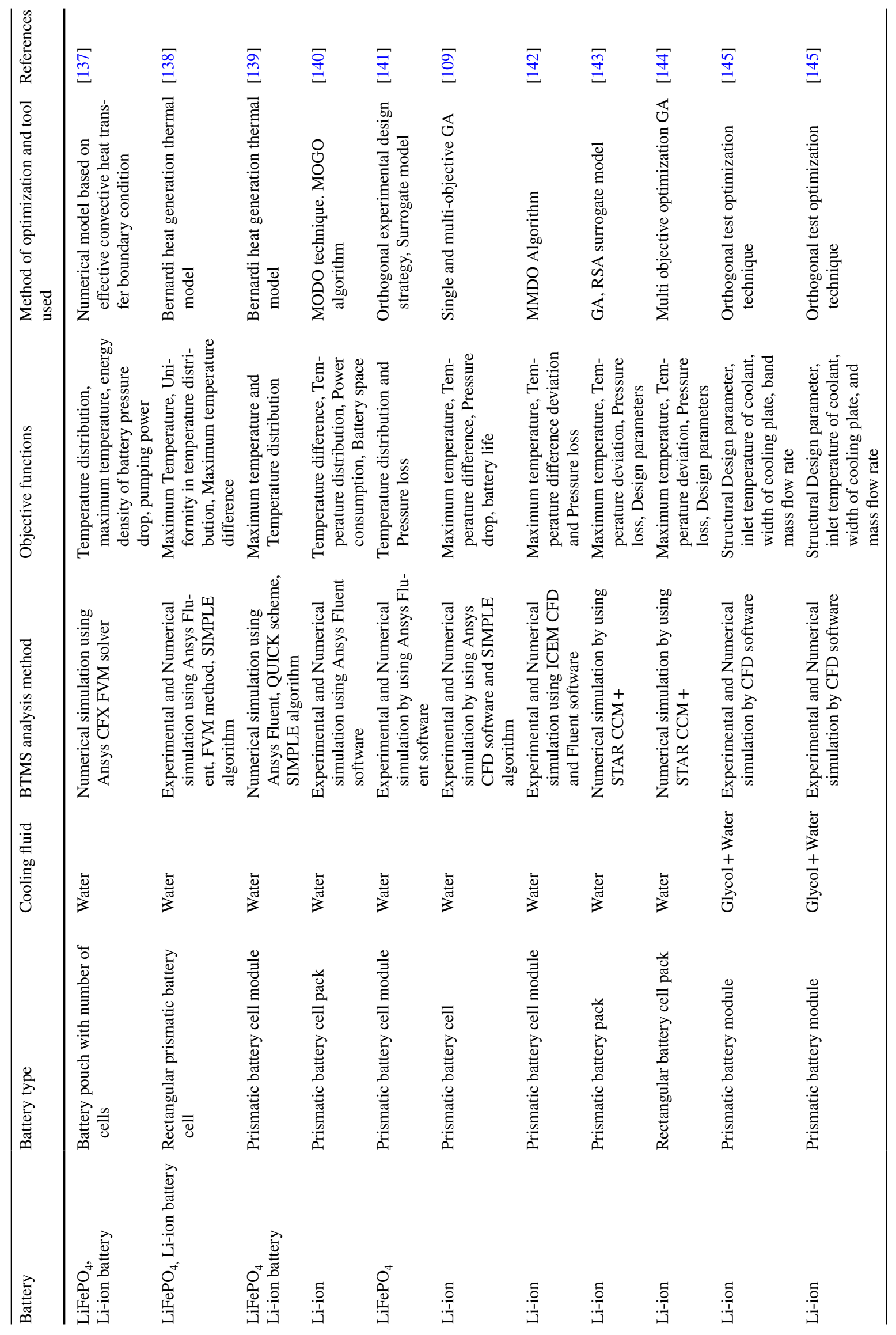




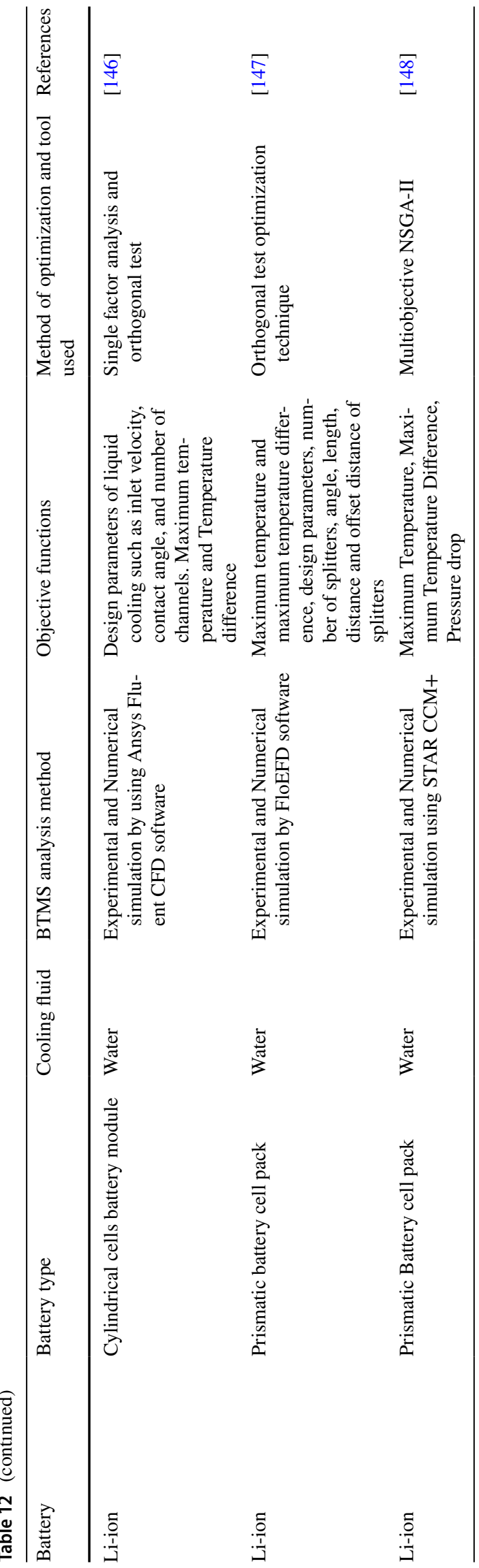

helps to enhance the overall thermal performance of LIBs under different discharge rates.

- It is necessary to determine the optimal structural design changes in battery system such as change in arrangement of inlet, outlet plenum for fluid flow or collecting tab for electric current, desired optimal spacing between the cells, arrangement of cells in the battery module, and type of cell geometry. These optimal parameters control the thermal performance of a battery system to greater extent and hence avoid the thermal runaway of the LIBs.

- The active air cooling method along with suitable numerical optimization algorithm or experimental iterative optimizing scheme shows a promising result in controlling the maximum temperature distribution on the battery cell surface, heat dissipation from the battery pack, better temperature uniformity and less power consumption.

- Usage of PCM with appropriate optimization technique helps to maintain the thermal stability of LIBs but increases the overall cost and weight of the BTMS. The studies related to PCM cooling suggested that by using optimal mass fraction, thickness, location, and shape of PCM particles one can drastically improves the thermal efficiency of LIBs.

- Different types of mini channel such as straight, serpentine, leaf, tree and bifurcated double layered network type were studied considering water combined with glycol as a coolant. The location of mini channel in a battery pack, inlet temperature of coolant, angle of branch channels, number of channels, area of mini channel, and number of splitters used in a cooling plate are the major parameters which can improve the energy density of battery and controls the maximum temperature difference between the cells placed in a battery module or pack and finally helps to reduce the pressure drop in the channel part.

- Cheap BTMS air cooling suits almost all cell configurations. It is observed that despite the attributes like exceptional simplicity, ease of installation and cheap price of naturally cooled air BTMS, it is nearly impossible for the systems to offer sufficient cooling situations for the high energy density LIBs used in EVs.

- A switch in orientation from a naturally air-cooled system to a pressured air-cooled system is seen from the amount of studies on the topics found during this study time period. Also pressured air based BTMS have high coefficient of heat transfer, simple structure, and low price relative to other cooling systems.

- Finding the least expensive, lightest and most efficient system like that of PCM and heat pipe is important to ensure effective cooling at low energy consumption, and therefore research must be strengthened at pack level so that the impact of heat accumulation from different cycle performance can be completely understood. In this regard, numerous experimental and computational analy- 
sis has been carried out to find the thermal performance of the BTMS.

- Regarding the CFD platforms used in performing numerical simulations by authors, Ansys-Fluent was found to be the most common platform used during modelling of thermal behaviour of BTMS. It has been also noted that problems with BTMS optimization are multi-objective problems with multiple functional restraints. For example, thermal performance and pressure drop of the battery pack are always contradictory to each other. To obtain the trade-off between the conflicting parameters or to obtain maximum heat transfer rate so as to maintain the temperature within the safety limits while minimizing the pumping power requirement, multi-optimization is performed and it plays a very important role in modern thermal management of batteries as experimentation or numerical simulation alone may not give the optimal results.

- The single objective optimization techniques are discussed which helps in obtaining the optimal value of important design parameters related to the thermal performance of battery cooling systems. Multi-objective optimization technique gives an idea of how to get the trade-off between the various conflicting parameters of interest such as energy, cost, pressure drop which is related to minimization and thermal efficiency or performance of the battery system related to maximization.

- Most of the studies carried out design parameter optimization (single or multi-objective) involving large number of parameters such as the mass flow rate of the cooling liquid, heat flux from the battery to the air, mass fraction of PCM, air velocity etc. The criteria of minimization of maximum temperature in the battery module, temperature difference between the battery cells, temperature distribution uniformity and the reduced pressure drop were used to analyse the thermal performance of the battery.

- Raising the overall mass flow rate could significantly reduce the peak temperature but also rises the drop in pressure. The heat flux had a major effect on the battery cell's peak temperature, and less impact on the pressure drop. An enormous heat flux could lead to worse thermal environment especially for the rearmost cells of the battery.

\section{Future Scope}

The exhaustive review made on different BTMS techniques along with different optimization schemes used in modern electric vehicle battery system (MEVBS) gives a wide scope for further future work which has been uncovered or remain untouched by the researchers. The following research areas may be exposed in the MEVBS.
- Maximum work is available related to LIBs in which more consideration is given to only two modes of heat transfer, i.e. Conduction and convection by totally neglecting the radiation effects. Hence a wide scope is available where radiation can be considered as important mode of heat transfer.

- Active method of heat transfer enhancement is widely reported by most of the researchers but passive method of heat transfer enhancement has got a very wide scope with iterative type of optimization techniques.

- PCM proves to be very good choice for improving the thermal performance of LIBs but PCM in combination with EG is rarely reported therefore for hybrid cooling CPCM with passive method will be a better area of research in future.

- Some comparative studies between J-type, U-type and Z-type flow channel are available which has predicted the best choice for the optimization of thermal parameters. In this area also the scope for passive BTMS system is widely available.

- The analysis of cylindrical type of battery cell is seldom reported having different discharge rate, and structural design parameters such as different width ratio, spacing between the cells, type of cooling plate used and its location.

- The influence of laminar flow with different flow Reynolds number on cell geometry, cell arrangement, heat generation rate, and temperature distribution within the battery module can be demonstrated for different types of mini-channel with active air-cooling method.

- In the above review none of the investigator has reported about the usage of nanofluids. The combination of nanofluids with PCM in cooling plate may be used to study the thermal (temperature behaviour) and electric (charging and discharging rate) performance of the LIBs.

- Liquid BTMS is considered a better option relative to air due to high heat transfer coefficient as compared to air BTMS. In addition, PCM is recommended for that it reduces the active cooling / heating system during most of the operating time, but poor thermal conductivity is troublesome when it applies to cooling or pre-heating the battery. So further research should be focussed to manufacture the PCM with high thermal conductivity. The use of heat pipes for BTMS is new, and it is necessary to further realize the possibilities of integrating heat pipes with air or liquid cooling.

Acknowledgements The authors extend their appreciation to the Deanship of Scientific Research at King Khalid University, Saudi Arabia for funding this work through General Research Project under Grant No: GRP/129/42. 
Funding Deanship of Scientific Research at King Khalid University, grant no. GRP/129/42.

\section{Declarations}

Conflict of interest The authors declare that they have no conflict of interest.

Ethical approval This article does not contain any studies with human participants or animals performed by any of the authors.

\section{References}

1. Afzal A, Samee ADM, Razak RKA, Ramis MK (2020) Thermal management of modern electric vehicle battery systems (MEVBS). J Therm Anal Calorim. https://doi.org/10.1007/ s10973-020-09606-x

2. Afzal A, Mohammed Samee AD, Abdul Razak RK, Ramis MK (2019) Effect of spacing on thermal performance characteristics of Li-ion battery cells. J Therm Anal Calorim 135:1797-1811. https://doi.org/10.1007/s10973-018-7664-2

3. Lu L, Han X, Li J, Hua J, Ouyang M (2013) A review on the key issues for lithium-ion battery management in electric vehicles. J Power Sources 226:272-288. https://doi.org/10.1016/j.jpowsour. 2012.10.060

4. Ma S, Jiang M, Tao P, Song C, Wu J, Wang J et al (2018) Temperature effect and thermal impact in lithium-ion batteries: a review. Prog Nat Sci Mater Int 28:653-666. https://doi.org/10. 1016/j.pnsc.2018.11.002

5. Murashko K, Pyrhönen J, Laurila L (2013) Optimization of the passive thermal control system of a lithium-ion battery with heat pipes embedded in an aluminum plate. In: 2013 IEEE 15th European conference on power electronics and applications, pp 1-10

6. Reddy TB (2011) Linden's handbook of batteries, vol 4. McgrawHill, New York

7. Hu M, Pang X, Zhou Z (2013) Recent progress in high-voltage lithium ion batteries. J Power Sources 237:229-242

8. Santhanam R, Rambabu B (2010) Research progress in high voltage spinel $\mathrm{LiNi}_{0} .5 \mathrm{Mn}_{1} .5 \mathrm{O}_{4}$ material. J Power Sources 195:5442-5451

9. Wang Y, Li H, He P, Hosono E, Zhou H (2010) Nano active materials for lithium-ion batteries. Nanoscale 2:1294-1305

10. Wanger TC (2011) The Lithium future-resources, recycling, and the environment. Conserv Lett 4:202-206

11. Liu C, Li F, Ma L-P, Cheng H-M (2010) Advanced materials for energy storage. Adv Mater 22:E28-E62

12. Scrosati B, Hassoun J, Sun Y-K (2011) Lithium-ion batteries. A look into the future. Energy Environ Sci 4:3287-3295

13. Smart MC, Ratnakumar BV, Whitcanack LD, Puglia FJ, Santee S, Gitzendanner R (2010) Life verification of large capacity Yardney Li-ion cells and batteries in support of NASA missions. Int J Energy Res 34:116-132

14. Pendergast DR, DeMauro EP, Fletcher M, Stimson E, Mollendorf JC (2011) A rechargeable lithium-ion battery module for underwater use. J Power Sources 196:793-800

15. Tarascon J-M, Armand M (2011) Issues and challenges facing rechargeable lithium batteries. Mater Sustain Energy a Collect. Peer-reviewed Res Rev Article from Nat Publ Gr, World Scientific, 171-179

16. Goodenough JB, Kim Y (2010) Challenges for rechargeable Li batteries. Chem Mater 22:587-603
17. Ji Y, Zhang Y, Wang C-Y (2013) Li-ion cell operation at low temperatures. J Electrochem Soc 160:A636-A649

18. Ren D, Smith K, Guo D, Han X, Feng X, Lu L et al (2018) Investigation of lithium plating-stripping process in $\mathrm{Li}$-ion batteries at low temperature using an electrochemical model. J Electrochem Soc 165:A2167-A2178

19. He F, Li X, Zhang G, Zhong G, He J (2018) Experimental investigation of thermal management system for lithium ion batteries module with coupling effect by heat sheets and phase change materials. Int J Energy Res 42:3279-3288

20. Finegan DP, Darcy E, Keyser M, Tjaden B, Heenan TMM, Jervis $\mathrm{R}$ et al (2017) Characterising thermal runaway within lithium-ion cells by inducing and monitoring internal short circuits. Energy Environ Sci 10:1377-1388

21. Yang Z, Huang Q, Li S, Mao J (2018) High-temperature effect on electrochemical performance of Li4Ti5O12 based anode material for Li-ion batteries. J Alloys Compd 753:192-202

22. Panchal S, Mcgrory J, Kong J, Fraser R, Fowler M, Dincer I et al (2017) Cycling degradation testing and analysis of a LiFePO4 battery at actual conditions. Int J Energy Res 41:2565-2575

23. Jaguemont J, Boulon L, Dubé Y (2016) A comprehensive review of lithium-ion batteries used in hybrid and electric vehicles at cold temperatures. Appl Energy 164:99-114

24. Bandhauer TM, Garimella S, Fuller TF (2011) A critical review of thermal issues in lithium-ion batteries. J Electrochem Soc 158:R1-R25

25. Bugga R, Smart M, Whitacre J, West W (2007) Lithium ion batteries for space applications. IEEE Aerosp Conf 2007:1-7

26. Shiao H-CA, Chua D, Lin H, Slane S, Salomon M (2000) Low temperature electrolytes for Li-ion PVDF cells. J Power Sources $87: 167-173$

27. Yuan Q, Zhao F, Wang W, Zhao Y, Liang Z, Yan D (2015) Overcharge failure investigation of lithium-ion batteries. Electrochim Acta 178:682-688

28. Yang K, An J, Chen S (2010) Thermal behavior analysis of nickel/metal hydride battery during overcharging. Sci China Chem 53:1177-1182

29. Shim J, Kostecki R, Richardson T, Song X, Striebel KA (2002) Electrochemical analysis for cycle performance and capacity fading of a lithium-ion battery cycled at elevated temperature. $\mathrm{J}$ Power Sources 112:222-230

30. Zhang Y, Wang C-Y, Tang X (2011) Cycling degradation of an automotive LiFePO4 lithium-ion battery. J Power Sources 196:1513-1520

31. Belt JR, Ho CD, Miller TJ, Habib MA, Duong TQ (2005) The effect of temperature on capacity and power in cycled lithium ion batteries. J Power Sources 142:354-360

32. Ramadass P, Haran B, White R, Popov BN (2002) Capacity fade of Sony 18650 cells cycled at elevated temperatures: Part II. Capacity fade analysis. J Power Sources 112:614-620

33. Ning G, Haran B, Popov BN (2003) Capacity fade study of lithium-ion batteries cycled at high discharge rates. J Power Sources 117:160-169

34. Pesaran AA, Swan D, Olson J, Guerin JT, Burch S, Rehn R et al (1998) Thermal analysis and performance of a battery pack for a hybrid electric vehicle. National Renewable Energy Laboratory

35. Spotnitz R, Franklin J (2003) Abuse behavior of high-power, lithium-ion cells. J Power Sources 113:81-100

36. Wang Q, Ping P, Zhao X, Chu G, Sun J, Chen C (2012) Thermal runaway caused fire and explosion of lithium ion battery. J Power Sources 208:210-224. https://doi.org/10.1016/j.jpowsour.2012. 02.038

37. Kumaresan K, Sikha G, White RE (2008) Thermal model for a Li-ion cell. J Electrochem Soc 155:A164-A171 
38. Hu X, Lin S, Stanton S (2010) A novel thermal model for HEV/ EV battery modeling based on CFD calculation. In: 2010 IEEE Energy Conversion Congress and Exposition, p 893-900

39. Williford RE, Viswanathan VV, Zhang J-G (2009) Effects of entropy changes in anodes and cathodes on the thermal behavior of lithium ion batteries. J Power Sources 189:101-107

40. Viswanathan VV, Choi D, Wang D, Xu W, Towne S, Williford RE et al (2010) Effect of entropy change of lithium intercalation in cathodes and anodes on Li-ion battery thermal management. J Power Sources 195:3720-3729

41. Lin C, Chen K, Sun F, Tang P, Zhao H (2009) Research on thermo-physical properties identification and thermal analysis of EV Li-ion battery. In: The 2009 IEEE vehicle power and propulsion conference, pp 1643-1648

42. Duan X, Naterer GF (2010) Heat transfer in phase change materials for thermal management of electric vehicle battery modules. Int J Heat Mass Transf 53:5176-5182. https://doi.org/10.1016/j. ijheatmasstransfer.2010.07.044

43. Huang C-K, Sakamoto JS, Wolfenstine J, Surampudi S (2000) The limits of low-temperature performance of Li-ion cells. J Electrochem Soc 147:2893

44. Kim H-S, Cho B-W, Cho W-I (2004) Cycling performance of $\mathrm{LiFePO}_{4}$ cathode material for lithium secondary batteries. $\mathrm{J}$ Power Sources 132:235-239

45. Vetter J, Novák P, Wagner MR, Veit C, Möller K-C, Besenhard JO et al (2005) Ageing mechanisms in lithium-ion batteries. J Power Sources 147:269-281

46. Khan MR, Swierczynski MJ, Kær SK (2017) Towards an ultimate battery thermal management system: a review. Batteries. https://doi.org/10.3390/batteries3010009

47. Khan MR (2017) Thermal management of battery systems in electric vehicle and smart grid application. Ph. D. Thesis, Aalborg University, Aalborg, Denmark

48. Wang X, Li M, Liu Y, Sun W, Song X, Zhang J (2017) Surrogate based multidisciplinary design optimization of lithium-ion battery thermal management system in electric vehicles. Struct Multidiscip Optim 56:1555-1570. https://doi.org/10.1007/ s00158-017-1733-1

49. Yu K, Yang X, Cheng Y, Li C (2014) Thermal analysis and twodirectional air flow thermal management for lithium-ion battery pack. J Power Sources 270:193-200. https://doi.org/10.1016/j. jpowsour.2014.07.086

50. Liu Y, Yang S, Guo B, Deng C (2014) Numerical analysis and design of thermal management system for lithium ion battery pack using thermoelectric coolers. Adv Mech Eng 6:852712

51. Saw LH, Somasundaram K, Ye Y, Tay AAO (2014) Electrothermal analysis of Lithium Iron Phosphate battery for electric vehicles. J Power Sources 249:231-238

52. Saw LH, Ye Y, Tay AAO, Chong WT, Kuan SH, Yew MC (2016) Computational fluid dynamic and thermal analysis of Lithiumion battery pack with air cooling. Appl Energy 177:783-792. https://doi.org/10.1016/j.apenergy.2016.05.122

53. Pesaran A (2001) Battery thermal management in EVs and HEVs : issues and solutions. In: Advanced automotive battery conference, vol 10

54. Pesaran A, Keyser M, Burch S (1999) An approach for designing thermal management systems for electric and hybrid vehicle battery packs

55. Sabbah R, Kizilel R, Selman JR, Al-Hallaj S (2008) Active (aircooled) vs. passive (phase change material) thermal management of high power lithium-ion packs: Limitation of temperature rise and uniformity of temperature distribution. J Power Sources 182:630-638

56. Xia G, Cao L, Bi G (2017) A review on battery thermal management in electric vehicle application. J Power Sources 367:90105. https://doi.org/10.1016/j.jpowsour.2017.09.046
57. Arora S (2018) Selection of thermal management system for modular battery packs of electric vehicles: a review of existing and emerging technologies. J Power Sources 400:621-640

58. Al-Zareer M, Dincer I, Rosen MA (2018) A review of novel thermal management systems for batteries. Int J Energy Res. https://doi.org/10.1002/er.4095

59. Jarrett A, Kim IY (2014) Influence of operating conditions on the optimum design of electric vehicle battery cooling plates. J Power Sources 245:644-655. https://doi.org/10.1016/j.jpowsour. 2013.06.114

60. Huo Y, Rao Z, Liu X, Zhao J (2015) Investigation of power battery thermal management by using mini-channel cold plate. Energy Convers Manag 89:387-395

61. Faghri A, Harley C (1994) Transient lumped heat pipe analyses. Heat Recov Syst CHP 14:351-363

62. Yang X, Yan YY, Mullen D (2012) Recent developments of lightweight, high performance heat pipes. Appl Therm Eng 33:1-14

63. Ting C-C, Chen C-C (2014) Analyzing the heat transfer property of heat pipe influenced by integrated cooling apparatus. Chin $\mathrm{J}$ Eng 2014:1

64. Li Y, Qi F, Guo H, Guo Z, Xu G, Liu J (2019) Numerical investigation of thermal runaway propagation in a Li-ion battery module using the heat pipe cooling system. Numer Heat Transf A Appl 75:183-199

65. Liang J, Gan Y, Li Y (2018) Investigation on the thermal performance of a battery thermal management system using heat pipe under different ambient temperatures. Energy Convers Manag 155:1-9. https://doi.org/10.1016/j.enconman.2017.10.063

66. Yang X-S, Deb S (2009) Cuckoo search via Lévy flights. World Congr Nat Biol Inspired Comput 2009:210-214

67. Geleta DK, Manshahia MS (2020) Artificial bee colony-based optimization of hybrid wind and solar renewable energy system. IGI Global, The Handbook of Research on Energy-Saving Technologies for Environmentally-Friendly Agricultural Development, pp 429-453

68. Zhang Y, Zeng P, Zang C (2015) Optimization algorithm for home energy management system based on artificial bee colony in smart grid. In: 2015 IEEE international conference on cyber technology in automation, control and intelligent systems, pp 734-740

69. Müller J, März M, Mauser I, Schmeck H (2016) Optimization of operation and control strategies for battery energy storage systems by evolutionary algorithms. In: European conference on the applications of evolutionary computation, pp 507-522

70. Kirkpatrick S, Gelatt CD, Vecchi MP (1983) Optimization by simulated annealing. Science (80-) 220:671-680

71. Cheng Y-H, Lai C-M (2017) Control strategy optimization for parallel hybrid electric vehicles using a memetic algorithm. Energies 10:305

72. Katsigiannis YA, Georgilakis PS (2008) Optimal sizing of small isolated hybrid power systems using tabu search. J Optoelectron Adv Mater 10:1241

73. Goud JS, Kalpana R, Singh B, Kumar S (2018) Maximum power point tracking technique using artificial bee colony and hill climbing algorithms during mismatch insolation conditions on PV array. IET Renew Power Gener 12:1915-1922

74. Mesbahi T, Khenfri F, Rizoug N, Chaaban K, Bartholomeues P, Le Moigne P (2016) Dynamical modeling of Li-ion batteries for electric vehicle applications based on hybrid Particle SwarmNelder-Mead (PSO-NM) optimization algorithm. Electr Power Syst Res 131:195-204

75. Brew JS, Brotton DM (1971) Non-linear structural analysis by dynamic relaxation. Int J Numer Methods Eng 3:463-483

76. Battiti R, Brunato M, Mascia F (2008) Reactive search and intelligent optimization, vol 45. Springer, New York 
77. Hamacher K (2006) Adaptation in stochastic tunneling global optimization of complex potential energy landscapes. Europhys Lett 74:944

78. Mirjalili S, Mirjalili SM, Lewis A (2014) Grey wolf optimizer. Adv Eng Softw 69:46-61

79. Yang X-S (2010) A new metaheuristic bat-inspired algorithm. Nat. inspired Coop. Strateg. Optim. (NICSO 2010). Springer, pp 65-74

80. Sadollah A, Bahreininejad A, Eskandar H, Hamdi M (2013) Mine blast algorithm: A new population based algorithm for solving constrained engineering optimization problems. Appl Soft Comput 13:2592-2612

81. Zames G, Ajlouni NM, Ajlouni NM, Ajlouni NM, Holland JH, Hills WD et al (1981) Genetic algorithms in search, optimization and machine learning. Inf Technol J 3:301-302

82. Martland CD (2013). Encyclopedia of Operations Research and Management Science. https://doi.org/10.1007/ 978-1-4419-1153-7

83. Wang J, Zhai Z, Jing Y, Zhang C (2010) Particle swarm optimization for redundant building cooling heating and power system. Appl Energy 87:3668-3679. https://doi.org/10.1016/J.APENE RGY.2010.06.021

84. Srinivas N, Deb K (1994) Muiltiobjective optimization using nondominated sorting in genetic algorithms. Evol Comput 2:221-248

85. Seshadri A (2007) A fast elitist multiobjective genetic algorithm: NSGA-II, Mathlab Central, file exchange, mathworks 2007.

86. Deb K, Agrawal RB (1994) Simulated binary crossover for continuous search space. Complex Syst 9:1-34

87. Dorigo M, Maniezzo V, Colorni A (1996) Ant system: optimization by a colony of cooperating agents. IEEE Trans Syst Man Cybern B 26:29-41

88. Dorigo M, Di CG, Gambardella LM (1999) Ant algorithms for discrete optimization. Artif Life 5:137-172

89. Mousavi M, Hoque S, Rahnamayan S, Dincer I, Naterer GF (2011) Optimal design of an air-cooling system for a Li-ion battery pack in electric vehicles with a genetic algorithm, pp 1848-1855

90. Gross O, Clark S (2018) Optimizing electric vehicle battery life through battery thermal management 4:1928-1943. https://doi. org/10.4271/2011-01-1370

91. Severino B, Gana F, Palma-Behnke R, Estévez PA, CalderónMuñoz WR, Orchard ME et al (2014) Multi-objective optimal design of lithium-ion battery packs based on evolutionary algorithms. J Power Sources 267:288-299. https://doi.org/10.1016/j. jpowsour.2014.05.088

92. Zhang L, Wang L, Hinds G, Lyu C, Zheng J, Li J (2014) Multiobjective optimization of lithium-ion battery model using genetic algorithm approach. J Power Sources 270:367-378. https://doi. org/10.1016/j.jpowsour.2014.07.110

93. Liu Y, Ouyang C, Jiang Q, Liang B (2015) Design and parametric optimization of thermal management of lithium-ion battery module with reciprocating air-flow. J Cent South Univ 22:3970-3976. https://doi.org/10.1007/s11771-015-2941-8

94. Smekens J, Omar N, Hubin A, Van Mierlo J, den Bossche P (2015) Optimization of Li-Ion batteries through modelling techniques. World Electr Veh J 7:52-58

95. Mohammadian SK, Zhang Y (2015) Thermal management optimization of an air-cooled Li-ion battery module using pin-fin heat sinks for hybrid electric vehicles. J Power Sources 273:431439. https://doi.org/10.1016/j.jpowsour.2014.09.110

96. Zhang C, Jiang J, Gao Y, Zhang W, Liu Q (2016) Polarization based charging time and temperature rise optimization for lithium-ion batteries. Energy Procedia 88:675-681. https://doi.org/ 10.1016/j.egypro.2016.06.097
97. Zhang C, Jiang J, Gao Y, Zhang W, Liu Q, Hu X (2016) Charging optimization in lithium-ion batteries based on temperature rise and charge time. Appl Energy. https://doi.org/10.1016/j.apene rgy.2016.10.059

98. Erb DC (2016) Optimizing hybrid vehicles : battery pack design, energy management, and collaborative learning by 2016

99. Matthias K, Felix H, Markus L (2017) Optimization through rapid meta-model based transient thermal simulation of lithium ion battery cells. In: 2017 IEEE transportation electrification conference \& expo, ITEC, pp 334-41. https://doi.org/10.1109/ ITEC.2017.7993294

100. Park YJ, Jun S, Kim S, Lee DH (2010) Design optimization of a loop heat pipe to cool a lithium ion battery onboard a military aircraft. J Mech Sci Technol 24:609-618. https://doi.org/10. 1007/s12206-009-1214-6

101. Ye Y, Shi Y, Huat L, Tay AAO (2016) Performance assessment and optimization of a heat pipe thermal management system for fast charging lithium ion battery packs. Int J Heat Mass Transf 92:893-903. https://doi.org/10.1016/j.ijheatmasstransfer.2015. 09.052

102. Ye Y, Huat L, Shi Y, Tay AAO (2015) Numerical analyses on optimizing a heat pipe thermal management system for lithiumion batteries during fast charging. Appl Therm Eng 86:281-291. https://doi.org/10.1016/j.applthermaleng.2015.04.066

103. Jarrett A, Kim IY (2011) Design optimization of electric vehicle battery cooling plates for thermal performance. J Power Sources 196:10359-10368. https://doi.org/10.1016/j.jpowsour.2011.06. 090

104. Jarrett A (2011) Multi-objective design optimization of electric vehicle battery cooling plates considering thermal and pressure objective functions

105. Smith J, Hinterberger M, Hable P, Koehler J (2014) Simulative method for determining the optimal operating conditions for a cooling plate for lithium-ion battery cell modules. J Power Sources 267:784-792. https://doi.org/10.1016/j.jpowsour.2014. 06.001

106. Zhang X, Chang X, Shen Y, Xiang Y (2017) Electrochemicalelectrical-thermal modeling of a pouch-type lithium ion battery: an application to optimize temperature distribution. J Energy Storage 11:249-257. https://doi.org/10.1016/j.est.2017.03.008

107. Jiang G, Huang J, Fu Y, Cao M, Liu M (2016) Thermal optimization of composite phase change material / expanded graphite for Li-ion battery thermal management. Appl Therm Eng 108:11191125. https://doi.org/10.1016/j.applthermaleng.2016.07.197

108. Javani N, Dincer I, Naterer GF, Yilbas BS (2014) Exergy analysis and optimization of a thermal management system with phase change material for hybrid electric vehicles. Appl Therm Eng 64:471-482. https://doi.org/10.1016/j.applthermaleng.2013.11. 053

109. Liu H, Shi H, Shen H, Xie G (2019) The performance management of a Li-ion battery by using tree-like mini-channel heat sinks: experimental and numerical optimization. Energy 189:116150. https://doi.org/10.1016/j.energy.2019.116150

110. Jaguemont J, Omar N, Bossche P Van Den, Mierlo J Van, Adams $\mathrm{K}$, Lic A (2017) Optimized passive thermal management for battery module

111. Zhao R, Gu J, Liu J (2017) Optimization of a phase change material based internal cooling system for cylindrical Li-ion battery pack and a hybrid cooling design. Energy 135:811-822. https:// doi.org/10.1016/j.energy.2017.06.168

112. Wu W, Wu W, Wang S (2017) Thermal optimization of composite PCM based large-format lithium-ion battery modules under extreme operating conditions. Energy Convers Manag 153:2233. https://doi.org/10.1016/j.enconman.2017.09.068

113. Ling Z, Cao J, Zhang W, Zhang Z, Fang X, Gao X (2018) Compact liquid cooling strategy with phase change materials for 
Li-ion batteries optimized using response surface methodology. Appl Energy 228:777-788. https://doi.org/10.1016/j.apenergy. 2018.06.143

114. Becker J, Nemeth T, Wegmann R, Sauer DU (2018) Dimensioning and optimization of hybrid Li-ion battery systems for EVs. World Electr Veh J. https://doi.org/10.3390/wevj9020019

115. Kong D, Peng R, Ping P, Du J, Chen G, Wen J (2019) A novel battery thermal management system coupling with PCM and optimized controllable liquid cooling for different ambient temperatures. Energy Convers Manag. https://doi.org/10.1016/j. enconman.2019.112280

116. Wang X, Li M, Liu Y, Sun W, Song X, Zhang J (2017). Surrogate based multidisciplinary design optimization of lithium-ion battery thermal management system in electric vehicles. https://doi. org/10.1007/s00158-017-1733-1

117. Shahid S, Agelin-Chaab M (2017) Analysis of cooling effectiveness and temperature uniformity in a battery pack for cylindrical batteries. Energies. https://doi.org/10.3390/en10081157

118. Wang X (2018) Multidisciplinary and multifidelity design optimization of electric vehicle battery thermal management system 1-8. https://doi.org/10.1115/1.4040484

119. Ye M, Xu Y, Huangfu Y (2018) The structure optimization of lithium-ion battery pack based on the structure optimization of lithium-ion battery pack based on fluid-solid conjugate thermodynamic analysis conjugate analysis assessing the feasibility of thermodynamic using the heat deman. Energy Procedia 152:643648. https://doi.org/10.1016/j.egypro.2018.09.224

120. Liu K, Li K, Ma H, Zhang J, Peng Q (2018) Multi-objective optimization of charging patterns for lithium-ion battery management. Energy Convers Manag 159:151-162. https://doi.org/10. 1016/j.enconman.2017.12.092

121. Chen K, Song M, Wei W, Wang S (2018) Structure optimization of parallel air-cooled battery thermal management system with U-type flow for cooling efficiency improvement. Energy 145:603-613. https://doi.org/10.1016/j.energy.2017.12.110

122. Mei W, Chen H, Sun J, Wang Q (2018) Numerical study on tab dimension optimization of lithium-ion battery from the thermal safety perspective. Appl Therm Eng 142:148-165. https://doi. org/10.1016/J.APPLTHERMALENG.2018.06.075

123. Lei Y, Zhang C, Gao Y, Li T (2018) Charging optimization of lithium-ion batteries based on capacity degradation speed and energy loss. Energy Procedia 152:544-549. https://doi.org/10. 1016/j.egypro.2018.09.208

124. Li W, Xiao M, Peng X, Garg A, Gao L (2019) A surrogate thermal modeling and parametric optimization of battery pack with air cooling for EVs. Appl Therm Eng 147:90-100. https://doi. org/10.1016/j.applthermaleng.2018.10.060

125. Li M, Liu Y, Wang X, Zhang J (2019) Modeling and optimization of an enhanced battery thermal management system in electric vehicles. Front Mech Eng 14:65-75. https://doi.org/10.1007/ s11465-018-0520-Z

126. Liu Y, Zhang J (2019) Design a J -type air-based battery thermal management system through surrogate-based optimization. Appl Energy 252:113426. https://doi.org/10.1016/j.apenergy.2019. 113426

127. Ji C, Wang B, Wang S, Pan S, Wang D, Qi P et al (2019) Optimization on uniformity of lithium-ion cylindrical battery module by different arrangement strategy. Appl Therm Eng 157:113683. https://doi.org/10.1016/j.applthermaleng.2019.04.093

128. Qian X, Xuan D, Zhao X, Shi Z (2019) Heat dissipation optimization of lithium-ion battery pack based on neural networks. Appl Therm Eng 162:114289. https://doi.org/10.1016/j.applt hermaleng.2019.114289

129. Li H, Liu C, Saini A, Wang Y, Jiang H, Yang T et al (2019) Coupling multi-physics simulation and response surface methodology for the thermal optimization of ternary prismatic lithium-ion battery. J Power Sources 438:226974. https://doi.org/10.1016/j. jpowsour.2019.226974

130. Liu Y, Ghassemi P, Chowdhury S, Zhang J (2019) Surrogate based multi-objective optimization of J-type battery thermal management system 1-9

131. Li Y, Du Y, Xu T, Wu H, Zhou X, Ling Z et al (2018) Optimization of thermal management system for Li-ion batteries using phase change material. Appl Therm Eng 131:766-778. https:// doi.org/10.1016/j.applthermaleng.2017.12.055

132. Parhizi M, Jain A (2018) Analytical modeling and optimization of phase change thermal management of a Li-ion battery pack. Appl Therm Eng. https://doi.org/10.1016/j.applthermaleng.2018. 11.017

133. Wu W, Wu W, Wang S (2018) Thermal management optimization of a prismatic battery with shape-stabilized phase change material. Int J Heat Mass Transf 121:967-977. https://doi.org/ 10.1016/j.ijheatmasstransfer.2018.01.062

134. Yang M, Wang H, Shuai W, Deng X (2019) Thermal optimization of a Kirigami-patterned wearable lithium-ion battery based on a novel design of composite phase change material. Appl Therm Eng 161:114141. https://doi.org/10.1016/j.appltherma leng.2019.114141

135. Weng J, Yang X, Zhang G, Ouyang D, Chen M, Wang J (2019) Optimization of the detailed factors in a phase-change-material module for battery thermal management. Int J Heat Mass Transf 138:126-134. https://doi.org/10.1016/j.ijheatmasstransfer.2019. 04.050

136. Ling Z, Lin W, Zhang Z, Fang X (2019) Computationally efficient thermal network model and its application in optimization of battery thermal management system with phase change materials and long-term performance assessment. Appl Energy. https://doi.org/10.1016/j.apenergy.2019.114120

137. An Z, Shah K, Jia L, Ma Y (2019) A parametric study for optimization of minichannel based battery thermal management system 154:593-601. https://doi.org/10.1016/j.applthermaleng.2019.02. 088

138. Tang A, Li J, Lou L, Shan C, Yuan X (2019) Optimization design and numerical study on water cooling structure for power lithium battery pack. Appl Therm Eng 159:113760. https://doi.org/10. 1016/j.applthermaleng.2019.113760

139. Li W, Zhuang X, Xu X (2019) Numerical study of a novel battery thermal management system for a prismatic Li-ion battery module. Energy Procedia 158:4441-4446. https://doi.org/10.1016/j. egypro.2019.01.771

140. Li W, Peng X, Xiao M, Garg A, Gao L (2019) Multi-objective design optimization for mini-channel cooling battery thermal management system in an electric vehicle. Int J Energy Res 43:3668-3680. https://doi.org/10.1002/er.4518

141. Ye B, Rubel MRH, Li H (2019) Design and optimization of cooling plate for battery module of an electric vehicle. Appl Sci. https://doi.org/10.3390/app9040754

142. Chen S, Peng X, Bao N, Garg A (2019) A comprehensive analysis and optimization process for an integrated liquid cooling plate for a prismatic lithium-ion battery module. Appl Therm Eng 156:324-339. https://doi.org/10.1016/j.applthermaleng.2019. 04.089

143. Deng T, Ran Y, Yin Y, Chen X, Liu P (2019) Multi-objective optimization design of double-layered reverting cooling plate for lithium-ion batteries. Int J Heat Mass Transf 143:118580. https:// doi.org/10.1016/j.ijheatmasstransfer.2019.118580

144. Deng T, Ran Y, Zhang G, Chen X, Tong Y (2019) Design optimization of bifurcating mini-channels cooling plate for rectangular Li-ion battery. Int J Heat Mass Transf 139:963-973. https://doi. org/10.1016/j.ijheatmasstransfer.2019.05.082

145. Shang Z, Qi H, Liu X, Ouyang C, Wang Y (2019) Structural optimization of lithium-ion battery for improving thermal 
performance based on a liquid cooling system. Int J Heat Mass Transf 130:33-41. https://doi.org/10.1016/j.ijheatmasstransfer. 2018.10.074

146. Wang Y, Zhang G, Yang X (2019) Optimization of liquid cooling technology for cylindrical power battery module. Appl Therm Eng 162:114200. https://doi.org/10.1016/j.applthermaleng.2019. 114200

147. Xu X, Tong G, Li R (2020) Numerical study and optimizing on cold plate splitter for lithium battery thermal management system. Appl Therm Eng 167:114787. https://doi.org/10.1016/j. applthermaleng.2019.114787
148. Deng T, Ran Y, Yin Y, Liu P (2020) Multi-objective optimization design of thermal management system for lithium-ion battery pack based on Non-dominated Sorting Genetic Algorithm II. Appl Therm Eng 164:114394. https://doi.org/10.1016/j.applt hermaleng.2019.114394

Publisher's Note Springer Nature remains neutral with regard to jurisdictional claims in published maps and institutional affiliations.

\section{Authors and Affiliations}

\section{H. Fayaz ${ }^{1} \cdot$ Asif Afzal $^{2}$ (D) A. D. Mohammed Samee ${ }^{2} \cdot$ Manzoore Elahi M. Soudagar $^{3} \cdot$ Naveed Akram $^{4}$. M. A. Mujtaba ${ }^{5} \cdot$ R. D. Jilte ${ }^{6} \cdot$ Md. Tariqul Islam $^{7} \cdot$ Ümit Ağbulut ${ }^{8} \cdot$ C. Ahamed Saleel ${ }^{9}$}

1 Modeling Evolutionary Algorithms Simulation and Artificial Intelligence, Faculty of Electrical \& Electronics Engineering, Ton Duc Thang University, Ho Chi Minh City, Vietnam

2 Department of Mechanical Engineering, P. A. College of Engineering (Affiliated To Visvesvaraya Technological University, Belagavi), Mangalore 574153, India

3 Department of Mechanical Engineering, Glocal University, Delhi-Yamunotri Marg, SH-57, Mirzapur Pole, Saharanpur District, Uttar Pradesh 247121, India

4 Department of Mechanical Engineering, Mirpur University of Science and Technology (MUST), Mirpur 10250 (AJK), Pakistan
5 Center for Energy Science, Department of Mechanical Engineering, University of Malaya, Kuala Lumpur 50603, Malaysia

6 Department of Mechanical Engineering, Lovely Professional University, Phagwara, Punjab 144411, India

7 School of Chemical Engineering, The University of Queensland, Brisbane, QLD 4072, Australia

8 Düzce University, Mechanical Engineering Department, Faculty of Engineering, Düzce 81620, Turkey

9 Department of Mechanical Engineering, College of Engineering, King Khalid University, PO Box 394, Abha 61421, Saudi Arabia 